\title{
Chemical Diversity and Therapeutic Effects of Essential Oils of Aniba Species from the Amazon: A Review
}

\author{
Rafaela C. S. da Trindade ${ }^{1}$, Júlia Karla A. M. Xavier ${ }^{2}{ }^{(}$, William N. Setzer ${ }^{3,4}{ }^{(}$, José Guilherme S. Maia ${ }^{2,5}{ }^{(D)}$ \\ and Joyce Kelly R. da Silva 1,2,*(D) \\ 1 Programa de Pós-Graduação em Biotecnologia, Instituto de Ciências Biológicas, Universidade Federal do \\ Pará, Belém 66075-900, Brazil; rafacabral.bio@gmail.com \\ 2 Programa de Pós-Graduação em Química, Universidade Federal do Pará, Belém 66075-900, Brazil; \\ julia.xavier@icen.ufpa.br (J.K.A.M.X.); gmaia@ufpa.br (J.G.S.M.) \\ 3 Department of Chemistry, University of Alabama in Huntsville, Huntsville, AL 35899, USA; \\ wsetzer@chemistry.uah.edu \\ 4 Aromatic Plant Research Center, 230 N 1200 E, Suite 102, Lehi, UT 84043, USA \\ 5 Programa de Pós-Graduação em Química, Universidade Federal do Maranhão, São Luís 65080-805, Brazil \\ * Correspondence: joycekellys@ufpa.br; Tel.: +55-91-3201-7297
}

check for updates

Citation: da Trindade, R.C.S.; Xavier, J.K.A.M.; Setzer, W.N.; Maia, J.G.S.; da Silva, J.K.R. Chemical Diversity and Therapeutic Effects of Essential Oils of Aniba Species from the Amazon: A Review. Plants 2021, 10, 1854. https:// doi.org/10.3390/plants10091854

Academic Editor: Barbara Sgorbini

Received: 10 August 2021

Accepted: 2 September 2021

Published: 7 September 2021

Publisher's Note: MDPI stays neutral with regard to jurisdictional claims in published maps and institutional affiliations.

Copyright: (c) 2021 by the authors. Licensee MDPI, Basel, Switzerland. This article is an open access article distributed under the terms and conditions of the Creative Commons Attribution (CC BY) license (https:/ / creativecommons.org/licenses/by/ $4.0 /)$.

\begin{abstract}
Lauraceae families have great diversity in the world's tropical regions and are represented mainly by aromatic shrubs and trees with significant production of essential oils (EOs). This work presents a review of the EO chemical profiles from specimens of Aniba, including their seasonal variations, geographical distributions, and biological activities in the Amazon biome. Based on the survey, 15 species were reviewed, representing 167 oil samples extracted from leaves, twig barks, and woods. Brazilian Amazon was the most representative geographic area in the number of specimens, highlighting the locations Belém, (Pará state, PA) (3 spp., 37 samples), Santarém (PA) (3 spp., 10 samples), Carajás (PA) (3 spp., 7 samples), and Manaus (Amazonas state, AM) (3 spp., 16 samples). The main compound classes identified in oils were benzenoids and phenylpropanoids, represented by 1-nitro-2-phenylethane, benzyl salicylate, benzyl benzoate and methyleugenol, along with terpenoids, especially monoterpenes and sesquiterpenes, such as linalool, $\alpha$-phellandrene, $\beta$-phellandrene, $\beta$ selinene, and spathulenol. The EOs from Aniba showed considerable variation in the chemical profiles according to season and collection site. The hierarchical cluster analysis classified the samples into two main groups according to chemical composition. This review highlights its comprehensive and up-to-date information on history, conservation, traditional uses, chemosystematics, pharmacological potential of Aniba species.
\end{abstract}

Keywords: Aniba spp.; Lauraceae; benzenoids and phenylpropanoids; monoterpenes and sesquiterpenes; biological properties

\section{Introduction}

The genus Aniba Alblet (1775) belongs to the Lauraceae family, considered one of the most primitive of the Magnoliids clade [1], and includes 48 accepted species, 25 of which occur in the Brazilian Amazon [2]. The genus originated in the Amazon because the center of species diversity is in the region of the Guianas and Central Amazon, spreading over the humid tropical plains, Antilles, Guyana, and Andes region, without occurrence in Central America [3]. In Brazil, they occur in regions with high rainfall, such as in the Amazon and dry areas in the central and southern regions of the country, with diverse phytophysiognomy such as ombrophilous forests, savannas, canga, and restinga vegetation $[2,4]$.

The first records known about this genus are from an expedition made by Aublet through French Guiana between the years 1762 and 1764, in which the species Licaria guianensis Aubl. (1775) was registered in reference to the name "likari", a tree named by the Galibis Indians. However, Aublet gave this name without having analyzed the fertile parts 
of the plant. Later, Koeller suggested that it was Ocotea caudata (Nees) Mez, which was circumscribed by Mez in 1888, as Aniba parviflora (Meisn.) Mez (1889). In 1926, naturalist Adolfo Ducke analyzed the same botanical material collected in the Oiapoque and classified the plant as Aniba rosaeodora Ducke. However, when comparing this material with another collected in Juruti Velho (PA, Brazil), Ducke made sure that they were different species, then it was proposed as the A. rosaeodora var. amazonica Ducke. Later, it was raised to the category of species, as Aniba duckei, by Kostermans in 1938 [5]. After reviewing the Aniba genus, [3] proposed that $A$. duckei Kosterm. and A. rosaeodora var. amazonica Ducke were synonymous with $A$. rosaeodora Ducke (1930).

Aniba species are generally large to small trees and rarely shrubs (A. lancifolia Kubitzki and Rodrigues). The presence of lenticels is common in the trunk, and when cut, it emits a strong odor, often observed in other parts of the plant, including herborized material due to the presence of oil cells. Aniba species have penninerved and alternate leaves, some presented leaves grouped at the top of the branches, and others are distributed equally in the branches. Inflorescences are usually panicles or botryoids containing hermaphrodite flowers, mostly small, pedicellate with erect tepals and bracts caducous. The androecium comprises nine fertile stamens and two valves, with fillets generally the same width as the anthers. The floral tube is conspicuous, the pistil slender, and the ovary ellipsoid or ovoid, glabrous or pilose, included in the floral tube. The ellipsoid or ovoid berry fruit is surrounded by a woody cupule usually containing lenticels [3,6-8]. Studies about floral biology showed that most Aniba species are strongly protogynous. Some species have asynchronous floral biology events to avoid self-fertilization. The main pollinators are bee species (Meliponinae), which recognize pollen receptivity and availability. However, Aniba flowers barely open and do not produce nectar, and the pollinators have only pollen as a reward. The fruits possibly have zoochoric dispersion mainly because they serve as food for birds and fish [7].

Like the other Lauraceae genera, Aniba's taxonomy needs studies supporting the understanding of the group's evolution. Species belonging to the genus are considered difficult to identify due to the extreme similarity between them. Thus, morphological [8] and anatomical [9-11] studies are essential to identify species and recognize their intraspecific variations. Phytochemical studies have also shown high importance for indicating the chemical variations that occur in the group [12,13], and molecular studies have increasingly helped to understand the genetic diversity of species and the phylogenetic relationships of the group $[14,15]$. Recently, the combination of phylogenetic data and secondary metabolites of Aniba species was evaluated. The chemical composition of essential oils and DNA sequences of matK, $p s b A-t r n H, r b c L$, and ITS regions of the species A. rosaeodora, A. parviflora, $A$. terminalis Ducke, and $A$. canelilla (Kunth) Mez showed close relationships according to their chemical and genetic aspects comparable to the traditional morphological classifications [16]. Thus, the combination of data from different areas of knowledge, complemented by information on geographic distribution [17], has revealed coherent information about the group's evolution [3]. However, the number of existing studies is not proportional to the great diversity of species within the genus, which are indispensable to understanding the evolutionary history, improved classification, and contributing to the conservation and management of Aniba species.

The secondary metabolites in Aniba extracts are characterized by neoligans, pyrones, benzophenones, allylphenols, and flavonoids [18-20]. The homogeneity of the genus is indicated by benzoyl esters and their derivatives and by the benzyltetrahydroisoquinoline alkaloids, practically ubiquitous in all analyzed species [20,21], which permit them to contribute to the chemosystematics of the genus [18].

Aniba species are excellent producers of essential oils (EOs), and from them, extensive chemical studies have been reported, resulting in the establishment of three groups according to their chemical nature and primary components. Group I, linalool: A. duckei and A. rosaeodora; group II, benzyl benzoate: $A$. burchellii Kosterm., A. fragrans Ducke, $A$. firmula (Nees and Mart. ex Nees) Mez, A. gardneri (Meisn.) Mez, A. guianensis (Aubl.), A. parviflora, 
and A. permollis (Nees) Mez; group III, alkylbenzenes: A. canelilla, A. hostmanniana (Nees) Mez and A. pseudocoto (Rusby) Kosterm. [12,13].

The EOs of Aniba are rich in volatile compounds that, when isolated or in synergy, presented several biological properties. The EO of Aniba canelilla (Kunth) Mez, known as "casca-preciosa," is rich in 1-nitro-2-phenylethane (50-90\%) and methyleugenol (5-40\%) and stands out in terms of its cardiovascular and cytotoxic potential [22-24]. The EOs of Aniba duckei Kosterm and A. rosaeodora Ducke, known as "pau-rosa" in the Brazilian Amazon region, display a significant content of linalool, with about $85 \%[25,26]$, where both species exhibit remarkable antifungal and cytotoxic activities [27-29]. Aniba parviflora (Meisn) Mez., popularly called "macacaporanga" or "louro-rosa", is often confused with A. duckei and A. rosaeodora, the "pau-rosa" (rosewood) plants. Despite the similarity, these species have distinct aromas in their wood and leaf oils [30,31]. Additionally, A. parviflora oil contains a lower percentage of linalool, about $40 \%[25,26]$. Among the several biological activities, the A. parviflora oil stands out for presenting a significant antimicrobial potential [32-35].

Considering the Aniba species diversity and its predominant occurrence in the Amazon biome, this study aims to present a broad and updated review of research on this plant group's chemical composition and biological activity.

\section{Economic and Traditional Uses and Conservation of Aniba Species}

Several Aniba species occurring in the Amazon region present significant economic value and great ecological importance in their native locations [36]. Many of these species are raw materials in public markets of medicinal plants, food, cosmetics, and regional perfumes, and suppliers of good quality wood. Additionally, most of them are essential oil producers, with high value in the national and international markets $[27,37]$.

Aniba terminalis Ducke and $A$. firmula have wood with a rigid structure suitable for carpentry and joinery [38]. Aniba canelilla is considered hardwood because it is resistant to fungi and xylophagous insects and has good impermeability in naval and civil carpentry. In addition, all parts of $A$. canelilla are aromatic, used as seasonings and ingredients for local dishes, fragrances, and flavoring sachets for clothes [27,38]. Aniba parviflora is also known for its quality wood and is used in the perfumery industry, sometimes confused with A. rosaeodora, both showing the linalool characteristic aroma, which for a long time have served as ingredients in fragrances and flavor for food and soft drink products [39-41].

Traditional Amazonian populations customarily use Aniba species to treat diseases and in religious rituals. For example, the leaves and woods of $A$. fragrans and $A$. rosaeodora are used in many Amazonian folk baths, such as the São João festival [42]. Aniba rosaeodora essential oil has been used in aromatherapy and home treatments for skincare and the immune and nervous systems [40,43]. In Santarém communities (Pará state), an A. fragrans bark decoction is orally used to treat snakebite victims [44]. Aniba canelilla powdered seeds are used as an antidiarrheal, and its bark infusion is used to treat coughs as an antispasmodic and stimulant for the central nervous system. Additionally, the A. canelilla bark tea is used to treat fever, headache and stomachache by Rorainópolis (Roraima state) and Novo Airão (Amazonas state) communities, located near the Jauaperi River [45-48]. Additionally, the Indians of Rio Negro (Amazonas state) use the A. canelilla bark tea as a stimulant, digestive, antispasmodic tonic and for the treatment of anemia, while the Xipaya, an ethnic Indian group of Altamira (Pará state), utilize the same bark tea as a tranquilizer $[49,50]$.

The aromatic characteristics of some Aniba species are mainly due to the presence of linalool, and the A. rosaeodora trunkwood is the primary source in the Amazon region, with a linalool content of about $80-97 \%$ [51]. However, due to the depletion of trees accessible for commercial exploration, it is usually replaced by other Aniba species, which causes variations in their oil yield, between $0.7 \%$ and $1.2 \%$. In addition, samples derived from oils of different populations have shown substantial variation in the physicochemical properties 
and fragrance of the oils, suggesting high genetic variation in the specimens or adulteration resulted from a mixture of other Aniba oils [36].

Extractivism is the main activity for the commercial exploitation of aromatic plants from the Amazon. Many species are now under pressure from exploitation, deforestation, and habitat burning [52]. Predatory exploitation and destruction of natural habitats of species with restricted distribution, like some Aniba species, has led to the inclusion of several species in the Red List of Threatened Species [53] and the Brazilian Flora Red List $[17,54]$. From the species surveyed in this review, only A. canelilla and A. rosaeodora are included in local management programs and subject to ex-situ conservation. Concerning in-situ conservation in protected areas, only A. canelilla and A. parviflora are listed within the genus [53]. The conservation status of Aniba species sampled for the study of chemical composition and biological activity, raised in this review, points out that all of them are in a situation of mostly minor concern, except $A$. rosaeodora, which is endangered due to decades of predatory exploitation that this species has been facing, as the destruction of its natural habitats by logging, livestock, and agriculture, which has culminated in the continued decline of its natural population [54].

Studies have shown that the density of rosewood trees in the forest is low; about 1 tree per 7 hectares [55]. Even so, the rosewood oil intended for trade is obtained exclusively by steam distillation of trunk wood and bark from A. rosaeodora trees, consisting of a predatory and a high-risk method of reduction in genetic variability of the species [56]. The indiscriminate cutting of many trees of reproductive age has prevented natural regeneration, leading to a drastic reduction in natural populations, which permitted the Brazilian Institute for the Environment and Natural Resources (IBAMA) to include it in the list of endangered species [57]. Consequently, IBAMA promulgated a set of rules, allowing for the extraction and controlled commercialization of rosewood from the Amazon, only through the preparation and approval of sustainable management and reforestation plans [58]. Rosewood essential oil industry has long been threatened by the scarcity of raw materials and increased environmental regulatory requirements to prevent species extinction [56]. The main limitations for developing production technologies for the species occur because their natural regeneration is irregular and infrequent. Although the propagation by cuttings has a survival rate of about $70 \%$, the availability of matrices for the production of seedlings on a large scale is limited [59,60]. Other limiting factors are the scarcity of information on natural variability, ecology, and distribution of the species [17]. In addition, there is a difficulty for $A$. rosaeodora to produce seedlings. Rosewood propagates naturally through seeds, but these are often preyed upon by birds and insects before maturation [61] and by rodents after maturation [62].

A project sponsored by the Benchimol award in 2005 was implemented to guarantee the sustainable supply of rosewood oil in the Brazilian Amazon [56]. As part of the proposal, a germplasm collection of $A$. rosaeodora and other Aniba species was created. Based on this, tissue culture studies were carried out, which demonstrated that the rosewood could be propagated satisfactorily in vitro from the cultivation of its stem apices [63]. These activities aimed to facilitate researchers' access to plant material and reintroduce representative germplasm in regions where the species had already been extirpated, aiming at its in vivo conservation. The researchers of the project highlighted that the articulation of the research sector, government agencies, and the productive sector, represented by distilleries, riverside communities, and small producers, was indispensable for the development of an efficient model of propagation and production of seedlings on a large scale, in order to restore populations in their natural environment [56].

\section{Scope of Collected Data}

In this review, data collection of Aniba species was performed electronically, based on published articles, conference proceedings, theses, and ethnobotanical textbooks. The research was carried out in the Google Scholar, Science Direct, Scopus, and PubMed databases focused on chemical diversity and biological activities of essential oils of Aniba 
species. The keywords used were "essential oils", "chemical profile", "biological activity", "chemical diversity", "chemical markers of Aniba species". The authors built the map of sample distribution based on the information of the collection sites, available in the bibliographic references to each access (see Figure 1). Based on the survey, there are reports on the species Aniba burchellii Kosterm., A. canelilla (Kunth) Mez, A. cinnamomiflora C.K. Allen, A. citrifolia (Nees) Mez, A. duckei Kosterm., A. fragrans Ducke, A. gardneri (Meisn.) Mez, A. guianensis Aubl., A. hostmanniana (Nees) Mez, A. panurensis (Meisn.) Mez., A. parviflora (Meisn) Mez., A. puchury-minor (Mart.) Mez., A. riparia (Nees) Mez., A. rosaeodora Ducke, and A. terminalis Ducke, corresponding to 167 samples of essential oils.

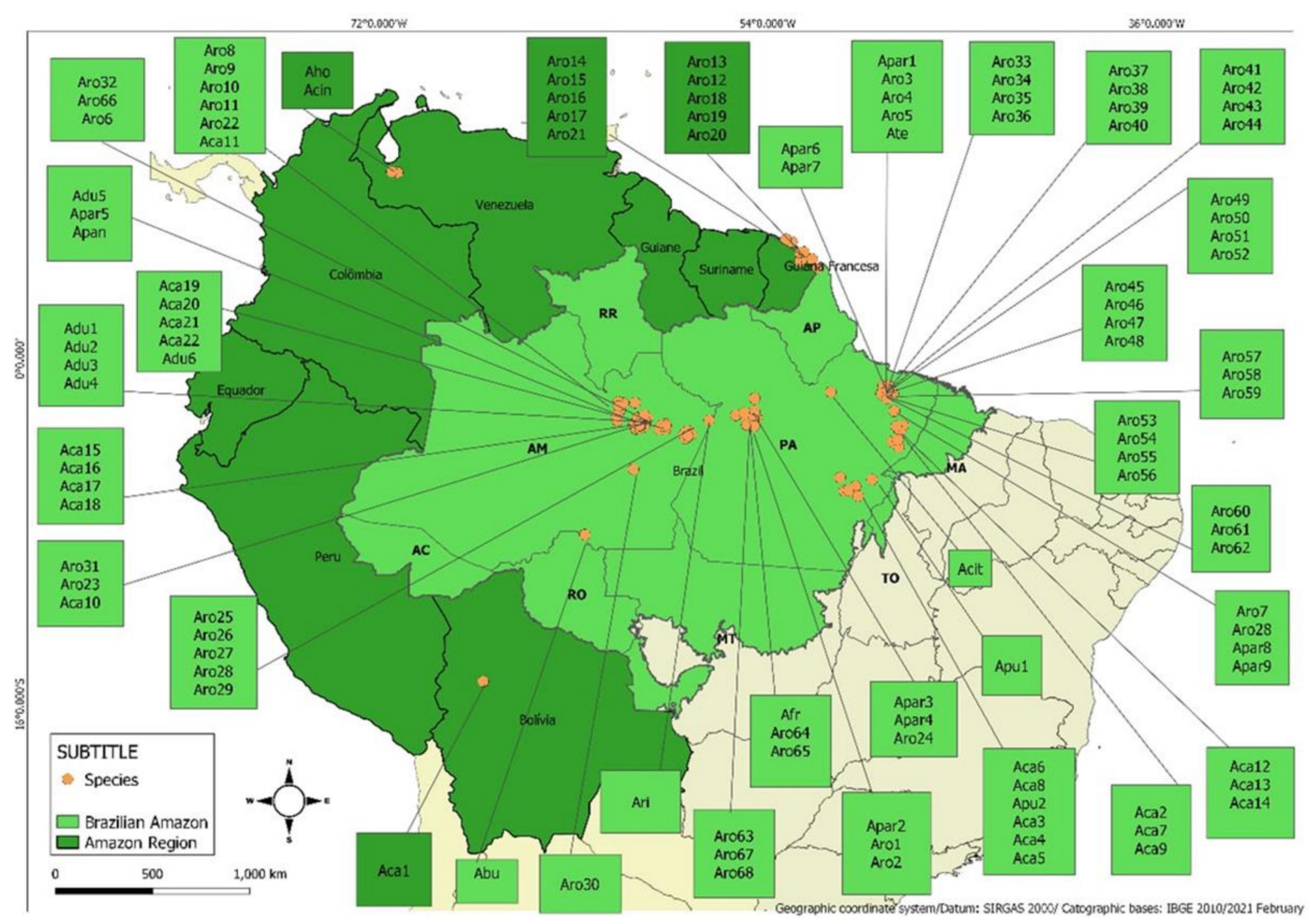

Figure 1. Geographical distribution from specimens of Aniba in the Amazon biome, based on its studies of essential oils. The authors built this map using the information of the collection sites available in the bibliographic references for each access. Aniba burchellii (Abu), A. canelilla (Aca1-Aca22), A. cinnamomiflora (Acin), A. citrifolia (Acit), A.duckei (Adu1-Adu6), A. fragrans (Afr), A. hostmanniana (Aho), A. panurensis (Apan), A. parviflora (Apar1-Apar-9), A. puchury-minor (Apu1, Apu2), A. riparia (Ari), A. rosaeodora (Aro1-Aro68), A. terminalis (Ate). Abbreviation list: AC: Acre, AM: Amazonas, AP: Amapá, MA: Maranhão, MT: Mato Grossso, PA: Pará, RR: Roraima, RO: Rondônia, TO: Tocantins.

Aniba species showed geographic distribution in four countries of the Amazon biome: Brazil, Bolivia, Venezuela, and French Guiana. The most representative geographic area in specimen number was Brazilian Amazon with highlight to Pará State (67 samples) and Amazonas State (35 samples), predominantly in the cities of Belém (PA) (3 spp., 37 samples) and Manaus (AM) (3 spp., 16 samples), respectively. Aniba rosaeodora (68 samples) and A. canelilla (22 samples) were the species with the most significant number of studies, followed by A. parviflora (9 samples) and A. duckei (6 samples). Additionally, studies on EO samples extracted from A. cinnamomiflora and A. hostmanniana were found only for specimens collected in Venezuela. 


\section{Multivariate Statistical Analysis Based on the Essential Oils of Aniba Species}

A multivariate statistical analysis was performed to group the compound classes as chemical markers of the Aniba species. The EOs from specimens of Aniba were divided into two groups according to the tissue: leaf, thin twig, and branch; stem, bark, and trunk wood. Seventy-six specimens of A. canelilla, A. duckei, A. fragrans, A. gardneri, A. hostmanniana, A. panurensis, A. parviflora, A. puchury-minor, A. riparia, and A. rosaeodora showed $84 \mathrm{EO}$ samples of leaves, thin twigs, and branches. In contrast, thirty-eight EO samples of stems, barks, and trunk woods of A. canelilla, A. cinnamomiflora, A. citrifolia, A. gardneri, A. guianensis, A. parviflora, A. puchury-minor, A. rosaeodora, and A. riparia were represented by thirty-one specimens (see Figure 2).

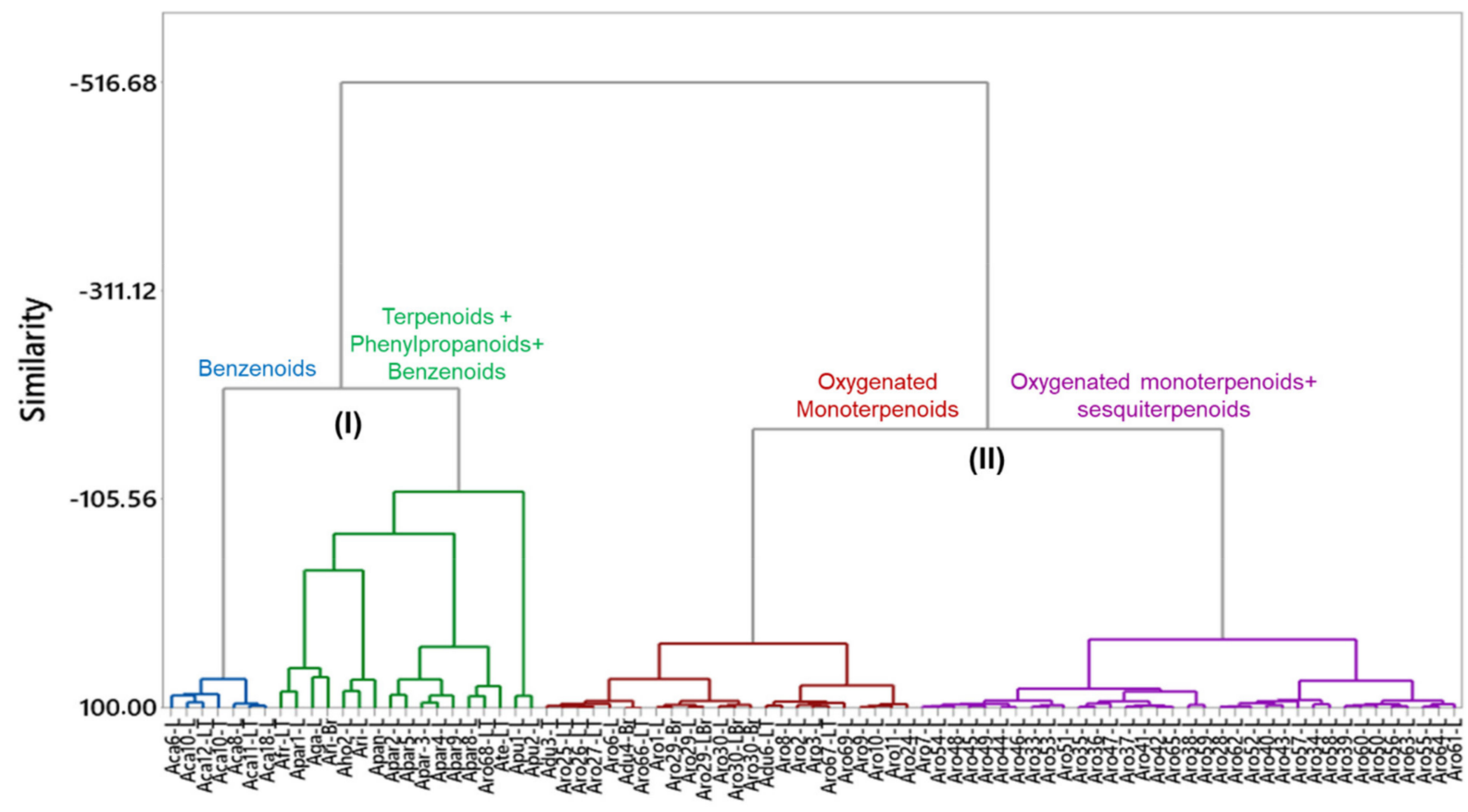

Figure 2. Hierarchical Clusters Analysis (HCA) obtained by Ward Linkage Method to the Aniba species based on compound class present in the essential oils extracted from leaves, thin twigs, and branches: Aniba canelilla (Aca6-L, Aca8-L, Aca10-L, Aca10-T, Aca11-LT, Aca12-LT, Aca18-L), A. duckei (Adu3-T, Adu4-Br, Adu6-LT), A. fragrans (Afr-LT), A. gardneri (Aga-L), A. hostmanniana (Aho2-L), A. panurensis (Apan-L), A. parviflora (Apar1-L, Apar2-L, Apar-3-L, Apar4-L, Apar5-L, Apar8-L, Apar9-L), A. puchury-minor (Apu1-L, Apu2-L), A. riparia (Ari-L, Ari-Br), A. rosaeodora (Aro1-L, Aro2-L, Aro3-L, Aro6-L, Aro7-L, Aro8-L, Aro9-L, Aro10-L, Aro11-L, Aro24-L, Aro25-LT, Aro26-LT, Aro27-LT, Aro28-L, Aro29-L, Aro29-Br, Aro29-LBr, Aro30-L, Aro30-Br, Aro30-LBr, Aro33-L, Aro34-L, Aro35-L, Aro36-L, Aro37-L, Aro38-L, Aro39-L, Aro40-L, Aro41-L, Aro42-L, Aro43-L, Aro44-L, Aro45-L, Aro46-L, Aro47-L, Aro48-L, Aro49-L, Aro50-L, Aro51-L, Aro52-L, Aro53-L, Aro54-L, Aro55-L, Aro56-L, Aro57-L, Aro58-L, Aro59-L, Aro60-L, Aro61-L, Aro62-L, Aro63-L, Aro64-L, Aro65-L, Aro66-LT, Aro67-LT, Aro68-LT, Aro69-L, Ate-LT). Abbreviation list: L: leaves, T: thin twigs, Br: branches.

Total percentage of the following compound classes, monoterpene hydrocarbons $(\mathrm{MH})$, oxygenated monoterpenes $(\mathrm{OM})$, sesquiterpene hydrocarbons $(\mathrm{SH})$, oxygenated sesquiterpenes (OS), phenylpropanoids (PP), and benzenoids (BZ), present in the leaves, thin twigs, branches, stems, barks, and trunk woods was applied as variables. The data matrix was standardized by subtracting the mean from each compound's value and then subtracting it by the standard deviation. The values were submitted to Hierarchical Cluster Analysis (HCA) based on Ward binding and Euclidean distance, using the software Minitab 17 (free 390 version, Minitab Inc., State College, PA, USA). 


\subsection{Essential Oils from Leaves, Thin Twigs and Branches of Aniba Species}

Based on the dendrogram obtained by HCA, using the classes of compounds as variables, $84 \mathrm{EO}$ from the leaves, thin twigs, and branches of Aniba species were classified into two main clusters, presenting a similarity of $-516.68 \%$. Cluster I was composed of twenty-four oils of A. canelilla, A. puchury-minor, A. gardneri, A. hostmanniana, A. riparia, A. fragans, A. parviflora, $A$. rosaeodora, and A. terminalis. The samples of cluster I were divided into two subgroups with a similarity of $-214.58 \%$. Subgroup I-1 was formed by seven oils from A. canelilla with a high concentration of benzenoids, especially 1-nitro-2-phenylethane $(68.7-95.3 \%)$, and with a similarity of $71.50 \%$. On the other hand, subgroup I-2 comprised oils rich in terpenoids (traces-89.3\%), benzenoids (traces-45.4\%), and phenylpropanoids (traces-44.5\%) with a similarity of $-112.69 \%$. In this I-2 subgroup, seventeen samples of A. fragrans, A. gardneri, A. hostmanniana, A. parviflora, A. riparia, A. parviflora, A. rosaeodora, $A$. terminalis, and A. puchury-minor were grouped.

In cluster II, sixty samples of $A$. duckei and A. rosaeodora were grouped and divided into two subgroups with a similarity of $-174.49 \%$. The subgroup II- 1 was composed of twenty-four oils of $A$. duckei and A. rosaeodora with a similarity of $36.69 \%$ and characterized by the high concentration oxygenated monoterpenes, such as linalool (79.0-88.60\%). The subgroup II-2 comprised thirty-six oils of $A$. rosaedora rich in oxygenated monoterpenes $(57.2 \%)$, sesquiterpene hydrocarbons $(12.69 \%)$, and oxygenated sesquiterpenes $(8.74 \%)$, showing a similarity of $32.51 \%$. According to the individual species, the disposition of the classes of compounds can be visualized in Figure 2. The information on the main compounds of EOs extracted from leaves, thin twigs, and branches of Aniba species, their corresponding collection data, and their extraction method are present in Table 1.

\subsubsection{Cluster I: Benzenoid-Rich Oils}

EO samples of Aniba canelilla (Aca) collected in Serra dos Carajás (PA, Brazil) (Aca6L and Aca8-L), Adolpho Ducke Forest Reserve (AM, Brazil) (Aca10-L and Aca10-LT), Ulianópolis (PA, Brazil) (Aca12-LT), and Novo Airão (AM, Brazil) (Aca11-LT) were arranged in the subgroup I-1 (Figure 2). These samples showed a higher similarity level $(71.50 \%)$ due to a higher concentration of benzenoids, characterized by the significant compound 1-nitro-2-phenylethane (68.2-95.3\%). However, small quantities of linalool $(5.2-8.8 \%)$, eugenol $(5.2 \%)$, benzaldehyde $(4.8 \%)$, spathulenol $(4.8 \%), \beta$-selinene $(4.5 \%)$, and $\beta$-caryophyllene (3.5\%) also were identified (Table 1) $[27,35,64,65]$.

\subsubsection{Cluster I: Terpenoid, Phenylpropanoid and Benzenoid-Rich Oils}

Seventeen samples formed subgroup I-2 with significant chemical diversity by their main compounds and a similarity level of $-112.69 \%$ (Figure 2). The EO of two specimens of A. puchury-minor, collected in Serra dos Carajás (PA, Brazil) (Apu1-L and Apu2-L), displayed sesquiterpene hydrocarbons (48.29\%) and phenylpropanoids (41.50\%) with significant contents. The major compounds were elemicin $(23.46 \%$ and $21.5 \%)$, bicyclogermacrene $(15.4 \%)$ and germacrene $(13.42 \%)$ (Table 1) [66,67].

The EO samples of A. gardneri, A. hostmanniana, and A. riparia were rich in sesquiterpene hydrocarbons (4.8-65.5\%), oxygenated sesquiterpenoids (10.7-43.5\%), and benzenoids $(3.2-45.4 \%)[12,68,69]$ (Figure 2). The oils of A. hostmanniana (Aho2-L) and A. gardneri (Aga-L) showed benzyl benzoate (29.3\% and $44.1 \%$ ) and $\delta$-cadinene $(12.0 \%$ and $4.8 \%$ ) as the most abundant compounds $[12,68]$. On the other hand, the majority compounds of A. riparia (Ari-Br and Ari-L) were $(E)$-nerolidol $(19.4 \%)$, $\beta$-caryophyllene $(16.9 \%)$, elemol $(16.2 \%)$, and $\alpha$-humulene $(14.9 \%, 10.9 \%)$ [69] (Table 1). These specimens were collected in Parintins (AM, Brazil) (Ari-L, Ari-Br), Mérida (Venezuela) (Aho2-L). The A. gardneri (Aga-L) was sampled in the Brazilian Amazon but without a collection site mentioned. The oil of A. panurensis (Apan-L), collected in Adolpho Ducke Forest Reserve (Manaus, AM, Brazil) was characterized by a high content of sesquiterpene hydrocarbons $(89.3 \%)$ and $\beta$-caryophyllene (33.5\%), germacrene-D $(25.4 \%)$, and $\alpha$-copaene $(7.5 \%)$ were most representative constituents [70]. 
The oils of $A$. fragans (Afr), A. parviflora (Apa), A. rosaeodora (Aro), and A. terminalis (Ate) showed monoterpene hydrocarbons (31.54\%), oxygenated monoterpenoids (32.07\%), sesquiterpene hydrocarbons (13.75\%), and oxygenated sesquiterpenoids $(17.72 \%)$ as the main compound classes (Figure 2). The most representative constituents were linalool (11.90-45.0\%), $\alpha$-phellandrene (4.1-32.8\%), and $\beta$-phellandrene (7.55-23.60\%) (Table 1). In the EO of $A$. fragrans were linalool (32.4\%), spathulenol (19.1\%), and limonene (14.5\%). The species were collected in the Curuá-Una (PA, Brazil) (Afr-L), Santarém (PA, Brazil) (Apa2-L, Apa3-L, and Apa4-L), Adolpho Ducke Forest Reserve (AM, Brazil) (Apar5-L), Tomé-Açu (PA, Brazil) (Apar8-L and Apar9-L), Arapiuns (PA, Brazil) (Aro68-LT) and Belém (PA, Brazil) (Ate-LT and Apar1-L) [32-35,51,71-75].

\subsubsection{Cluster II: Oxygenated Monoterpene-Rich Oils}

Twenty-four oils of Aniba duckei and A. rosaeodora were arranged in subgroup II1, comprising samples collected in Pará and Amazonas state, Brazil, with a similarity level of $36.69 \%$ (Figure 2). The A. rosaeodora EOs from Pará state showed oxygenated monoterpenes contents varying from $81.12-91.80 \%$. The major compound was linalool $(79.0-88.60 \%)$, followed of $\beta$-selinene $(2.0 \%)$, aromadendrene oxide $(2.5 \%),(E)$-nerolidyl acetate $(1.5 \%)$ and cis-linalool oxide $(1.84 \%)$ (Table 1$)$. These samples were collected in Belém (Aro3-L), Curuá-Una (Aro1-L, Aro24-L), Santarém (Aro2-L), and Rurópolis (Aro67-LT) (PA, Brazil) [33,51,71,74,76].

Specimens of $A$. duckei and A. rosaoedora collected in the Amazonas state exhibited significant variation in their oxygenated monoterpenes (71.8-98.5\%) contents and chemical diversity of the oils. Linalool varied from $71.76 \%$ to $93.60 \%$, followed by $\beta$ selinene $(0.64-6.41 \%)$, $\alpha$-terpineol (1.11-5.6\%), spathulenol $(0.34-4.0 \%)$, caryophyllene oxide (2.0-3.2\%), and cis-linalool oxide (1.6-3.03\%), in smaller proportions (Table 1). The Amazonas collection sites were Itacoatiara (Adu6-LT), Presidente Figueiredo (Aro6-L), Novo Airão (Aro8-L, Aro9-L, Aro10-L and Aro11-L), Maués (Aro25-LT, Aro26-LT, Aro27LT, Aro29-L, Aro29-Br and Aro29-LBr), Novo Aripuanã (Aro30-L, Aro30-Br and Aro30-LBr), Adolpho Ducke Forest Reserve in Manaus (Adu3-L, AduBr-4 and Aro66-LT) and Aro69-L (collection site not indicated) [25,29,30,77-82].

\subsubsection{Cluster II: Oils Rich in Oxygenated Mono- and Sesquiterpenes}

Subgroup II-2 was represented by thirty-six samples of $A$. rosaeodora oils collected in Tomé-Açu (PA, Brazil) (Aro7-L and Aro28-L), Novo Aripuanã (AM, Brazil) (Aro30-LBr), Belém (PA, Brazil) (Aro33-L to Aro62-L), and Curuá Una (PA, Brazil) (Aro63-L to Aro65-L) (Figure 2). These oils showed a similarity level of $32.51 \%$, and the oxygenated monoterpenes, sesquiterpene hydrocarbons, and oxygenated sesquiterpenes contents were $57.54 \%$, $12.62 \%$ and $8.74 \%$, respectively. The major constituents were linalool (38.48-71.05\%), spathulenol (3.73-7.20\%), and $\beta$-selinene (3.79-6.41\%) (Table 1) [73,80].

\subsection{Essential Oils from Stem, Bark and Trunkwood of Aniba Species}

Based on the dendrogram resulting from the HCA, thirty-eight oils from the stem, bark, and trunkwood of Aniba species were classified into four main clusters. Cluster I comprised fifteen oils of A. canelilla, A. gardineri, and A. guianensis rich in benzenoids (34.4-92.5\%), phenylpropanoids (traces-65.3\%), and sesquiterpene hydrocarbons (traces-15.6\%), showing a similarity of $28.2 \%$. Four samples of $A$. puchury-minor were grouped in cluster II, characterized by a high content of phenylpropanoids $(99.14 \%)$ and a similarity level of $98.65 \%$. Cluster III was composed of seven samples of A. canelilla, A. cinnamomiflora, A. citrifolia, $A$. parviflora, and $A$. riparia with a similarity of $-5 \%$. The main classes were benzenoids (traces-47.4\%), oxygenated monoterpenes (4.2-45.4\%), monoterpene hydrocarbons (traces-43.7\%), sesquiterpene hydrocarbons (4.0-33.3\%), phenylpropanoids (traces-16.7\%), and oxygenated monoterpenes (traces-13.6\%), with significant contents. Finally, cluster IV grouped all oil samples of $A$. rosaeodora, presenting a high level of similarity $(77.39 \%)$. These samples were characterized by significant amounts of oxygenated 
monoterpenes, especially linalool (81.6-95.0\%). According to the related species, the disposition of the classes of compounds can be visualized in Figure 3, and the information on the main compounds of the stem, bark, and trunk wood EOs from Aniba species and their collection data, are present in Table 1.

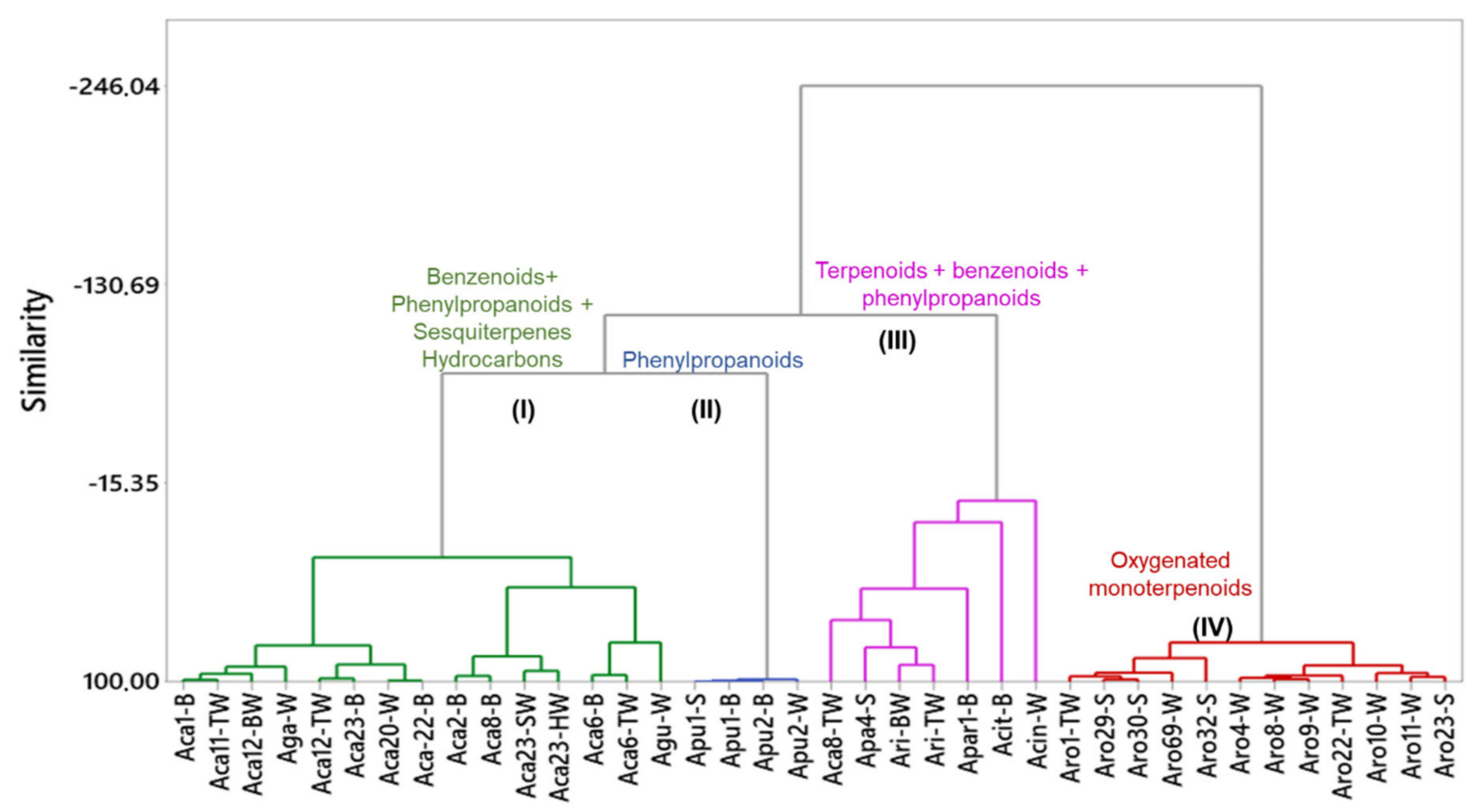

Figure 3. Hierarchical Clusters Analysis (HCA) obtained by Ward Linkage Method to Aniba species based on compound class present in the essential oil extracted from barks and woods: Aniba canelilla (Aca1-B, Aca2-B, Aca6-B, Aca6-TW, Aca8-B, Aca8-TW, Aca11-TW, Aca12-BW, Aca12-TW, Aca20-W, Aca22-B, Aca23-SW, Aca23-HW, Aca23-B), Aniba cinnamomiflora (AcinW), Aniba citrifolia (Acit-B), A. gardneri (Aga-W), A. guianensis (Agu-W), A. parviflora (Apar1-B, Apar4-S), A. puchury-minor (Apu1-S, Apu1-B, Apu2-B, Apu2-W), A. rosaeodora (Aro1-TW, Aro4-W, Aro8-W, Aro9-W, Aro10-W, Aro11-W, Aro22-TW, Aro23-S, Aro29-S, Aro30-S, Aro32-S, Aro69-W), Aniba riparia (Ari-BW, Ari-TW). Abbreviation list: B: bark, S: steam, W: wood, BW: barkwood, HW: heartwood, SW: sapwood, TW: trunk wood.

\subsubsection{Cluster I: Oils Rich in Benzenoids, Phenylpropanoids and} Sesquiterpene Hydrocarbons

Fifteen oils extracted from A. canelilla (Aca), A. gardneri (Aga) and A. guianensis (Agu) were grouped in cluster I, presenting a similarity of $28.02 \%$ (Figure 3 ). The EOs of $A$. canelilla, collected in Serra dos Carajás (PA, Brazil) (Aca6-B, Aca6-TW and Aca8-W), and A. guianensis (Agu-W, collection site not informed) showed benzenoids (34.4-65.4\%), phenylpropanoids (8.5-65.3\%) and sesquiterpene hydrocarbons (traces-15.6\%) as predominant compound classes. 1-Nitro-2-phenylethane (50.2-60.5\%), methyleugenol (21.3-34.7\%), and $\beta$-sesquiphellandrene (5.4-6.4\%) were the main compounds presented in A. canelilla oil samples. On the other hand, the most abundant compounds of A. guianensis oil were benzyl benzoate (59.0\%), benzyl salicylate (6.4\%), and methyl isoeugenol (5.0\%) (Table 1) [12,64].

Aniba canelilla and A. gardneri collected in Fatima de Chimanes (Bolivia) (Aca1-SB), Novo Airão (PA, Brazil) (Aca11-TW), Ulianópolis (PA, Brazil) (Aca12-BW and Aca12-TW), Itacoatiara (AM, Brazil) (Aca20-W, Aca22-B, Aca23-B and Aga-W with not reported collection site) were rich in benzenoids (34.4-92.5\%) and phenylpropanoids (traces-65.3\%) (Figure 2). In general, the main compounds identified in A. canelilla oils were 1-nitrophenylethane (47.4-92.1\%) and methyleugenol (2.0-38.6\%). However, high contents of methyleugenol were reported in the sapwood $(65.3 \%)$ and heartwood $(52.9 \%)$ tissues of A. canelilla. Additionally, significant contents of benzenoids, such as benzyl ben- 
zoate $(78.1 \%)$ and phenylethyl benzoate (14.3\%), were identified in the EO of $A$. gardineri (Table 1) [12,27,83-87].

\subsubsection{Cluster II: Phenylpropanoid-Rich Oils}

Cluster II was formed by oils of A. puchury-minor collected in the Serra dos Carajás (PA, Brazil) (Apu1-S and Apu1-B), and Canaã do Carajás (PA, Brazil) (Apu-B and Apu2-W) (Figure 3). The oils samples showed a similarity of $98.65 \%$ due to the high contents of phenylpropanoids $(99.14 \%)$. The main compounds of the oils were $(E)$-asarone $(29.95-52.75 \%)$, methyleugenol (17.62-43.10\%) and $(E)$-isoelemicin $(11.87-23.1 \%)$ (Table 1) [66,67].

\subsubsection{Cluster III: Oils Rich in Terpenoids, Benzenoids and Phenylpropanoids}

The oils of A. canelilla (Aca), A. cinnamomiflora (Acin), A. citrifolia (Acit), A. parviflora (Apa) and $A$. riparia (Ari) showed significant chemical diversity for their main compounds, grouped in Cluster III, showing a similarity level of $-5.0 \%$ (Figure 3). The most representative compound classes were benzenoids (traces- $-47.4 \%$ ), oxygenated sesquiterpenes (4.2-45.4\%), monoterpene hydrocarbons (traces-43.7\%), sesquiterpene hydrocarbons (4.0-33.3\%), oxygenated monoterpenes (traces-13.6\%) and phenylpropanoids (traces-16.7\%). The oil of the trunk wood of A. canelilla was rich in benzenoids (47.4\%), oxygenated sesquiterpenes $(20.5 \%)$, and phenylpropanoids (12.5\%), showing 1-nitro-2phenylethane (47.4\%), epi- $\alpha$-cadinol $(19.9 \%)$, and methyleugenol $(10.5 \%)$ as the main constituents (Table 1) [64]. The oil of A. cinnamomiflora from Los Andes (Merida, Venezuela) (Acin-W) showed a high content of the lipid $\gamma$-palmitolactone (54.0\%), followed by 1-epicubenol $(9.56 \%)$ and $\delta$-cadinene $(6.05 \%)$ [88].

Oils of A. riparia (Ari-BW and Ari-TW), collected in Parintins (AM, Brazil), were characterized by the presence of sesquiterpene hydrocarbons $(21.7 \%, 27.2 \%)$, benzenoids $(39.2 \%$, $44.0 \%)$, and oxygenated sesquiterpenes $(14.2 \%, 16.1 \%)$. The most abundant compounds were benzyl benzoate $(30.9 \%, 36.2 \%)$, terpinen-4-ol $(9.3 \%)$, benzyl salicylate $(7.9 \%, 7.7 \%)$, and cis-calamenene (7.2\%) (Table 1) [69].

The EO samples of A. citrifolia collected from Melgaço (PA, Brazil) (Acit-W) showed safrole $(16.7 \%), \alpha$-pinene $(10.6 \%)$, and $\beta$-pinene $(11.2 \%)$ as the main constituents. Monoterpene hydrocarbons (43.7\%), sesquiterpene hydrocarbons $(17.8 \%)$, and phenylpropanoids $(16.7 \%)$ were the main compound classes [89]. Aniba parviflora oils from Belém (PA, Brazil) (Apar1-B) and Santarém (PA, Brazil) (Apar4-S) showed an abundance of oxygenated sesquiterpenes (33.3\% and $24.25 \%)$, sesquiterpene hydrocarbons $(45.4 \%$ and $18.67 \%)$, and oxygenated monoterpenes (13.6\% and $13.35 \%)$. Linalool (11.90\%), aristolene $(11.07 \%)$ and $\beta$-eudesmol (3.97\%) predominated in the A. parviflora oil from Belém (PA), while $\gamma$-eudesmol (16.8\%), $\beta$-caryophyllene (15.7\%), and linalool (12.4\%) were the majority compounds of $A$. parviflora from Santarém (PA) (Table 1) [32,34].

\subsubsection{Cluster IV: Oxygenated Monoterpenoid-Rich Oils}

Cluster IV was composed of twelve samples of A. rosaeodora from Pará and Amazonas states, with a similarity level of $77.39 \%$ (Figure 3). Pará state samples, collected in CuruáUna (PA, Brazil) (Aro1-TW) and Belém (PA, Brazil) (Aro4-W), exhibited a significant content of oxygenated monoterpenes $(91.86 \%)$. The primary compound was linalool $(87.93 \%)$, followed by minor amounts of $\alpha$-terpineol (2.9\%), cis-linalool oxide (1.0-1.68\%), and translinalool oxide (0.90-1.60\%) $[25,76,90,91]$. On the other hand, the oils from Amazonas state, collected in Novo Airão (AM, Brazil) (Aro8-W, Aro9-W, Aro10-W, Aro11-W, and Aro22TW), Maués (AM, Brazil) (Aro29-W), Manaus (AM, Brazil) (Aro23-S and Aro32-S), Novo Aripuanã (AM, Brazil) (Aro30-S) and Aro69-W (collection site not reported), showed a percentage of oxygenated monoterpenes varying from $81.6 \%$ to $95.0 \%$. The linalool content ranged from $63.16 \%$ to $86.12 \%$, followed by trans-linalool oxide $(0.90-9.73 \%)$, $\alpha$-terpineol (3.8-5.6\%), benzyl benzoate (2.7\%), and cis-linalool oxide (1.6-2.7\%) [25,30,70,80,92,93]. 


\section{Aniba Commercial Samples}

Leaf essential oils from A. canelilla purchased at Ver-o-peso market (Belém, Brazil) were dominated by 1-nitro-2-phenylethane (99.1\%). On the other hand, the trunk wood oil of A. canelilla, obtained by a donation from a Manaus oil producer (AM, Brazil), presented 1-nitro-2-phenylethane (68.8\%) and a significant amount of methyleugenol (28.1\%) [77].

The oils of A. rosaeodora obtained from Dr. Josif Pancic, Institute for Medicinal Plants Research (Belgrade, Serbia), Erbamea (Istrana, Treviso, Italy), and Oshadhi Ltd. (Cambridge, UK) showed a total of oxygenated monoterpenes ranging from $51.7 \%$ to $92.4 \%$. Linalool $(44.1-81.3 \%)$ and linalyl acetate $(31.4 \%)$ were the main compounds, followed by minor concentrations of limonene $(19.2 \%), \beta$-caryophyllene $(10.5 \%)$, geraniol $(7.8 \%)$ and $\alpha$-terpineol (4.78\%) [94-96]. In other commercial samples, with origins not reported, the oxygenated monoterpenes contents varied from $74.6 \%$ to $100 \%$. The most representative compound was linalool (72.0-86.5\%), followed by cis-linalool oxide (1.06-5.8\%), trans-linalool oxide (1.1-5.2\%), and $\alpha$-terpineol (4.5\%) [76,77,97,98].

\section{Seasonal Variation in the Aniba Volatile Constituents}

The essential oil chemical composition of Aniba species can be influenced by environmental factors, such as light, humidity, soil, harvest time, as well as by oil variation in the plant organs and their stage of development [84,99-101]. Different responses in EO production by Aniba species can be evaluated to improve the oil productivity in natural or cultivation conditions [102].

Seasonal changes influenced the oil yield and chemical composition from different tissues of A. canelilla (Aca3, Aca4 and Aca5) collected in the Serra dos Carajás (PA, Brazil) during the rainy and dry seasons. In the leaf EO, 1-nitro-2-phenylethane production was higher in the rainy season (70.6-95.3\%) in comparison to the dry season (39.0-42.1\%) (Figure 3). Conversely, the bark and trunk wood oils exhibited high contents of 1-nitro2-phenylethane (69.2-94.3\%) followed by low amounts of methyleugenol (1.0-17.7\%) in the rainy season, while in the dry season, the content of 1-nitro-2-phenylethane and methyleugenol ranged between $48.6-73.3 \%$ and $22.2-45.8 \%$, respectively (Figure 3) [84].

Aniba canelilla leaf EO (Aca16), collected in Manaus (AM, Brazil) during the dry and rainy season, showed similar chemical profiles with contents of 1-nitro-2-phenylethane of $88.5 \%$ and $88.9 \%$, respectively (Figure 4 ) [22]. However, the EO composition from a specimen of A. canelilla (Aca19) collected in Itacoatiara (AM, Brazil) changed drastically according to season. The average percentages of 1-nitro-2-phenylethane identified in the leaves and thin twigs of $A$. canelilla were $52.2 \%$ and $92.7 \%$ in the rainy and dry season, respectively (Figure 4) [102]. In another study, the content of 1-nitro-2-phenylethane in the leaves of A. canelilla (Aca21) collected in Itacotiara (AM, Brazil) showed a high variation during the months of collection. The dry season showed variable contents (13.17-74.55\%) compared to the rainy season $(31.22-84.33 \%)$. On the other hand, these abrupt changes of 1-nitro-2-phenylethane were not observed in the stems (Aca21) (Figure 4) [101].

Linalool production in the leaf oils of two specimens of $A$. duckei (Adu2), collected in Manaus (AM, Brazil), showed significant variations according to season. The leaf oil content was higher in the dry season (62.4-76.69\%) than in the rainy season (56.26-60.38\%) (Figure 5) [103]. In another study, conversely, a higher percentage of linalool was observed in the rainy season $(63.16 \%)$ in comparison to the dry season $(54.5 \%)$ for the leaves of A. duckei (Adu5). However, the linalool content of the thin twigs was maintained between $69.38 \%$ and $71.98 \%$ in the rainy and dry seasons, respectively (Figure 5) [99].

Leaf oils of $A$. rosaeodora (Aro3) from Belém (PA, Brazil) exhibited the highest linalool content in the dry season with percentages varying from $86.6 \%$ to $96.1 \%$. In the rainy season, the production of linalool varied from $74.8 \%$ to $84.3 \%$, except in March, when the percentage decreased to $68.0 \%$, coinciding with more extensive water precipitation (Figure 5) [25]. Essential oils of A. rosaeodora (Aro31) from Manaus (AM, Brazil) showed linalool contents of $69.0 \%$ (leaves) and $71.0 \%$ (branches) in the dry season, compared to $78.0 \%$ (leaves) and $84.0 \%$ (branches) in the rainy period (Figure 5) [28]. The leaves of 
A. parviflora (Apa7), collected in Belém (PA, Brazil), showed linalool content of 14.07\% and $24.37 \%$ in the dry and rainy seasons, respectively (Figure 5) [104]. The variation of sesquiterpene content could be a consequence of dilution by increased expression of another component [105]. The seasonal variation of linalool content in the leaves of A. duckei, A. parviflora, and A. rosaeodora can be visualized in Figure 5.

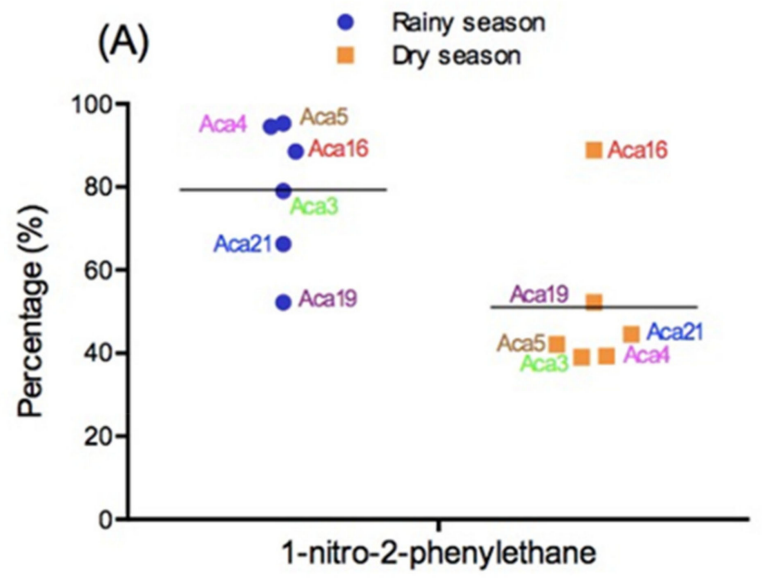

(B)

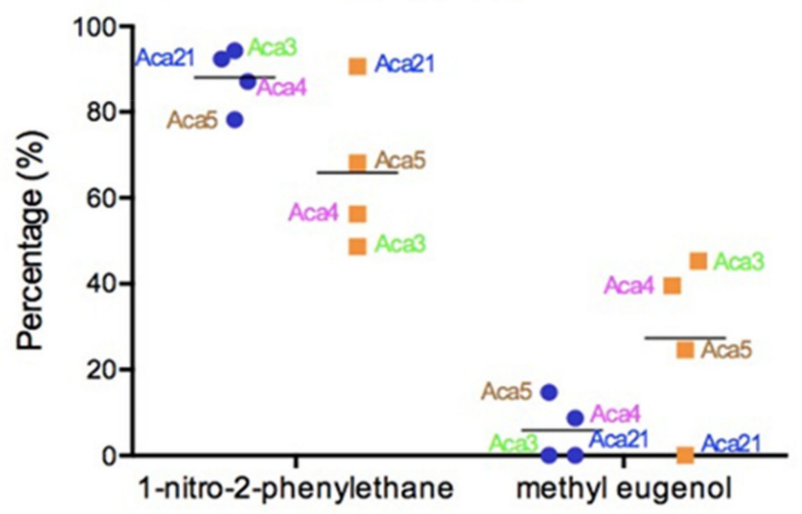

(C)

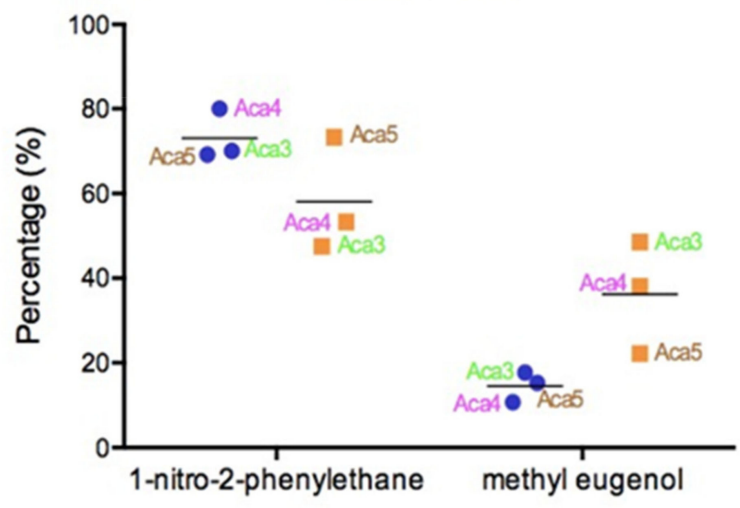

Figure 4. Content variation of 1-nitro-2-phenylethane and methyleugenol in the oils of leaves (A) stems and thin twigs (B) and trunk wood (C) from Aniba canelilla (Aca) during seasonal studies.

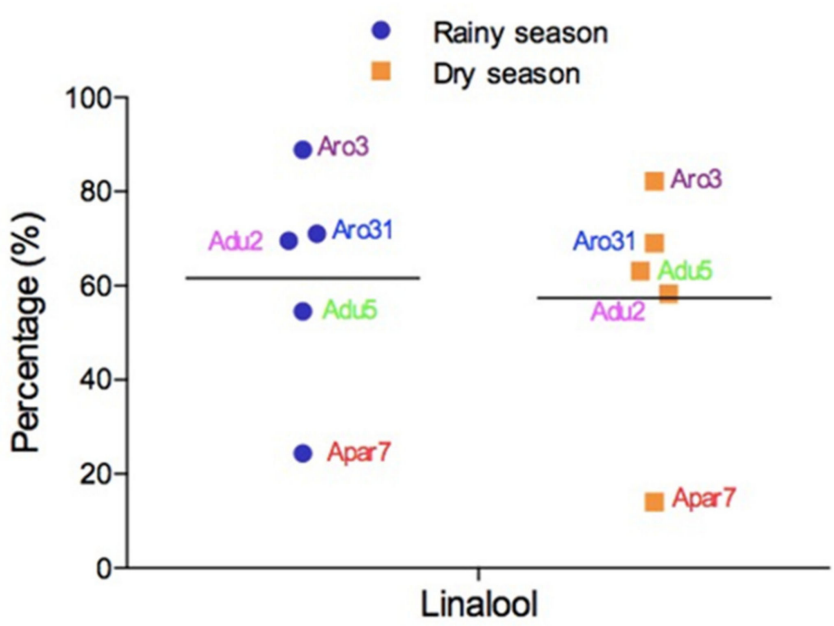

Figure 5. Linalool variation in the leaf oils from A. parviflora (Apa), A. duckei (Adu), and A. rosaeodora (Aro) during seasonal studies. 
Table 1. Main constituents of Aniba essential oils from the Amazon.

\begin{tabular}{|c|c|c|c|c|c|}
\hline Species & Collection Site & Plant Part & Extraction Type & Major Components & References \\
\hline A. burchellii & Humaitá, AM, Brazil & Leaf & SD & $\begin{array}{l}\text { Benzyl salicylate }(45.6 \%), \alpha \text {-pinene }(12,1 \%) \text {, and } \\
\text { benzyl benzoate }(5.2 \%)\end{array}$ & [106] \\
\hline A. canelilla & Manaus, AM, Brazil & Sapwood & HD & Methyleugenol (65.3\%) and eugenol (34.4\%) & [12] \\
\hline A. canelilla & Manaus, AM, Brazil & Heartwood & $\mathrm{HD}$ & $\begin{array}{c}\text { 1-Nitro-2-phenylethane (46.0\%), methyleugenol (52.9\%), and } \\
\text { linalool (5.0\%) }\end{array}$ & [12] \\
\hline A. canelilla & Manaus, AM, Brazil & Bark & HD & 1-Nitro-2-phenylethane (72.6\%) and methyleugenol (24.9\%) & [12] \\
\hline A. canelilla & Carajás National Forest, Marabá, PA, Brazil & Leaf & not reported & 1-Nitro-2-phenylethane (95.3\%) and limonene (1.2\%) & [64] \\
\hline A. canelilla & Carajás National Forest, Marabá, PA, Brazil & Bark & HD & $\begin{array}{l}\text { 1-Nitro-2-phenylethane (58.2\%), methyleugenol (34.7\%), and } \\
\text { epi- } \alpha \text {-cadinol (1.5\%) }\end{array}$ & {$[64]$} \\
\hline A. canelilla & Carajás National Forest, Marabá, PA, Brazil & Trunkwood & HD & $\begin{array}{c}\text { 1-Nitro-2-phenylethane }(47.4 \%) \text {, epi- } \alpha \text {-cadinol }(19.9 \%) \text {, and } \\
\text { methyleugenol (10.5\%) }\end{array}$ & {$[64]$} \\
\hline A. canelilla & Carajás National Forest, Marabá, PA, Brazil & Leaf & HD & $\begin{array}{l}\text { 1-Nitro-2-phenylethane (68.5\%), linalool }(8.8 \%) \text {, and } \\
\text { spathulenol }(4.8 \%)\end{array}$ & {$[64]$} \\
\hline A. canelilla & Carajás National Forest, Marabá, PA, Brazil & Bark & HD & $\begin{array}{c}\text { 1-Nitro-2-phenylethane }(60.5 \%) \text {, methyleugenol }(21.3 \%) \text {, and } \\
\beta \text {-sesquiphellandrene }(5.4 \%)\end{array}$ & [64] \\
\hline A. canelilla & Carajás National Forest, Marabá, PA, Brazil & Trunkwood & HD & $\begin{array}{c}\text { 1-Nitro-2-phenylethane }(50.2 \%) \text {, methyleugenol }(23.0 \%) \text {, and } \\
\beta \text {-sesquiphellandrene }(6.4 \%)\end{array}$ & {$[64]$} \\
\hline A. canelilla & Carajás National Forest, Marabá, PA, Brazil & Leaf & HD & $\begin{array}{l}\text { Rainy season, Mn Mine: 1-nitro-2-phenylethane }(70.6 \%) \text { and } \\
\text { methyleugenol }(3.4 \%)\end{array}$ & [84] \\
\hline \multirow{2}{*}{ A. canelilla } & \multirow{2}{*}{ Carajás National Forest, Marabá, PA, Brazil } & \multirow{2}{*}{ Leaf } & \multirow{2}{*}{$\mathrm{HD}$} & $\begin{array}{l}\text { Rainy season: } \mathrm{Cu} \text { Mine: 1-nitro-2-phenylethane }(94.5 \%) \text { and } \\
\text { methyleugenol }(0.2 \%)\end{array}$ & {$[84]$} \\
\hline & & & & $\begin{array}{c}\text { Zoobotanic park: 1-nitro-2-phenylethane (95.3\%) and } \\
\text { methyleugenol }(0.2 \%)\end{array}$ & \\
\hline \multirow{3}{*}{ A. canelilla } & \multirow{3}{*}{ Carajás National Forest, Marabá, PA, Brazil } & \multirow{3}{*}{ Leaf } & \multirow{3}{*}{ HD } & $\begin{array}{l}\text { Dry season, Mn Mine: 1-nitro-2-phenylethane }(39.0 \%) \text { and } \\
\text { methyleugenol }(0.5 \%)\end{array}$ & \multirow{3}{*}{ [84] } \\
\hline & & & & $\mathrm{Cu}$ Mine: 1-nitro-2-phenylethane (39.3\%) and methyleugenol $(0.5 \%)$ & \\
\hline & & & & $\begin{array}{c}\text { Zoobotanic park: 1-nitro-2-phenylethane }(42.1 \%) \text { and } \\
\text { methyleugenol }(0.6 \%)\end{array}$ & \\
\hline
\end{tabular}


Table 1. Cont.

\begin{tabular}{|c|c|c|c|c|c|}
\hline Species & Collection Site & Plant Part & Extraction Type & Major Components & References \\
\hline \multirow{3}{*}{ A. canelilla } & \multirow{3}{*}{ Carajás National Forest, Marabá, PA, Brazil } & \multirow{3}{*}{ Bark } & \multirow{3}{*}{ HD } & $\begin{array}{c}\text { Rainy season, Mn Mine: 1-nitro-2-phenylethane (94.3\%) and } \\
\text { methyleugenol (1.0\%) }\end{array}$ & \multirow{3}{*}{ [84] } \\
\hline & & & & $\begin{array}{c}\text { Cu Mine: 1-nitro-2-phenylethane }(87.1 \%) \text { and } \\
\text { methyleugenol }(8.7 \%)\end{array}$ & \\
\hline & & & & $\begin{array}{c}\text { Zoobotanic park: 1-nitro-2-phenylethane }(78.2 \%) \text { and } \\
\text { methyleugenol }(14.7 \%)\end{array}$ & \\
\hline \multirow{3}{*}{ A. canelilla } & \multirow{3}{*}{ Carajás National Forest, Marabá, PA, Brazil } & \multirow{3}{*}{ Bark } & \multirow{3}{*}{ HD } & $\begin{array}{l}\text { Dry season: Mn Mine: 1-nitro-2-phenylethane (48.6\%) and } \\
\text { methyleugenol (45.3\%) }\end{array}$ & \multirow{3}{*}[84]{} \\
\hline & & & & $\begin{array}{l}\text { Cu Mine: 1-nitro-2-phenylethane (56.2\%) and } \\
\text { methyleugenol (39.5\%) }\end{array}$ & \\
\hline & & & & $\begin{array}{c}\text { Zoobotanic park: 1-nitro-2-phenylethane }(68.1 \%) \text { and } \\
\text { methyleugenol }(24.6 \%)\end{array}$ & \\
\hline A. canelilla & Carajás National Forest, Marabá, PA, Brazil & Trunkwood & HD & $\begin{array}{l}\text { Rainy season, Mn Mine: 1-nitro-2-phenylethane }(70.0 \%) \text { and } \\
\text { methyleugenol }(17.7 \%)\end{array}$ & [84] \\
\hline \multirow[b]{2}{*}{ A. canelilla } & \multirow{2}{*}{ Carajás National Forest, Marabá, PA, Brazil } & \multirow[b]{2}{*}{ Trunkwood } & \multirow[b]{2}{*}{ HD } & $\begin{array}{l}\text { Rainy season, } \mathrm{Cu} \text { Mine: 1-nitro-2-phenylethane }(80.0 \%) \text { and } \\
\text { methyleugenol }(10.7 \%)\end{array}$ & \multirow{2}{*}{ [84] } \\
\hline & & & & $\begin{array}{c}\text { Zoobotanic park: 1-nitro-2-phenylethane }(69.2 \%) \text { and } \\
\text { methyleugenol }(15.3 \%)\end{array}$ & \\
\hline \multirow{3}{*}{ A. canelilla } & \multirow{3}{*}{ Carajás National Forest, Marabá, PA, Brazil } & \multirow{3}{*}{ Trunkwood } & \multirow{3}{*}{ HD } & $\begin{array}{l}\text { Dry season, Mn Mine: 1-nitro-2-phenylethane (47.5\%) and } \\
\text { methyleugenol (48.5\%) }\end{array}$ & \multirow{3}{*}{ [84] } \\
\hline & & & & $\mathrm{Cu}$ Mine: 1-nitro-2-phenylethane (53.3\%) and methyleugenol (38.0\%) & \\
\hline & & & & $\begin{array}{c}\text { Zoobotanic park: 1-nitro-2-phenylethane }(73.3 \%) \text { and } \\
\text { methyleugenol }(22.2 \%)\end{array}$ & \\
\hline A. canelilla & Cauaxi River, Paragominas, PA, Brazil & Bark & HD & $\begin{array}{l}\text { 1-Nitro-2-phenylethane (52.4\%), methyleugenol (38.6\%) and } \\
\text { selin-11-en-4- } \alpha \text {-ol }(2.5 \%)\end{array}$ & {$[84,85]$} \\
\hline A. canelilla & $\begin{array}{l}\text { Adolpho Ducke Forest Reserve, Manaus, } \\
\qquad \text { AM, Brazil }\end{array}$ & Leaf & HD & $\begin{array}{c}\text { 1-Nitro-2-phenylethane }(71.2 \%) \text {, benzaldehyde }(4.8 \%) \text {, and } \\
\beta \text {-selinene }(4.5 \%)\end{array}$ & [65] \\
\hline A. canelilla & $\begin{array}{c}\text { Adolpho Ducke Forest Reserve, Manaus, } \\
\text { AM, Brazil }\end{array}$ & Thin twig & HD & 1-Nitro-2-phenylethane (68.2\%), eugenol (5.2\%), and linalool (5.2\%) & [65] \\
\hline
\end{tabular}


Table 1. Cont.

\begin{tabular}{|c|c|c|c|c|c|}
\hline Species & Collection Site & Plant Part & Extraction Type & Major Components & References \\
\hline A. canelilla & Not reported & Leaf & SD & $\begin{array}{c}\text { Commercial sample (market Ver-o-peso): } \\
\text { 1-Nitro-2-phenylethane }(99.1 \%) \text { and eugenol }(0.9 \%)\end{array}$ & [77] \\
\hline A. canelilla & Not reported & Wood & SD & $\begin{array}{l}\text { Commercial sample: } 1 \text {-Nitro-2-phenylethane }(68.8 \%) \text {, methyleugenol } \\
\qquad(28.1 \%) \text {, and safrole }(1.7 \%)\end{array}$ & [77] \\
\hline A. canelilla & Jatapu River, Novo Airão, AM, Brazil & $\begin{array}{l}\text { Leaf and } \\
\text { thin twig }\end{array}$ & HD & $\begin{array}{l}\text { 1-Nitro-2-phenylethane (91.8\%), } \beta \text {-caryophyllene }(1.6 \%) \text {, and } \\
\text { selin-11-en-4- } \alpha \text {-ol }(1.3 \%)\end{array}$ & [27] \\
\hline A. canelilla & Jatapu River, Novo Airão, AM, Brazil & Trunkwood & HD & $\begin{array}{c}\text { 1-Nitro-2-phenylethane (92.1\%), methyleugenol (4.30\%), and } \\
\text { eugenol (1.2\%) }\end{array}$ & [27] \\
\hline A. canelilla & Cauaxi River, Ulianópolis, PA, Brazil & $\begin{array}{l}\text { Leaf and } \\
\text { thin twig }\end{array}$ & HD & $\begin{array}{c}\text { 1-Nitro-2-phenylethane (74.0\%), linalool (7.6\%), and } \\
\beta \text {-caryophyllene (3.5\%) }\end{array}$ & [27] \\
\hline A. canelilla & Cauaxi River, Ulianópolis, PA, Brazil & Barkwood & HD & $\begin{array}{c}\text { 1-Nitro-2-phenylethane (90.3\%), selin-11-en-4- } \alpha \text {-ol (3.5\%), and } \\
\text { methyleugenol (2.0\%) }\end{array}$ & [27] \\
\hline A. canelilla & Cauaxi River, Ulianópolis, PA, Brazil & Trunkwood & HD & $\begin{array}{l}\text { 1-Nitro-2-phenylethane (70.2\%), methyleugenol (25.8\%), and } \\
\text { selin-11-en-4- } \alpha \text {-ol (1.2\%) }\end{array}$ & [27] \\
\hline A. canelilla & $\begin{array}{l}\text { Adolpho Ducke Forest Reserve, Manaus, } \\
\text { AM, Brazil }\end{array}$ & Leaf & HD & $\begin{array}{l}\text { Dry season: } 1 \text {-nitro-2-phenylethane }(88.9 \%), \\
\beta \text {-caryophyllene }(4.21 \%) \text {, and } \beta \text {-phellandrene }(0.80 \%)\end{array}$ & [22] \\
\hline A. canelilla & $\begin{array}{c}\text { Adolpho Ducke Forest Reserve, Manaus, } \\
\text { AM, Brazil }\end{array}$ & Leaf & HD & $\begin{array}{l}\text { Rainy season: 1-nitro-2-phenylethane }(88.5 \%), \beta \text {-caryophyllene }(5.04 \%), \\
\text { and } \beta \text {-phellandrene }(1.14 \%)\end{array}$ & [22] \\
\hline A. canelilla & Itacoatiara, AM, Brazil & Leaf & HD & $\begin{array}{c}\text { 1-Nitro-2-phenylethane (52.2\%), eugenol (8.71\%) and } \\
\text { methyleugenol (5.09\%) }\end{array}$ & [102] \\
\hline A. canelilla & Itacoatiara, AM, Brazil & Thin twig & HD & $\begin{array}{c}\text { 1-Nitro-2-phenylethane }(92.7 \%) \text {, eugenol }(0.3 \%) \text { and } \\
\text { methyleugenol }(0.33 \%)\end{array}$ & [102] \\
\hline A. canelilla & Itacoatiara, AM, Brazil & Leaf & HD & $\begin{array}{c}\text { Rainy season: 1-nitro-2-phenylethane (31.22-84.33\%), } \\
\beta \text {-caryophyllene (1.89-16.34\%), and } \beta \text {-selinene }(0.77-8.82 \%)\end{array}$ & [101] \\
\hline A. canelilla & Itacoatiara, AM, Brazil & Leaf & HD & $\begin{array}{l}\text { Dry season: 1-nitro-2-phenylethane }(13.17-74.55 \%), \\
\beta \text {-caryophyllene }(4.19-12.64 \%) \text {, and } \beta \text {-selinene }(1.09-14.98 \%)\end{array}$ & [101] \\
\hline A. canelilla & Itacoatiara, AM, Brazil & Stem & HD & $\begin{array}{l}\text { Rainy season: 1-nitro-2-phenylethane (90.94-93.58\%), } \\
\text { benzeneacetaldehyde }(0.48-1.98 \%) \text { and eugenol }(0.07-1.45 \%)\end{array}$ & [101] \\
\hline
\end{tabular}


Table 1. Cont.

\begin{tabular}{|c|c|c|c|c|c|}
\hline Species & Collection Site & Plant Part & Extraction Type & Major Components & References \\
\hline A. canelilla & Itacoatiara, AM, Brazil & Stem & HD & $\begin{array}{l}\text { Dry season: 1-nitro-2-phenylethane }(87.85-94.16 \%) \\
\text { linalool }(0.05-3.08 \%) \text {, eugenol }(0.08-1.19 \%)\end{array}$ & [101] \\
\hline A. canelilla & Itacoatiara, AM, Brazil & Trunkwood & HD & $\begin{array}{l}\text { 1-Nitro-2-phenylethane }(83.68 \%) \text {, methyleugenol }(14.83 \%) \text { and } \\
\text { neo-intermedeol }(0.31 \%)\end{array}$ & [86] \\
\hline A. canelilla & Itacoatiara, AM, Brazil & Bark & $\mathrm{HD}$ & $\begin{array}{c}\text { 1-Nitro-2-phenylethane }(83.2 \%) \text {, methyleugenol }(16.2 \%) \text {, and } \\
\text { benzaldehyde }(0.4 \%)\end{array}$ & [87] \\
\hline A. canelilla & $\begin{array}{l}\text { Adolpho Ducke Forest Reserve, Manaus, } \\
\text { AM, Brazil }\end{array}$ & Leaf & $\mathrm{HD}$ & $\begin{array}{l}\text { 1-Nitro-2-phenylethane }(87.34 \%) \text {, ethyl butanoate }(3.10 \%) \text {, and } \\
\alpha \text {-humulene }(0.68 \%)\end{array}$ & [35] \\
\hline A. cinnamomiflora & Los Andes, Merida, Venezuela & wood & $\mathrm{HD}$ & $\begin{array}{c}\gamma \text {-Palmitolactone (54.0\%), 1-epi-cubenol }(9.56 \%) \text {, and } \\
\delta \text {-cadinene }(6.05 \%)\end{array}$ & [88] \\
\hline A. citrifolia & Melgaço, PA, Brazil & Bark & HD & Safrole $(16.7 \%), \alpha$-pinene $(10.6 \%)$, and $\beta$-pinene $(11.2 \%)$ & [73] \\
\hline A. duckei & Manaus, AM, Brazil & Leaf & SD & $\begin{array}{c}\text { Seasonal study, linalool }(27.3-85.3 \%) \text { and } \\
\text { linalool oxides }(5.3-19.7 \%)\end{array}$ & [99] \\
\hline A. duckei & Manaus, AM, Brazil & Thin twig & SD & $\begin{array}{c}\text { Seasonal study, linalool }(35.7-94.3 \%) \text { and } \\
\text { linalool oxides }(3.0-18.7 \%)\end{array}$ & [99] \\
\hline A. duckei & $\begin{array}{l}\text { Adolpho Ducke Forest Reserve, Manaus, } \\
\text { AM, Brazil }\end{array}$ & Leaf & $\mathrm{HD}$ & Rainy season: linalool $(60.38 \%, 56.26 \%)$ & [103] \\
\hline A. duckei & $\begin{array}{l}\text { Adolpho Ducke Forest Reserve, Manaus, } \\
\text { AM, Brazil }\end{array}$ & Leaf & $\mathrm{HD}$ & Dry season: linalool $(62.40 \%, 76.69 \%)$ & [103] \\
\hline A. duckei & $\begin{array}{l}\text { Adolpho Ducke Forest Reserve, Manaus, } \\
\text { AM, Brazil }\end{array}$ & Thin twig & $\mathrm{HD}$ & Linalool $(89.34 \%)$, $\alpha$-terpineol $(3.06 \%)$, and cis-linalool oxide $(1.94 \%)$ & [81] \\
\hline A. duckei & $\begin{array}{l}\text { Adolpho Ducke Forest Reserve, Manaus, } \\
\text { AM, Brazil }\end{array}$ & Branch & HD & $\begin{array}{c}\text { Linalool (93.60\%), } \alpha \text {-terpinolene }(3.37 \%) \text {, and } \\
\text { cis-linalool oxide }(3.03 \%)\end{array}$ & [29] \\
\hline A. gardneri & Not reported & Leaf & HD & Benzyl benzoate $(44.1 \%)$, cadinene $(4.8 \%)$, and 1,8 -cineole $(3.6 \%)$ & [12] \\
\hline A. gardneri & Not reported & Trunkwood & HD & Benzyl benzoate $(78.1 \%)$ and phenylethyl benzoate $(14.3 \%)$ & [12] \\
\hline A. guianensis & Not reported & Leaf & HD & Benzyl benzoate ( $44.8 \%)$ and benzyl salicylate $(16.7 \%)$ & [12] \\
\hline
\end{tabular}


Table 1. Cont.

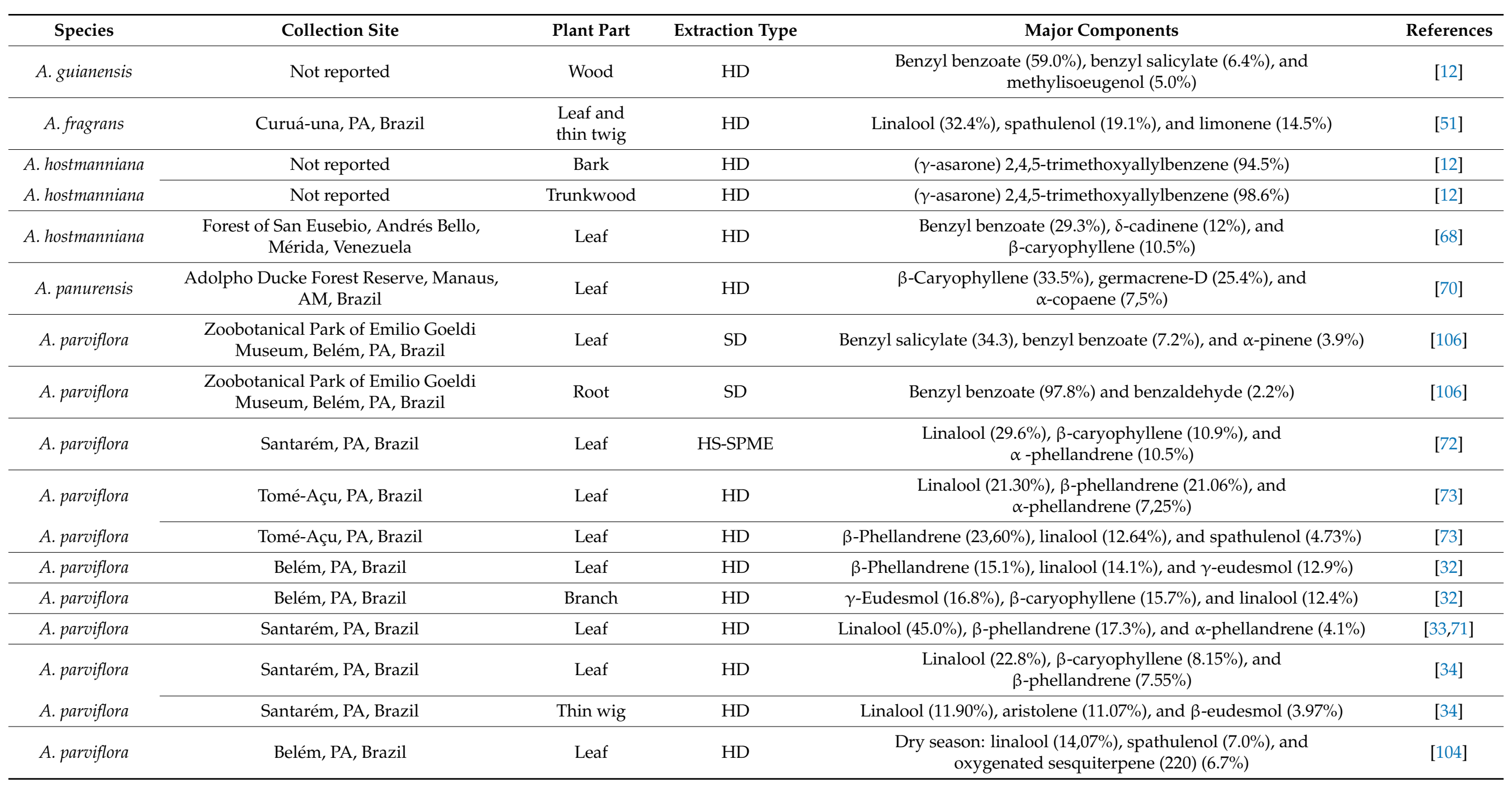


Table 1. Cont

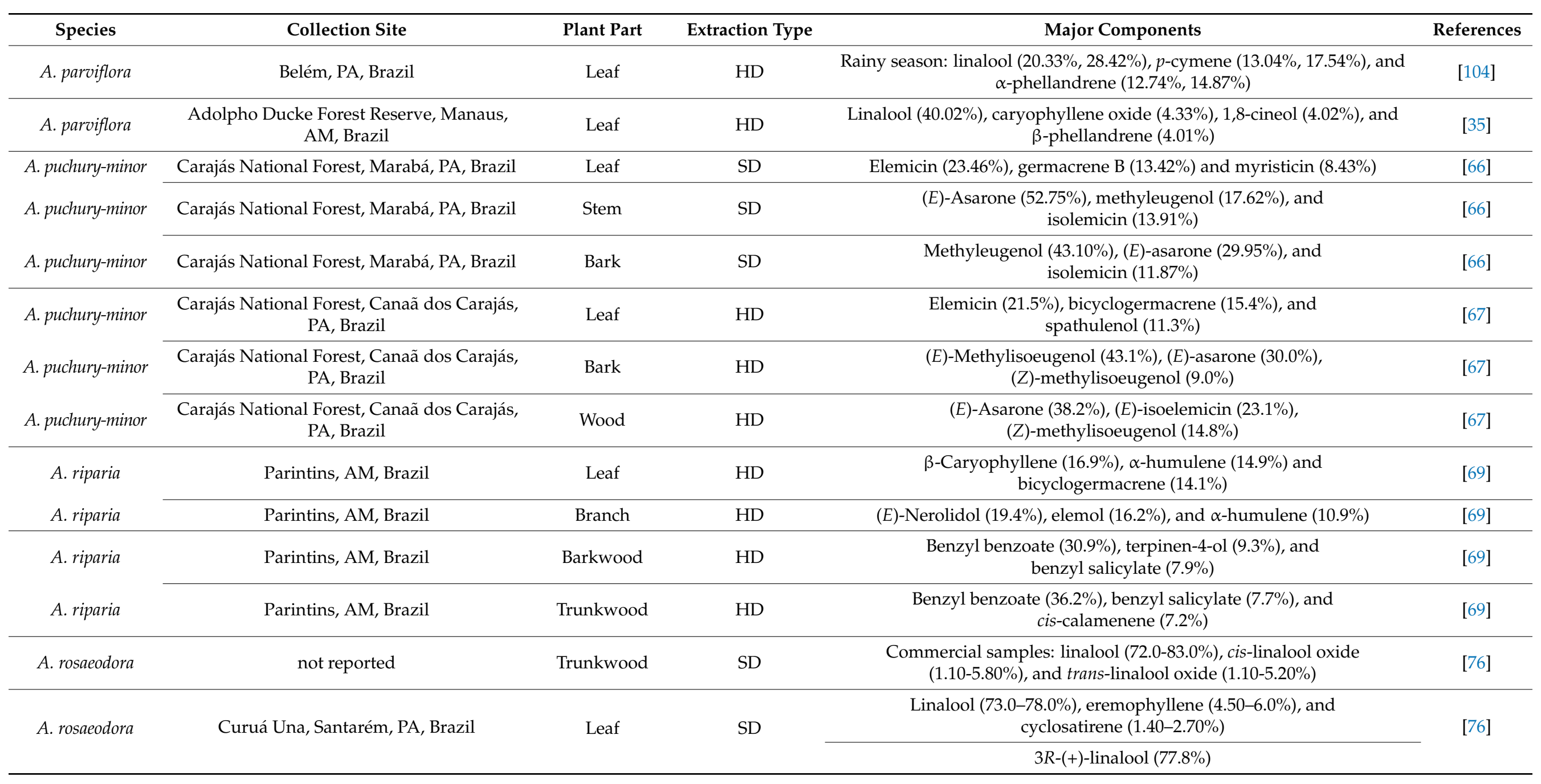


Table 1. Cont.

\begin{tabular}{|c|c|c|c|c|c|}
\hline Species & Collection Site & Plant Part & Extraction Type & Major Components & References \\
\hline \multirow[t]{2}{*}{ A. rosaeodora } & \multirow[t]{2}{*}{ Curuá Una, Santarém, PA, Brazil } & \multirow[t]{2}{*}{ Trunkwood } & \multirow[t]{2}{*}{ SD } & $\begin{array}{c}\text { Linalool (87.0-92.0\%), cis-linalool oxide }(1.0-1.68 \%) \text {, and } \\
\text { trans-linalool oxide }(0.90-1.60 \%)\end{array}$ & \multirow[t]{2}{*}{ [76] } \\
\hline & & & & $3 R-(-)$-linalool $>50.0 \%$ & \\
\hline A. rosaeodora & Curuá Una, Santarém, PA, Brazil & Leaf & HD & $\begin{array}{c}\text { Linalool }(79.0 \%) \text {, oxygenated sesquiterpene (MW220) }(5.4 \%) \text {, and } \\
\beta \text {-selinene }(2.0 \%)\end{array}$ & {$[51]$} \\
\hline A. rosaeodora & not reported & Not reported & HD & $\begin{array}{c}\text { Commercial sample (Institute for Medicinal Plants Research Dr. Josif Pancic, } \\
\text { Belgrade, Serbia): linalool }(81.27 \%), \alpha \text {-terpineol }(4.78 \%), \text { trans-linalool } \\
\text { oxide }(2.10 \%)\end{array}$ & [94] \\
\hline \multirow{2}{*}{ A. rosaeodora } & \multirow{2}{*}{ Not reported } & \multirow{2}{*}{ Leaf } & \multirow{2}{*}{$\mathrm{HD}$} & Linalool $(81.45 \%), \beta$-selinene $(1.65 \%)$, and $\alpha$-selinene $(1.39 \%)$ & \multirow{2}{*}[30]{} \\
\hline & & & & 3R-(-)-linalool (29.3\%) and 3S-(+)-linalool $(70.7 \%)$ & \\
\hline \multirow{2}{*}{ A. rosaeodora } & \multirow{2}{*}{ Not reported } & \multirow{2}{*}{ Trunkwood } & \multirow{2}{*}{ HD } & Linalool ( $85.0 \%)$, trans-linalool oxide $(2.43 \%)$, and cis-linalool oxide $(2.21 \%)$ & \multirow{2}{*}[30]{} \\
\hline & & & & 3R-(-)-linalool (38.3\%) and 3S-(+)-linalool (61.7\%) & \\
\hline A. rosaeodora & Presidente Figueiredo, AM, Brazil & Leaf & HS-SPME & $\begin{array}{c}\text { Linalool }(77.5 \%) \text {, cis-linalool oxide }(7.7 \%) \text {, and } \\
\text { trans-linalool oxide }(5.6 \%)\end{array}$ & [77] \\
\hline A. rosaeodora & $\begin{array}{c}\text { Zoobotanical Park of Emilio Goeldi Museum, } \\
\text { Belém, PA, Brazil }\end{array}$ & Leaf & $\mathrm{HD}$ & Seasonal study, linalool (68.0-96.1\%) & [25] \\
\hline A. rosaeodora & $\begin{array}{c}\text { Zoobotanical Park of Emilio Goeldi Museum, } \\
\text { Belém, PA, Brazil }\end{array}$ & Leaf & HD & Linalool $(85.5 \%)$, $\beta$-selinene $(0.9 \%)$, and trans-linalool oxide $(0.8 \%)$ & [25] \\
\hline \multirow{2}{*}{ A. rosaeodora } & \multirow{2}{*}{$\begin{array}{c}\text { Zoobotanical Park of Emilio Goeldi Museum, } \\
\text { Belém, PA, Brazil }\end{array}$} & \multirow{2}{*}{ Wood } & \multirow{2}{*}{ HD } & Linalool $(84.8 \%), \alpha$-terpineol $(2.9 \%)$, and geraniol $(1.0 \%)$ & {$[25,91]$} \\
\hline & & & & 3S-(-)-linalool (50.62\%) and of 3R-(+)-linalool (49.38\%) & [90] \\
\hline A. rosaeodora & Novo Airão, AM, Brazil & Leaf & HD & $\begin{array}{l}\text { Tachi morphological type: linalool }(82.1 \%) \text {, spathulenol }(2.0 \%) \text {, } \\
\text { caryophyllene oxide }(2.0 \%)\end{array}$ & [25] \\
\hline A. rosaeodora & Novo Airão, AM, Brazil & Trunkwood & HD & $\begin{array}{c}\text { Tachi morphological type: linalool }(84.8 \%) \text {, cis-linalool oxide }(1.8 \%) \text {, and } \\
\text { trans-linalool oxide }(1.8 \%)\end{array}$ & [25] \\
\hline A. rosaeodora & Novo Airão, AM, Brazil & Leaf & $\mathrm{HD}$ & $\begin{array}{c}\text { Preciosa morphological type: linalool (83.9\%), caryophyllene oxide }(2.0 \%), \\
\text { and trans-linalool oxide }(1.7 \%)\end{array}$ & [25] \\
\hline
\end{tabular}


Table 1. Cont

\begin{tabular}{|c|c|c|c|c|c|}
\hline Species & Collection Site & Plant Part & Extraction Type & Major Components & References \\
\hline A. rosaeodora & Novo Airão, AM, Brazil & Trunkwood & HD & $\begin{array}{l}\text { Preciosa morphological type: linalool }(79.7 \%), \alpha \text {-terpineol (5.6\%), and } \\
\text { cis-linalool oxide }(2.7 \%)\end{array}$ & [25] \\
\hline A. rosaeodora & Novo Airão, AM, Brazil) & Leaf & HD & $\begin{array}{c}\text { Itaúba morphological type: linalool (79.7\%), caryophyllene oxide }(3.2 \%) \text {, } \\
\text { and } \beta \text {-selinene }(1.6 \%)\end{array}$ & [25] \\
\hline A. rosaeodora & Novo Airão, AM, Brazil & Trunkwood & HD & $\begin{array}{c}\text { Itaúba morphological type: linalool }(78.9 \%) \text {, benzyl benzoate }(2.7 \%) \text {, and } \\
\beta \text {-selinene }(1.0 \%)\end{array}$ & [25] \\
\hline A. rosaeodora & Novo Airão, AM, Brazil & Leaf & HD & $\begin{array}{c}\text { Imbaúba morphological type: linalool }(79.8 \%) \text {, spathulenol }(4.0 \%) \text {, and } \\
\text { trans-linalool oxide }(1.7 \%)\end{array}$ & [25] \\
\hline A. rosaeodora & Novo Airão, AM, Brazil & Trunkwood & HD & $\begin{array}{c}\text { Imbaúba morphological type: linalool }(76.9 \%), \alpha \text {-terpineol (3.8\%), and } \\
\text { cis-linalool oxide }(1.6 \%)\end{array}$ & [25] \\
\hline A. rosaeodora & French Guiana & Leaf & HD & 3S-(+)-linalool (78-89\%) & [107] \\
\hline A. rosaeodora & French Guiana & Branch & HD & 3S-(+)-linalool (5-28\%) & [107] \\
\hline A. rosaeodora & French Guiana & Trunkwood & HD & 3R-(-)-linalool (95-99\%) & [107] \\
\hline A. rosaeodora & French Guiana & Trunkwood & HD & 3S-(+)-linalool (73.0\%), $\alpha$-terpineol (18.8\%), nerol $(1.7 \%)$ & [107] \\
\hline A. rosaeodora & $\begin{array}{c}\text { Adolpho Ducke Forest Reserve, Manaus, } \\
\text { AM, Brazil }\end{array}$ & Stem & HD & $\begin{array}{c}\text { Linalool }(86.0 \%) \text {, caryophyllene oxide }(2.8 \%) \text {, and } \\
\text { trans-linalool oxide }(1.5 \%)\end{array}$ & [70] \\
\hline A. rosaeodora & not reported & Not reported & SD & $\begin{array}{c}\text { Commercial sample (Erbamea-Istrana, Treviso, Italy): linalool }(60.1 \%) \text {, } \\
\text { limonene }(19.2 \%) \text {, and geraniol }(7.8 \%)\end{array}$ & [95] \\
\hline A. rosaeodora & not reported & Not reported & SD & Commercial sample: linalool ( $80 \%)$, and $\alpha$-terpineol $(4.5 \%)$ & [97] \\
\hline A. rosaeodora & Maués, AM, Brazil & $\begin{array}{l}\text { Leaf and thin } \\
\text { twig }\end{array}$ & SD & $\begin{array}{l}\text { A four years sample: linalool }(82.15 \%), \alpha \text {-terpineol }(3.60 \%) \text {, and } \\
\text { geraniol }(1.33 \%)\end{array}$ & {$[78,79]$} \\
\hline A. rosaeodora & Maués, AM, Brazil & $\begin{array}{l}\text { Leaf and thin } \\
\text { twig }\end{array}$ & SD & $\begin{array}{c}\text { A ten years sample: linalool (90.5\%), } \alpha \text {-terpineol }(1.11 \%) \text {, and } \\
\alpha \text {-selinene }(0.73 \%)\end{array}$ & [79] \\
\hline A. rosaeodora & Maués, AM, Brazil & $\begin{array}{l}\text { Leaf and thin } \\
\text { twig }\end{array}$ & SD & $\begin{array}{c}\text { A twenty years sample: linalool }(87.1 \%), \text { benzyl benzoate }(1.61 \%) \text {, and } \\
\qquad \text {-terpineol }(1.21 \%)\end{array}$ & [79] \\
\hline A. rosaeodora & Tomé-Açu, PA, Brazil & Leaf & HD & Linalool (50.81\%), spathulenol (4.46\%), and $\beta$-selinene (4.35\%) & [73] \\
\hline
\end{tabular}


Table 1. Cont.

\begin{tabular}{|c|c|c|c|c|c|}
\hline Species & Collection Site & Plant Part & Extraction Type & Major Components & References \\
\hline A. rosaeodora & Tomé-Açu, PA, Brazil & Leaf & HD & $\begin{array}{c}\text { Linalool (55.91\%), cis-linalool furanoxide }(5.59 \%) \text {, and } \\
\text { trans-linalool furanoxide }(4.43 \%)\end{array}$ & [73] \\
\hline A. rosaeodora & Belém, PA, Brazil & Leaf & HD & Linalool (51.75\%), spathulenol (3.82\%), and $\beta$-selinene $(3.79 \%)$ & [73] \\
\hline A. rosaeodora & Belém, PA, Brazil & Leaf & HD & Linalool (57.17\%), cis-linalool furanoid (4.21\%), spathulenol (3.92\%) & [73] \\
\hline A. rosaeodora & Belém, PA, Brazil & Leaf & $\mathrm{HD}$ & Linalool (43.02\%), $\beta$-selinene (5.84\%), and spathulenol (4.46\%) & [73] \\
\hline A. rosaeodora & Belém, PA, Brazil & Leaf & HD & Linalool (42.61\%), $\beta$-selinene (5.23\%), and $\alpha$-selinene $(4.26 \%)$ & [73] \\
\hline A. rosaeodora & Belém, PA, Brazil & Leaf & HD & Linalool (42.67\%), spathulenol (7.20\%), and $\beta$-selinene $(4.88 \%)$ & [73] \\
\hline A. rosaeodora & Belém, PA, Brazil & Leaf & HD & Linalool (52.22\%), $\beta$-selinene (4.24\%), and $\alpha$-selinene (3.53\%) & [73] \\
\hline A. rosaeodora & Belém, PA, Brazil & Leaf & HD & $\begin{array}{c}\text { Linalool (55.10\%), cis-linalool furanoid (4.28\%), and } \\
\text { spathulenol }(4.25 \%)\end{array}$ & [73] \\
\hline A. rosaeodora & Belém, PA, Brazil & Leaf & HD & Linalool (43.96\%), $\beta$-selinene (5.25\%), and $\alpha$-selinene (4.24\%) & [73] \\
\hline A. rosaeodora & Belém, PA, Brazil & Leaf & HD & Linalool (44.66\%), $\beta$-selinene (5.40\%), and $\alpha$-selinene $(4.49 \%)$ & [73] \\
\hline A. rosaeodora & Belém, PA, Brazil & Leaf & HD & Linalool (52.72\%), spathulenol (5.12\%), and $\beta$-selinene (4.0\%) & [73] \\
\hline A. rosaeodora & Belém, PA, Brazil & Leaf & HD & Linalool $(46.90 \%), \beta$-selinene $(4.92 \%)$, and spathulenol (4.53\%) & [73] \\
\hline A. rosaeodora & Belém, PA, Brazil & Leaf & HD & Linalool $(49.24 \%)$, spathulenol $(6.47 \%)$, and $\beta$-selinene $(4.09 \%)$ & [73] \\
\hline A. rosaeodora & Belém, PA, Brazil & Leaf & HD & Linalool (38.48\%), $\beta$-selinene (6.41\%), and $\alpha$-selinene $(5.58 \%)$ & [73] \\
\hline A. rosaeodora & Belém, PA, Brazil & Leaf & HD & Linalool $(47.49 \%)$, benzyl benzoate $(6.25 \%)$, and $\beta$-selinene $(4.02 \%)$ & [73] \\
\hline A. rosaeodora & Belém, PA, Brazil & Leaf & HD & Linalool (45.41\%), $\beta$-selinene (4.31\%), and spathulenol (4.70\%) & [73] \\
\hline A. rosaeodora & Belém, PA, Brazil & Leaf & HD & Linalool (45.99\%), $\alpha$-copaene $(5.06 \%)$, and $\beta$-selinene $(4.04 \%)$ & [73] \\
\hline A. rosaeodora & Belém, PA, Brazil & Leaf & HD & Linalool (57.22\%), spathulenol (6.53\%), and $\alpha$-copaene $(5.48 \%)$ & [73] \\
\hline A. rosaeodora & Belém, PA, Brazil & Leaf & HD & Linalool $(64.26 \%), \alpha$-copaene $(3.27 \%)$, and spathulenol $(3.26 \%)$ & [73] \\
\hline A. rosaeodora & Belém, PA, Brazil & Leaf & HD & Linalool (52.68\%), spathulenol (4.56\%), and $\beta$-selinene $(4.19 \%)$ & [73] \\
\hline
\end{tabular}


Table 1. Cont.

\begin{tabular}{|c|c|c|c|c|c|}
\hline Species & Collection Site & Plant Part & Extraction Type & Major Components & References \\
\hline A. rosaeodora & Belém, PA, Brazil & Leaf & $\mathrm{HD}$ & Linalool $(49.93 \%)$, spathulenol $(4.44 \%)$, and $\beta$-selinene $(3.89 \%)$ & [73] \\
\hline A. rosaeodora & Belém, PA, Brazil & Leaf & $\mathrm{HD}$ & $\begin{array}{l}\text { Linalool }(51.88 \%) \text {, } \beta \text {-selinene }(4.12 \%) \text {, and } \\
\text { cis-linalool furanoid }(3.18 \%)\end{array}$ & [73] \\
\hline A. rosaeodora & Belém, PA, Brazil & Leaf & $\mathrm{HD}$ & Linalool $(54.36 \%), \beta$-selinene $(4.13 \%)$, and $\alpha$-copaene $(3.95 \%)$ & [73] \\
\hline A. rosaeodora & Belém, PA, Brazil & Leaf & $\mathrm{HD}$ & Linalool $(71.05 \%)$, spathulenol (3.73\%), and $\alpha$-copaene $(2.90 \%)$ & [73] \\
\hline A. rosaeodora & Belém, PA, Brazil & Leaf & HD & Linalool $(70.3 \%)$, spathulenol $(6.20 \%)$, and $\alpha$-copaene $(2.07 \%)$ & [73] \\
\hline A. rosaeodora & Belém, PA, Brazil & Leaf & HD & Linalool ( $50.35 \%), \beta$-selinene (4.22\%), and $\alpha$-selinene (3.50\%) & [73] \\
\hline A. rosaeodora & Belém, PA, Brazil & Leaf & $\mathrm{HD}$ & Linalool $(48.39 \%), \alpha$-copaene $(3.73 \%)$, and $\beta$-selinene $(3.55 \%)$ & [73] \\
\hline A. rosaeodora & Belém, PA, Brazil & Leaf & $\mathrm{HD}$ & Linalool $(61.96 \%)$, spathulenol (3.75\%), and $\beta$-selinene $(3.10 \%)$ & [73] \\
\hline A. rosaeodora & Curuá-una, Santarém, PA, Brazil & Leaf & HD & Linalool (55.09\%), $\beta$-selinene (4.49\%), and $\alpha$-selinene $(4.14 \%)$ & [73] \\
\hline A. rosaeodora & Curuá-una, Santarém, PA, Brazil & Leaf & HD & Linalool (55.93\%), $\beta$-selinene (3.79\%), and $\alpha$-selinene $(3.18 \%)$ & [73] \\
\hline A. rosaeodora & Curuá-una, Santarém, PA, Brazil & Leaf & HD & Linalool (48.10\%), $\beta$-selinene (4.81\%), and spathulenol $(4.62 \%)$ & [73] \\
\hline A. rosaeodora & Brazil & Trunkwood & $\mathrm{SD}$ & $\begin{array}{l}\text { Commercial sample (Oshadhi Ltd. (Cambridge, England): linalool } \\
(44.4 \%) \text {, linalyl acetate }(31.4 \%) \text {, and } \beta \text {-caryophyllene }(10.5 \%)\end{array}$ & [96] \\
\hline A. rosaeodora & not reported & Trunkwood & $\mathrm{SD}$ & $\begin{array}{l}\text { Commercial sample: linalool }(86.23 \%) \text {, cis-linalool oxide }(1.06 \%) \text {, and } \\
\qquad \beta \text {-selinene }(0.95 \%)\end{array}$ & [98] \\
\hline A. rosaeodora & Maués, AM, Brazil & Leaf & $\mathrm{HD}$ & $\begin{array}{l}\text { Linalool }(81.32 \%, 83.59 \%) \text {, spathulenol }(2.52 \%, 1.98 \%), \\
\beta \text {-selinene }(1.4 \%, 1.4 \%) \text {, and camphene }(0.04 \%, 0.30 \%)\end{array}$ & [80] \\
\hline A. rosaeodora & Maués, AM, Brazil & Branch & $\mathrm{HD}$ & $\begin{array}{c}\text { Linalool }(83.88 \%, 79.49 \%) \text {, } \beta \text {-selinene }(0.38 \%, 0.63 \%) \text {, spathulenol }(0.37 \% \text {, } \\
1.04 \%) \text {, and camphene }(0.17 \%, 1.03 \%)\end{array}$ & [80] \\
\hline A. rosaeodora & Maués, AM, Brazil & $\begin{array}{l}\text { Leaf and } \\
\text { branch }\end{array}$ & HD & $\begin{array}{c}\text { Linalool }(82.11 \%, 81.33 \%) \text {, spathulenol }(1.01 \%, 2.06 \%) \\
\beta \text {-selinene }(0.64 \%, 1.15 \%) \text {, camphene }(0.04 \%, 0.71 \%)\end{array}$ & {$[80]$} \\
\hline A. rosaeodora & Maués, AM, Brazil & Stem & HD & $\begin{array}{c}\text { Linalool }(86.12 \%), \beta \text {-selinene }(0.43 \%) \text {, camphene }(0.11 \%) \text {, } \\
\text { and spathulenol }(0.11 \%)\end{array}$ & [80] \\
\hline
\end{tabular}


Table 1. Cont

\begin{tabular}{|c|c|c|c|c|c|}
\hline Species & Collection Site & Plant Part & Extraction Type & Major Components & References \\
\hline A. rosaeodora & Novo Aripuanã, AM, Brazil & Leaf & HD & $\begin{array}{c}\text { Linalool }(71.76 \%, 73.89 \%) \text {, spathulenol }(3.16 \%, 2.13 \%) \\
\quad \beta \text {-selinene }(2.71 \%, 2.19 \%) \text {, and camphene }(0.76 \%)\end{array}$ & {$[80]$} \\
\hline A. rosaeodora & Novo Aripuanã, AM, Brazil & Branch & $\mathrm{HD}$ & $\begin{array}{c}\text { Linalool }(81.53 \%, 65.08 \%) \text {, } \beta \text {-selinene }(0.61 \%, 0.76 \%) \text {, camphene }(0.29 \% \text {, } \\
1.62 \%) \text {, and spathulenol }(0.34 \%, 0.93 \%)\end{array}$ & [80] \\
\hline A. rosaeodora & Novo Aripuanã, AM, Brazil & $\begin{array}{l}\text { Leaf and } \\
\text { branch }\end{array}$ & HD & $\begin{array}{c}\text { Linalool }(75.57 \%, 73.24 \%) \text {, spathulenol }(2.03 \%, 2.15 \%) \\
\beta \text {-selinene }(1.62 \%, 1.79 \%) \text {, and camphene }(0.97 \%)\end{array}$ & [80] \\
\hline A. rosaeodora & Novo Aripuanã, AM, Brazil & Stem & HD & $\begin{array}{c}\text { Linalool }(81.77 \%), \beta \text {-selinene }(0.64 \%) \text {, spathulenol }(0.24 \%) \text {, and } \\
\text { camphene }(0.16 \%)\end{array}$ & {$[80]$} \\
\hline A. rosaeodora & Manaus, AM, Brazil & Leaf & $\mathrm{HD}$ & $\begin{array}{c}\text { Dry season: linalool }(69.0 \%), \beta \text {-phellandrene }(2.9 \%) \text {, and } \\
\text { bulnesol }(1.8 \%)\end{array}$ & [28] \\
\hline A. rosaeodora & Manaus, AM, Brazil & Leaf & HD & $\begin{array}{c}\text { Rainy season: linalool }(71.0 \%) \text {, butanoic acid }(3.5 \%) \text {, and } \\
\text { trans-linalool oxide }(2.8 \%)\end{array}$ & [28] \\
\hline A. rosaeodora & Manaus, AM, Brazil & Thin twig & HD & $\begin{array}{c}\text { Dry season: linalool }(78.0 \%), \beta \text {-phellandrene }(1.5 \%) \text {, and } \\
\alpha \text {-eudesmol }(1.4 \%)\end{array}$ & [28] \\
\hline A. rosaeodora & Manaus, AM, Brazil & Thin twig & $\mathrm{HD}$ & $\begin{array}{c}\text { Rainy season: linalool }(84.0 \%) \text {, butanoic acid }(3.0 \%) \text {, and } \\
\text { cis-linalool oxide }(2.0 \%)\end{array}$ & {$[28]$} \\
\hline A. rosaeodora & $\begin{array}{l}\text { Floresta Nacional do Tapajós- Rurópolis } \\
\text { (PA, Brazil) }\end{array}$ & $\begin{array}{l}\text { Leaf and } \\
\text { thin twig }\end{array}$ & HD & $\begin{array}{c}\text { Linalool }(83.7 \%) \text {, aromadendrene oxide }(2.5 \%) \text {, and } \\
\text { spathulenol }(1.6 \%)\end{array}$ & [74] \\
\hline A. rosaeodora & $\begin{array}{l}\text { Reserva Extrativista Tapajós-Arapiuns } \\
\text { (PA, Brazil) }\end{array}$ & $\begin{array}{l}\text { Leaf and } \\
\text { thin twig }\end{array}$ & HD & Linalool $(39.6 \%), \alpha$-phellandrene $(22.8 \%)$ and $p$-cymene $(7.0 \%)$ & [74] \\
\hline A. rosaeodora & $\begin{array}{l}\text { Adolpho Ducke Forest Reserve, Manaus, } \\
\qquad \text { AM, Brazil }\end{array}$ & $\begin{array}{l}\text { Leaf and } \\
\text { thin twig }\end{array}$ & HD & $\begin{array}{c}\text { Linalool }(93.60 \%), \alpha \text {-terpinolene }(3.37 \%) \text {, and } \\
\text { cis-linalool oxide }(3.03 \%)\end{array}$ & {$[81,82]$} \\
\hline A. rosaeodora & $\begin{array}{l}\text { Adolpho Ducke Forest Reserve, Manaus, } \\
\text { AM, Brazil }\end{array}$ & Stem & HD & $\begin{array}{c}\text { Linalool (63.16\%), trans-linalool oxide }(9.73 \%) \text { and } \\
\text { cis-linalool oxide }(7.69 \%)\end{array}$ & [93] \\
\hline A. terminalis & $\begin{array}{l}\text { Zoobotanical Park of Emilio Goeldi } \\
\text { Museum, Belém, PA, Brazil }\end{array}$ & $\begin{array}{l}\text { Leaf and } \\
\text { thin twig }\end{array}$ & HD & $\alpha$-Phellandrene (32.8\%), linalool (21.7\%), and $p$-cymene $(16.7 \%)$ & [75] \\
\hline A. terminalis & $\begin{array}{l}\text { Zoobotanical Park of Emilio Goeldi } \\
\text { Museum, Belém, PA, Brazil }\end{array}$ & Inflorescence & HD & Linalool (36.2\%), $\alpha$-phellandrene (30.7\%), and $(E)$ - $\beta$-ocimene $(22.3 \%)$ & [75] \\
\hline
\end{tabular}




\section{Biological Activities}

The studies on biological activities of EOs of Aniba species from the Amazon correspond to 63 oil samples. Among them, six samples had no chemical composition analysis. Several oils presented more than one specific activity, and the most frequent were antibacterial, toxicological, antifungal, antioxidant, and cytotoxic activities. The percentages of biological activities report the essential oils of Aniba species from the Amazon, and their details of biological assays are presented in Figure 6 and Table 2.

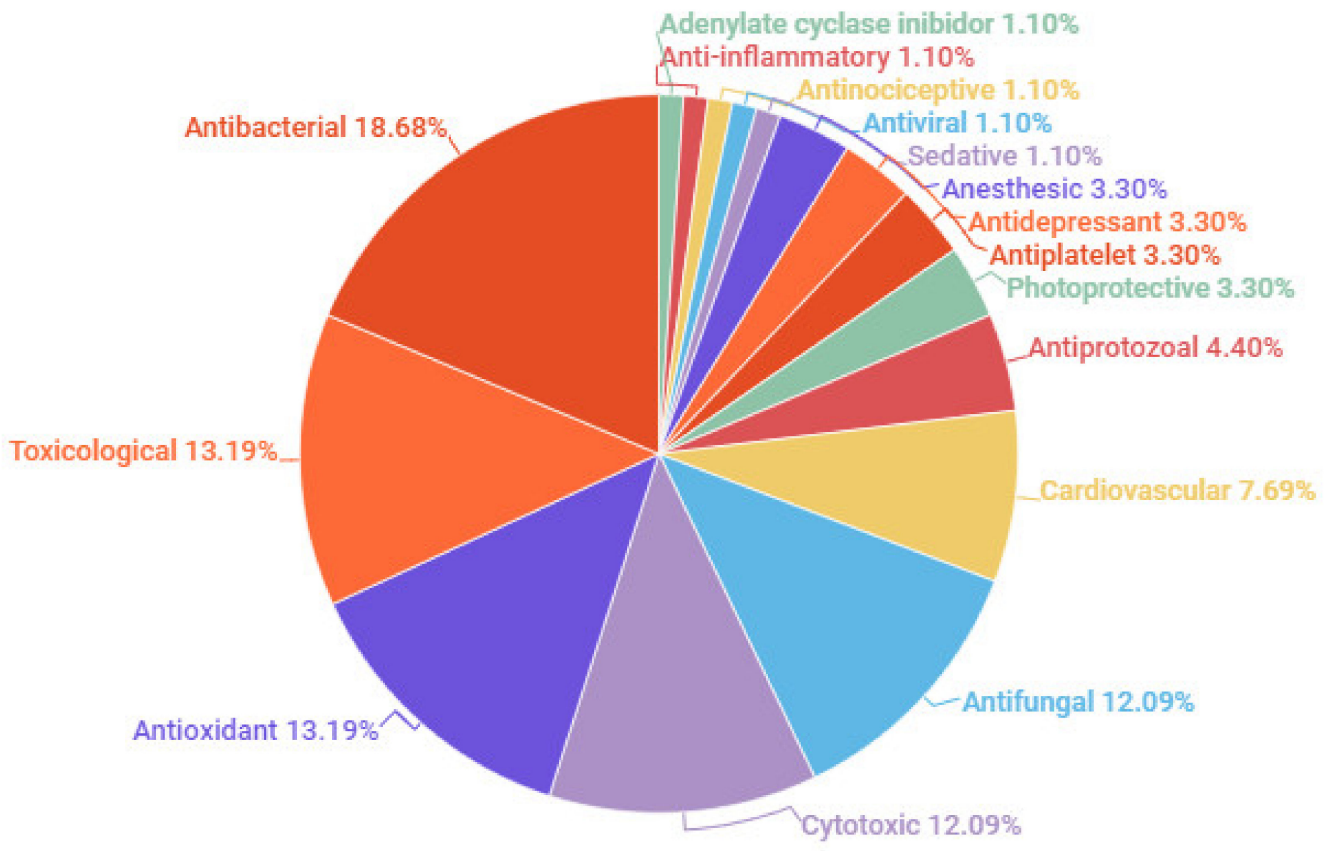

Figure 6. Studies reported on biological activities of essential oil of Aniba species from the Amazon.

\subsection{Antibacterial Activity}

Antibacterial properties of various Aniba essential oils were evaluated using the disk diffusion and plate microdilution bioassay.

The oil of $A$. canelilla trunkwood was tested against the human pathogenic bacteria Staphylococcus aureus and S. homini. Oil $(50 \mathrm{mg} / \mathrm{mL})$ containing 1-nitro-2-phenylethane (73.0\%) and methyleugenol (19.2\%) was active against S. aureus (S-methicillin sensitive and R-methicillin resistant) with a zone of inhibition of $12 \mathrm{~mm}$ and $15 \mathrm{~mm}$, respectively [77]. According to [108], inhibition zones diameter can be scored as weak (10-13.9 mm), moderate (14-18 mm), or strong (>18 mm).

The leaf oil of A. parviflora, composed of linalool (45.0\%), $\beta$-phellandrene (17.3\%) and $\alpha$-phellandrene (4.1\%), and the leaf oil of Aniba rosaeodora, containing linalool (88.6\%), collected in Santarém (PA, Brazil), showed effective antibacterial activity against Escherichia coli, Klebsiella pneumoniae, Staphylococcus aureus, S. epidermidis Enterococcus faecalis, and Streptococcus pyogenes (MIC $1.3-10 \mu \mathrm{L} / \mathrm{mL}$ ), and the antibiotics ampicillin and gentamicin (10 $\mu \mathrm{g} /$ disk) were applied as the reference standard [33]. Usually, the antimicrobial activity of essential oil is classified according to MIC values as strong (MIC from 50 to $500 \mu \mathrm{g} / \mathrm{mL}$ ), moderate (MIC from 600 to $1500 \mu \mathrm{g} / \mathrm{mL}$ ), and weak (MIC > $1500 \mu \mathrm{g} / \mathrm{mL}$ ) [109]. Essential oils of leaves and branches from A. parviflora, also occurring at Santarém, PA, Brazil, containing linalool $(22.8 \%), \beta$-caryophyllene $(8.15 \%)$, and $\beta$-phellandrene $(7.55 \%)$ in the leaves, and linalool (11.90\%), aristolene (11.7\%) and $\beta$-eudesmol (3.97\%) in the branches were tested against S. aureus, E. faecalis, E. coli, and Pseudomonas aeruginosa. Both oils exhibited activity against S. aureus and E. faecalis (MIC, $2000 \mu \mathrm{g} / \mathrm{mL}$ ), considered weak or inactive. Gentamicin $(10 \mu \mathrm{g})$ was used as positive control [34].

Essential oils have been used in diets for chickens as alternative antibiotic products and growth promoters. Due to their antimicrobial properties, the trunkwood oil of A. rosaeodora, 
collected in Belém (PA, Brazil), was evaluated in vivo against E. coli from the gastrointestinal tract broiler of chickens. Linalool (84.8\%), $\alpha$-terpineol $(2.9 \%)$, and geraniol $(1.0 \%)$ were the main compounds in the tested oil. Broilers were fed with rosewood oil at 40 days of age, and samples from the gastrointestinal tracts were inoculated on plates. The rosewood oil was also evaluated as a growth promoter but did not influence broilers' growth or fattening performance. The oil at $0.45 \%$ reduced the relative weight of the intestines. The commercial growth promoter virginiamycin (100 ppm) was used as control [110].

The oil of leaves and thin branches from A. rosaeodora, sampled in Adolpho Ducke Forest Reserve (AM, Brazil), containing linalool (93.6\%), $\alpha$-terpinolene $(3.3 \%)$, and cislinalool oxide (3.0\%) was evaluated by disk-diffusion method against bacteria isolated from a marine environment. The MIC of $A$. rosaeodora oil ranged from 250 to $450 \mu \mathrm{g} / \mathrm{mL}$, compared to standard linalool (550-650 $\mathrm{\mu g} / \mathrm{mL})$, and the antibiotics amoxicillin $(8-16 \mu \mathrm{g} / \mathrm{mL})$, gentamycin $(2-8 \mu \mathrm{g} / \mathrm{mL})$, and polymyxin B $(16 \mu \mathrm{g} / \mathrm{mL})$. Aniba rosaeodora oil was more efficient against Aeromonas caviae and Enterococcus faecalis than the standard linalool. Linalool exhibited more significant activity against Klebsiella pneumonia and Providencia stuartii compared to the oil, while the oil and linalool presented the same activity against Aeromonas hydrophila [81]. The oil from stems of A. rosaeodora was also tested against $E$. coli and S. aureus and presented MIC of 200 and $150 \mu \mathrm{g} / \mathrm{mL}$, respectively. The inhibition halos ranging from 11 to $15 \mathrm{~mm}$, and the minimum bactericidal concentration (MBC) ranging from $400-350 \mu \mathrm{g} / \mathrm{mL}$ [82].

Antibacterial properties of other Aniba oils were also evaluated using the microdilution method. The leaf oil of A. hostmanniana, dominated by benzyl benzoate $(29.3 \%)$, $\delta$-cadinene $(12.0 \%)$, and $\beta$-caryophyllene (10.5\%), was tested against the bacteria E. coli, P. aeruginosa, and K. pneumoniae (Gram-negative), and S. aureus (Gram-positive). Oil displayed significant MIC values to P. aeruginosa $(900 \mu \mathrm{g} / \mathrm{mL})$, S. aureus $(900 \mu \mathrm{g} / \mathrm{mL})$, and $K$. pneumoniae $(1250 \mu \mathrm{g} / \mathrm{mL})$, while to E. coli, the oil did not display sensitivity [68]. The essential oils of $A$. parviflora from Belém (PA, Brazil), containing $\beta$-phellandrene (15.1\%), linalool $(14.1 \%)$, and $\gamma$-eudesmol (12.9\%) in the leaves, and $\gamma$-eudesmol (16.8\%), $\beta$-caryophyllene $(15.4 \%)$, and linalool (12.4\%) in the branches, showed potent activity against E. coli (MIC: $19.5 \mu \mathrm{g} / \mathrm{mL}$ ) and moderate activity against S. aureus (MIC: $625.0 \mu \mathrm{g} / \mathrm{mL}$ ), S. epidermidis $(625.0-1250.0 \mu \mathrm{g} / \mathrm{mL})$ and P. aeruginosa $(1250.0 \mu \mathrm{g} / \mathrm{mL})$. On the other hand, for Bacillus cereus, the same leaf oil displayed a variable activity (MIC: $312.5-1250.0 \mu \mathrm{g} / \mathrm{mL}$ ). Gentamicin $(19.5 \mu \mathrm{g} / \mathrm{mL})$ was used as control [32]. 
Table 2. Main constituents and biological activities of essential oils of Aniba species from the Amazon.

\begin{tabular}{|c|c|c|c|c|c|}
\hline Aniba Species & Collection Site & Plant Part & Major Componentes & Bioactivities & References \\
\hline A. canelilla & $\begin{array}{c}\text { Adolpho Ducke Forest } \\
\text { Reserve, Manaus, AM, Brazil }\end{array}$ & Leaf & $\begin{array}{l}\text { 1-Nitro-2-phenylethane }(88.9 \%) \text {, } \\
\beta \text {-caryophyllene }(4.21 \%), \text { and } \\
\beta \text {-phellandrene }(0.80 \%)\end{array}$ & $\begin{array}{l}\text { Anti-leishmanial }\left(\mathrm{IC}_{50} 40 \mu \mathrm{g} / \mathrm{mL} \text {, Leishmania }\right. \\
\text { amazonensis promastigotes); cytotoxic (mice BALB-c } \\
\text { macrophage, MTT assay, } \mathrm{IC}_{50} 9.3 \mu \mathrm{g} / \mathrm{mL} \text { ); toxicological } \\
\left(\mathrm{LC}_{50} 68.37 \mu \mathrm{g} / \mathrm{mL} \text {, Artemia salina lethality) }\right.\end{array}$ & [22] \\
\hline A. canelilla & $\begin{array}{l}\text { Adolpho Ducke Forest } \\
\text { Reserve, Manaus, AM, Brazil }\end{array}$ & Leaf & $\begin{array}{l}\text { 1-Nitro-2-phenylethane }(88.9 \%) \text {, } \\
\beta \text {-caryophyllene }(4.21 \%) \text {, and } \\
\beta \text {-phellandrene }(0.80 \%)\end{array}$ & $\begin{array}{l}\text { Anti-leishmanial }\left(\mathrm{IC}_{50} 40 \mu \mathrm{g} / \mathrm{mL} \text {, Leishmania }\right. \\
\text { amazonensis promastigotes); cytotoxic (mice BALB-c } \\
\left.\text { macrophage, MTT assay, IC } \mathrm{IC}_{50} 9.3 \mu \mathrm{g} / \mathrm{mL}\right) \text {; toxicological } \\
\left(\mathrm{LC}_{50} 68.37 \mu \mathrm{g} / \mathrm{mL} \text {, Artemia salina lethality) }\right.\end{array}$ & [22] \\
\hline A. canelilla & $\begin{array}{l}\text { Cauaxi River, Paragominas, } \\
\text { PA, Brazil }\end{array}$ & Bark & $\begin{array}{l}\text { 1-Nitro-2-phenylethane (52.4\%), methyleugenol } \\
\quad(38.6 \%) \text { and selin-11-en-4- } \alpha \text {-ol }(2.5 \%) ;\end{array}$ & $\begin{array}{l}\text { Cardiovascular, hypotension and bradycardia, EO at } \\
1-10 \mathrm{mg} / \mathrm{kg} \text {; vasorelaxant effects, } \mathrm{IC}_{50} 19 \mu \mathrm{g} / \mathrm{mL} \text {; }\end{array}$ & [23] \\
\hline A. canelilla & $\begin{array}{l}\text { Cauaxi River, Paragominas, } \\
\text { PA, Brazil }\end{array}$ & Bark & 1-Nitro-2-phenylethane, isolated & $\begin{array}{l}\text { Cardiovascular, hypotension and bradycardia, EO at } \\
1-20 \mathrm{mg} / \mathrm{kg} \text {; vasorelaxant effects, } \mathrm{IC}_{50} 29.6 \mu \mathrm{g} / \mathrm{mL}\end{array}$ & [23] \\
\hline A. canelilla & $\begin{array}{l}\text { Cauaxi River, Paragominas, } \\
\text { PA, Brazil }\end{array}$ & Bark & $\begin{array}{l}\text { 1-Nitro-2-phenylethane }(52.4 \%) \text {, methyleugenol } \\
\text { (38.6\%) and selin-11-en- } 4 \alpha \text {-ol ( } 2.5 \%) \text {, and } \\
\text { 1-nitro-2-phenylethane, isolated }\end{array}$ & $\begin{array}{l}\text { Cardiovascular, vasorelaxant effects }\left(\mathrm{IC}_{50}\right. \\
294.19 \mu \mathrm{g} / \mathrm{mL}) \text { and 1-nitro-2-phenylethane isolated } \\
\left(\mathrm{IC}_{50} 501.27 \mu \mathrm{g} / \mathrm{mL}\right)\end{array}$ & {$[24]$} \\
\hline A. canelilla & $\begin{array}{l}\text { Jatapu River, Novo Airão, } \\
\text { AM, Brazil }\end{array}$ & Trunk wood & $\begin{array}{l}\text { 1-Nitro-2-phenylethane (92.1\%), methyleugenol } \\
\qquad(4.30 \%) \text {, and eugenol }(1.2 \%)\end{array}$ & $\begin{array}{c}\text { Antioxidant }\left(\mathrm{EC}_{50} 223.81 \mu \mathrm{g} / \mathrm{mL}, \mathrm{DPPH} \text { method }\right) \\
\text { toxicological }\left(\mathrm{LC}_{50} 21.61 \mu \mathrm{g} / \mathrm{mL}\right. \\
\text { Artemia salina lethality) }\end{array}$ & [27] \\
\hline A. canelilla & $\begin{array}{l}\text { Cauaxi River, Ulianópolis, } \\
\text { PA, Brazil }\end{array}$ & Trunk wood & $\begin{array}{l}\text { 1-Nitro-2-phenylethane }(70.2 \%) \text {, methyleugenol } \\
\quad(25.8 \%) \text {, and selin-11-en- } 4 \alpha-\text { ol }(1.2 \%)\end{array}$ & $\begin{array}{c}\text { Antioxidant }\left(\mathrm{EC}_{50} 172.52 \mu \mathrm{g} / \mathrm{mL}, \mathrm{DPPH} \text { method); }\right. \\
\text { toxicological (LC } \mathrm{LC}_{50} 21.61 \mu \mathrm{g} / \mathrm{mL} \text {, Artemia salina } \\
\text { lethality assay) }\end{array}$ & [27] \\
\hline A. canelilla & $\begin{array}{l}\text { Adolpho Ducke Forest } \\
\text { Reserve, Manaus, AM, Brazil }\end{array}$ & Leaf & $\begin{array}{l}\text { 1-Nitro-2-phenylethane (87.34\%), ethyl } \\
\text { butanoate (3.10\%), and } \alpha \text {-humulene }(0.68 \%)\end{array}$ & $\begin{array}{c}\text { Antifungal (Aspergillus flavus, Colletotrichum guaranicola, } \\
\text { MIC } 0.15 \mu \mathrm{g} / \mathrm{mL} \text {; A. niger, MIC } 0.3 \mu \mathrm{g} / \mathrm{mL} ; \text { Fusarium } \\
\text { oxysporum, F. solani, C. gloeosporioides, C. musae, MIC } \\
0.62 \mu \mathrm{g} / \mathrm{mL} \text {; Alternaria alternata MIC } 5.0 \mu \mathrm{g} / \mathrm{mL} \text {, } \\
\text { agar-well diffusion method) }\end{array}$ & [35] \\
\hline A. canelilla & not reported & Bark stem & $\begin{array}{l}\text { 1-Nitro-2-phenylethane }(73.0 \%) \text {, methyleugenol } \\
(19.2 \%) \text {, safrole }(3.7 \%) \text {, and eugenol }(1.5 \%)\end{array}$ & $\begin{array}{l}\text { Antimicrobial (Staphylococcus aureus, Candida albicans, } \\
\text { C. parapsilosis and C. krusei, agar diffusion method) }\end{array}$ & {$[77]$} \\
\hline A. canelilla & $\begin{array}{l}\text { Cauaxi River, Paragominas, } \\
\text { PA, Brazil }\end{array}$ & Bark & $\begin{array}{l}\text { 1-Nitro-2-phenylethane (52.4\%), methyleugenol } \\
\quad(38.6 \%) \text { and selin-11-en- } 4 \alpha \text {-ol }(2.5 \%)\end{array}$ & $\begin{array}{c}\text { Cardiovascular (Rattus norvegicus male Wistar rat } \\
\text { model), hypotension and bradycardia EO at 1,5, 10, } \\
\text { and } 20 \mathrm{mg} / \mathrm{kg} \text {; vasorelaxant effects, } \mathrm{IC}_{50} 109.5 \mu \mathrm{g} / \mathrm{mL}\end{array}$ & {$[85]$} \\
\hline
\end{tabular}


Table 2. Cont.

\begin{tabular}{|c|c|c|c|c|c|}
\hline Aniba Species & Collection Site & Plant Part & Major Componentes & Bioactivities & References \\
\hline A. canelilla & Itacoatiara, AM, Brazil & Wood & $\begin{array}{l}\text { 1-Nitro-2-phenylethane }(83.68 \%) \\
\text { methyleugenol }(14.83 \%) \text { and } \\
\text { neointermedeol }(0.31 \%)\end{array}$ & $\begin{array}{c}\text { Trypanocide (Trypanosoma evansi, mortality after } 6 \mathrm{~h}, \mathrm{EO} \\
\text { at } 0.5 \text { to } 2.0 \% \text { ); Cytotoxic (human lymphocytes, EO at } \\
0.5 \text { to } 2.0 \% \text {, MTT assay) }\end{array}$ & [86] \\
\hline A. canelilla & $\begin{array}{l}\text { Cauaxi River, Ulianópolis, } \\
\text { PA, Brazil }\end{array}$ & Bark wood & 1-Nitro-2-phenylethane & $\begin{array}{l}\text { Antinociceptive and anti-inflammatory } \\
\text { (abdominal writhing method) }\end{array}$ & [110] \\
\hline A. canelilla & $\begin{array}{l}\text { Cauaxi River, Ulianópolis, } \\
\text { PA, Brazil }\end{array}$ & Trunk wood & 1-Nitro-2-phenylethane, isolated & $\begin{array}{l}\text { Anti-inflammatory ( } 25 \text { and } 50 \mathrm{mg} / \mathrm{kg} \text {, paw and ear } \\
\text { edema in male Swiss mice and Wistar rats) }\end{array}$ & [111] \\
\hline A. canelilla & $\begin{array}{c}\text { Adolpho Ducke Forest } \\
\text { Reserve, Manaus, AM, Brazil. }\end{array}$ & Thin twig & Not reported & $\begin{array}{l}\text { Photoprotective (dry season, FPS 5.49; rainy season FPS } \\
6.93 \text {, spectrophotometric method) }\end{array}$ & [112] \\
\hline A. canelilla & $\begin{array}{l}\text { Cauaxi River, Paragominas, } \\
\text { PA, Brazil }\end{array}$ & Bark & 1-Nitro-2-phenylethane, isolated & $\begin{array}{c}\text { Cardiovascular (male Wistar rat model), induced } \\
\text { hypotensive and bradycardic, EO at } 1-10 \mathrm{mg} / \mathrm{kg} ; \\
\text { vasorelaxant effects, } \mathrm{IC}_{50} 60.1 \mu \mathrm{g} / \mathrm{mL}\end{array}$ & [113] \\
\hline A. canelilla & $\begin{array}{l}\text { Cauaxi River, Paragominas, } \\
\text { PA, Brazil }\end{array}$ & Bark & 1-Nitro-2-phenylethane, isolated & $\begin{array}{c}\text { Cardiovascular (Male Wistar rat model); vasorelaxant } \\
\text { effects } \mathrm{IC}_{50} 203.1 \mu \mathrm{M} \text {, contractions induced by } \\
\text { phenylephrine; Hyp9 } \mathrm{IC}_{50} 119.0 \mu \mathrm{M} \text { and phorbol } \\
12,13 \text {-dibutyrate } \mathrm{IC}_{50} 43 \mu \mathrm{M}\end{array}$ & [114] \\
\hline A. canelilla & not reported & Not reported & 1-Nitro-2-phenylethane, isolated & $\begin{array}{l}\text { Cardiovascular, vasorelaxant effects at concentration of } \\
\qquad 0.1-100 \mu \mathrm{g} / \mathrm{mL}\end{array}$ & [115] \\
\hline A. canelilla & $\begin{array}{l}\text { Cauaxi River, Ulianópolis, } \\
\text { PA, Brazil }\end{array}$ & Trunk wood & $\begin{array}{l}\text { 1-Nitro-2-phenylethane }(70.2 \%) \text {, methyleugenol } \\
\text { (25.8\%), and selin- } 11-\text { en- } 4 \alpha \text {-ol }(1.2 \%) \\
\text { 1-nitro-2-phenylethane, isolated }\end{array}$ & $\begin{array}{l}\text { Acetylcholinesterase (detection limit of } 0.01 \mathrm{ng} \text { to EO } \\
\text { and 1-nitro-2-phenylethane, isolated, TLC } \\
\text { bioautography method) }\end{array}$ & [116] \\
\hline A. duckei & $\begin{array}{c}\text { Adolpho Ducke Forest } \\
\text { Reserve, Manaus, AM, Brazil }\end{array}$ & Twig & $\begin{array}{c}\text { Linalool }(93.6 \%), \alpha \text {-terpinolene }(3.37 \%) \text {, and } \\
\text { cis-linalool oxide }(3.03 \%)\end{array}$ & $\begin{array}{l}\text { Antifungal (Colletotrichum gloesporioides and Fusarium } \\
\text { oxysporum, mycelial growth inhibition in } 100 \% \text { at } 0.4 \% \text { ) }\end{array}$ & [29] \\
\hline \multirow[t]{2}{*}{ A. duckei } & \multirow[t]{2}{*}{$\begin{array}{l}\text { Adolpho Ducke Forest } \\
\text { Reserve, Manaus, AM, Brazil }\end{array}$} & \multirow[t]{2}{*}{ Twig } & $\begin{array}{l}\text { Linalool }(89.34 \%), \alpha \text {-terpineol }(3.06 \%) \text {, and } \\
\text { cis-linalool oxide }(1.94 \%)\end{array}$ & \multirow{2}{*}{$\begin{array}{l}\text { Toxicological (Aedes aegypti, LC } 50250.61 \mu \mathrm{g} / \mathrm{mL}, \mathrm{EO} \\
\text { LC }_{50} 279.89 \mu \mathrm{g} / \mathrm{mL}, 3 R-(-) \text {-linalool; } \mathrm{LC}_{50} 346 \mu \mathrm{g} / \mathrm{mL} \\
( \pm) \text {-linalool }\end{array}$} & \multirow[t]{2}{*}[81]{} \\
\hline & & & 3R-(-)-linalool and $( \pm)$-linalool standard & & \\
\hline A. duckei & $\begin{array}{c}\text { Adolpho Ducke Forest } \\
\text { Reserve, Manaus, AM, Brazil }\end{array}$ & Leaf & Not reported & $\begin{array}{c}\text { Toxicological (Artemia franciscana, } 100 \% \text { of larval } \\
\text { mortality after } 10 \mathrm{~min}, \mathrm{EO} \text { at } 2 \mu \mathrm{g} / \mathrm{mL} \text { ) }\end{array}$ & [117] \\
\hline
\end{tabular}


Table 2. Cont.

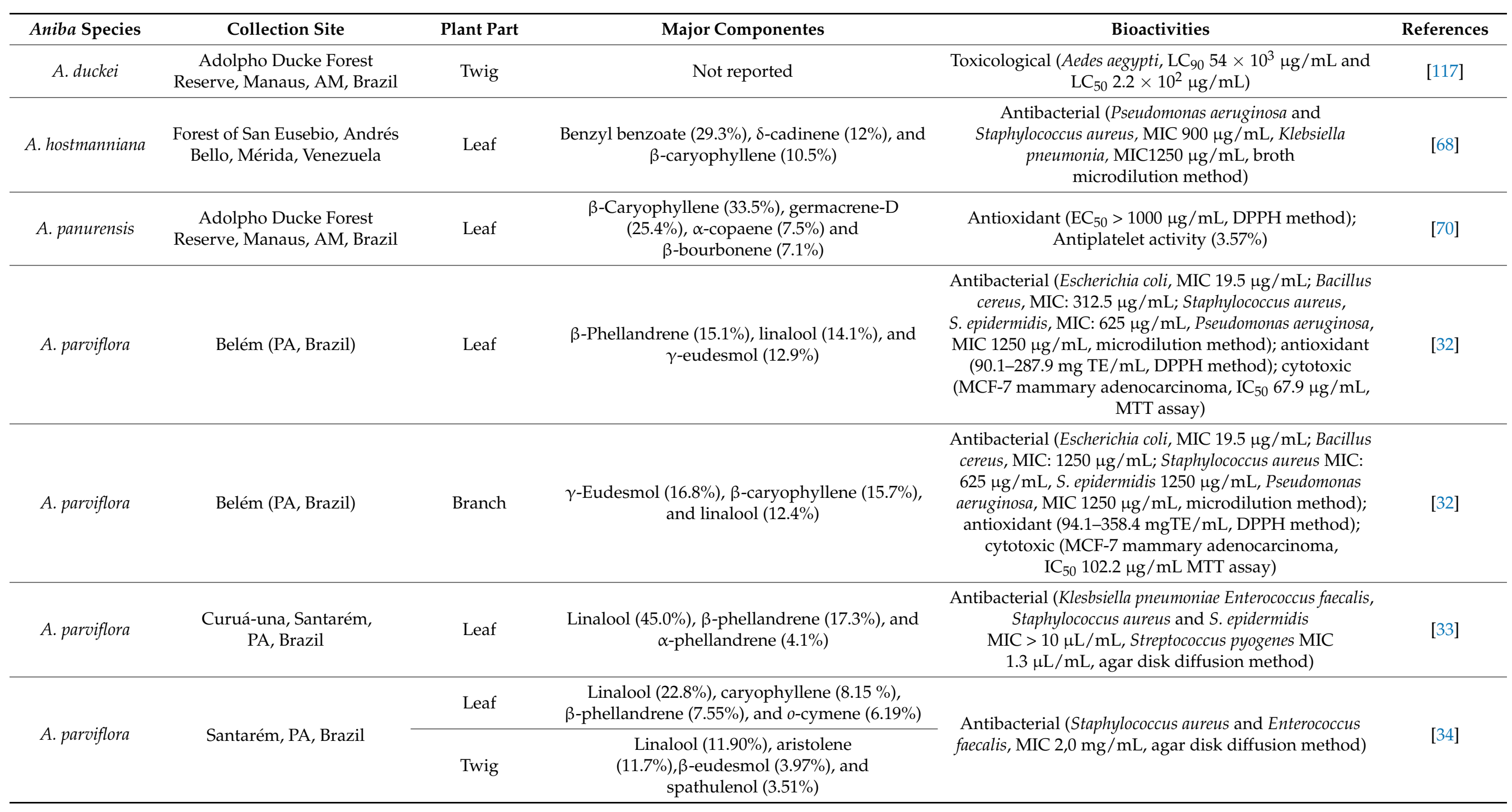


Table 2. Cont.

\begin{tabular}{|c|c|c|c|c|c|}
\hline Aniba Species & Collection Site & Plant Part & Major Componentes & Bioactivities & References \\
\hline A. parviflora & $\begin{array}{l}\text { Adolpho Ducke Forest } \\
\text { Reserve, Manaus, AM, Brazil }\end{array}$ & Leaf & $\begin{array}{l}\text { Linalool }(40.02 \%) \text {, caryophyllene oxide }(4.33 \%) \text {, } \\
\text { 1,8-cineole }(4.02 \%) \text {, and } \beta \text {-phellandrene }(4.01 \%)\end{array}$ & $\begin{array}{l}\text { Antifungal (Aspergillus flavus, Fusarium solani, F. } \\
\text { oxysporum, MIC } 0.62 \mu \mathrm{L} / \mathrm{mL} ; \text { A. niger, Colletotrichum } \\
\text { guaranicola, MIC } 2.5 \mu \mathrm{L} / \mathrm{mL} \text {; C. gloeosporioides, MIC } \\
0.62 \mu \mathrm{L} / \mathrm{mL} ; \text { Alternaria alternata, C. musae, MIC } \\
5.0 \mu \mathrm{L} / \mathrm{mL} \text {, agar-well diffusion method) }\end{array}$ & {$[35]$} \\
\hline A. parviflora & $\begin{array}{l}\text { Curuá-una, Santarém, } \\
\text { PA, Brazil }\end{array}$ & Leaf & $\begin{array}{l}\text { Linalool }(45.0 \%), \beta \text {-phellandrene }(17.3 \%), \\
\alpha \text {-phellandrene }(4.1 \%), \text { and } \\
(E) \text {-caryophyllene }(3.9 \%)\end{array}$ & $\begin{array}{l}\text { Antidepressant activity (Male Wistar rats, } \\
\text { EO at } 85 \mathrm{mg} / \mathrm{kg} \text { ) }\end{array}$ & {$[71]$} \\
\hline A. parviflora & Santarém, PA, Brazil & Leaf & $\begin{array}{c}\text { Linalool (29.60\%), } \beta \text {-caryophyllene }(10.9 \%) \text {, and } \\
\alpha \text {-phellandrene }(10.5 \%)\end{array}$ & $\begin{array}{l}\text { Anesthetic potential to the fish species Colossoma } \\
\text { macropomum. EO at } 0.1 \mu \mathrm{L} / \mathrm{mL} \text { light sedation }(46.4 \mathrm{~s}) \text {, } \\
\text { deep sedation }(120.8 \mathrm{~s}) \text {, deep anesthesia (333.2 s) }\end{array}$ & [118] \\
\hline A. parviflora & Curauá, Santarém, PA, Brazil & Bark & $\begin{array}{c}\text { Linalool }(16.3 \%), \alpha \text {-humulene }(14.5 \%) \\
\delta \text {-cadinene }(10.2 \%), \alpha \text {-copaene }(9.51 \%) \text { and } \\
\text { germacrene B }(7.58 \%)\end{array}$ & $\begin{array}{l}\text { Cytotoxic (Human hepatocellular carcinoma cells } \\
\text { HepG2; } \mathrm{IC}_{50} \text { values of } 9.05 \mu \mathrm{g} / \mathrm{mL} \text {; xenograft model). }\end{array}$ & [119] \\
\hline \multirow{2}{*}{ A. rosaeodora } & \multirow{2}{*}{ Manaus, AM, Brazil } & \multirow{2}{*}{ Leaf } & $\begin{array}{l}\text { Dry season: linalool }(69.0 \%), \beta \text {-phellandrene } \\
(2.9 \%) \text {, and bulnesol }(1.8 \%)\end{array}$ & $\begin{array}{l}\text { Antifungal activity (Colletotrichum gloeosporioides, MIC } \\
1.25 \mu \mathrm{L} / \mathrm{mL} \text {, Colletotrichum sp., MIC } 2.5 \mu \mathrm{L} / \mathrm{mL} \text {; } \\
\text { C. guaranicola, MIC } 0.62 \mu \mathrm{L} / \mathrm{mL} \text {; Alternaria alternata, } \\
\text { MIC } 1.25 \mu \mathrm{L} / \mathrm{mL} \text {, agar-well diffusion method) }\end{array}$ & \multirow{2}{*}[28]{} \\
\hline & & & $\begin{array}{l}\text { Rainy season: linalool }(71.0 \%) \text {, butanoic acid } \\
(3.5 \%) \text {, and trans-linalool oxide }(2.8 \%)\end{array}$ & $\begin{array}{l}\text { Antifungal activity (Colletotrichum gloeosporioides rainy } \\
\text { season, MIC } 2.5 \mu \mathrm{L} / \mathrm{mL} \text {; Colletotrichum sp., MIC } \\
5.0 \mu \mathrm{L} / \mathrm{mL} \text {; C. guaranicola, MIC } 1.25 \mu \mathrm{L} / \mathrm{mL} \text {; Alternaria } \\
\text { alternata, MIC } 2.5 \mu \mathrm{L} / \mathrm{mL} \text {, agar well diffusion method) }\end{array}$ & \\
\hline \multirow{2}{*}{ A. rosaeodora } & \multirow{2}{*}{ Manaus, AM, Brazil } & \multirow{2}{*}{ Thin twig } & $\begin{array}{l}\text { Dry season: linalool }(78.0 \%), \beta \text {-phellandrene } \\
(1.5 \%) \text {, and } \alpha \text {-eudesmol }(1.4 \%)\end{array}$ & $\begin{array}{l}\text { Antifungal activity (Colletotrichum gloeosporioides, MIC } \\
1.25 \mu \mathrm{L} / \mathrm{mL} \text {; Colletotrichum sp., dry season, MIC } \\
2.5 \mu \mathrm{L} / \mathrm{mL} ; \text { C. guaranicola, MIC } 1.25 \mu \mathrm{L} / \mathrm{mL} \text {; Alternaria } \\
\text { alternata, MIC } 1.25 \mu \mathrm{L} / \mathrm{mL} \text {, agar well diffusion method) }\end{array}$ & \multirow{2}{*}{ [28] } \\
\hline & & & $\begin{array}{l}\text { Rainy season: linalool }(84.0 \%) \text {, butanoic acid } \\
(3.0 \%) \text {, and cis-linalool oxide }(2.0 \%)\end{array}$ & $\begin{array}{l}\text { Antifungal activity (Colletotrichum gloeosporioides, MIC } \\
2.5 \mu \mathrm{L} / \mathrm{mL} \text {; Colletotrichum sp., MIC } 5.0 \mu \mathrm{L} / \mathrm{mL} ; \\
\text { C. guaranicola, MIC } 1.25 \mu \mathrm{L} / \mathrm{mL} \text {; Alternaria alternata, } \\
\text { MIC } 2.5 \mu \mathrm{L} / \mathrm{mL} \text {, agar well diffusion method) }\end{array}$ & \\
\hline
\end{tabular}


Table 2. Cont.

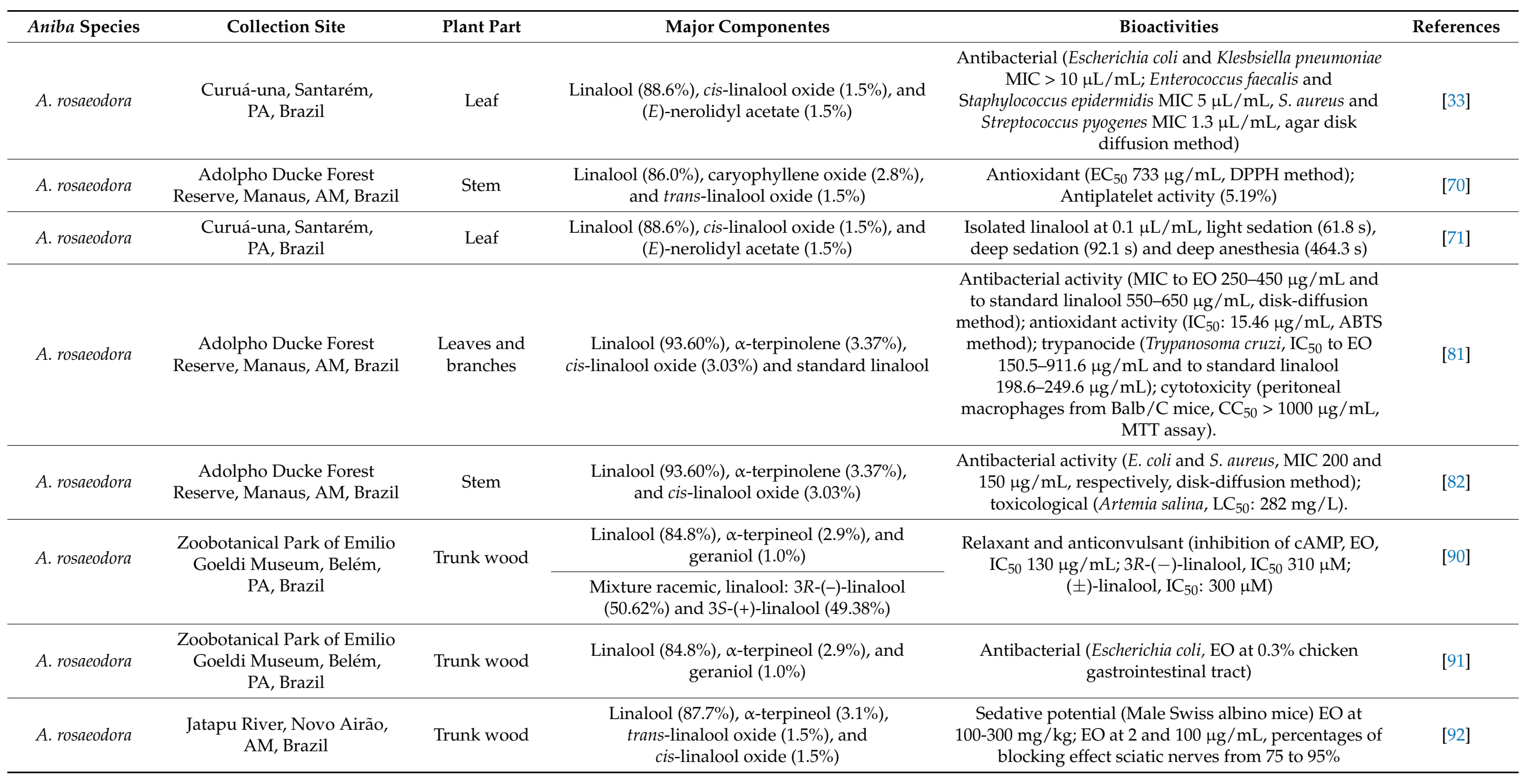


Table 2. Cont

\begin{tabular}{|c|c|c|c|c|c|}
\hline Aniba Species & Collection Site & Plant Part & Major Componentes & Bioactivities & References \\
\hline A. rosaeodora & $\begin{array}{l}\text { Adolpho Ducke Forest } \\
\text { Reserve, Manaus, AM, Brazil }\end{array}$ & Stem & $\begin{array}{l}\text { Linalool }(63.16 \%) \text {, trans-linalool furanoid } \\
(9.73 \%) \text { and cis-linalool furanoid }(7.69 \%)\end{array}$ & $\begin{array}{l}\text { Antioxidant activity }\left(\mathrm{IC}_{50}: 48.67 \text { and } 40.06 \mu \mathrm{g} / \mathrm{mL}\right. \\
\text { ABTS and DPPH methods, respectively); toxicological } \\
\text { (Artemia salina, } \mathrm{LC}_{50} 282-582 \mu \mathrm{g} / \mathrm{mL} \text {; Aedes aegypti, } \\
\mathrm{LC}_{50} 41.07 \mu \mathrm{g} / \mathrm{mL} \text { ) }\end{array}$ & [93] \\
\hline A. rosaeodora & Maués, AM, Brazil & Leaf & $\begin{array}{l}\text { Linalool (90.5\%), synthetic linalool and } \\
\text { isolated linalool }\end{array}$ & $\begin{array}{l}\text { Anesthetic potential to the fish species Colossoma } \\
\text { macropomum. EO at } 0.050 \mu \mathrm{L} / \mathrm{mL} \text { light sedation }(68.3 \mathrm{~s}) \text {, } \\
\text { deep sedation (204.1 s) and deep anesthesia (636.4 s) }\end{array}$ & [118] \\
\hline \multirow[t]{2}{*}{ A. rosaeodora } & \multirow[t]{2}{*}{ Maués, AM, Brazil } & \multirow[t]{2}{*}{ Leaf } & \multirow{2}{*}{$\begin{array}{l}\text { Linalool }(90.5 \%) \text {, synthetic linalool and } \\
\text { isolated linalool }\end{array}$} & $\begin{array}{l}\text { Synthetic linalool at } 0.1 \mu \mathrm{L} / \mathrm{mL} \text {, light sedation (32.7 s), } \\
\text { deep sedation }(68.9 \mathrm{~s}) \text { and deep anesthesia }(198.7 \mathrm{~s})\end{array}$ & \multirow[t]{2}{*}{ [118] } \\
\hline & & & & $\begin{array}{l}\text { Isolated linalool at } 0.1 \mu \mathrm{L} / \mathrm{mL} \text {, light sedation }(61.8 \mathrm{~s}) \text {, } \\
\text { deep sedation }(92.1 \mathrm{~s}) \text { and deep anesthesia }(464.3 \mathrm{~s})\end{array}$ & \\
\hline A. rosaeodora & $\begin{array}{l}\text { Zoobotanical Park of Emilio } \\
\text { Goeldi Museum, Belém, } \\
\text { PA, Brazil }\end{array}$ & Trunk wood & Not reported & $\begin{array}{l}\text { Antiviral (Avian metapneumovirus, } \mathrm{EC}_{50} \text { : } \\
20.86 \mu \mathrm{g} / \mathrm{mL}) \text {; cytotoxicity, cells derived from bovine } \\
\text { kidney (CRIB), chicken embryo (CRER), mouse } \\
\text { fibroblast cell (L929) and feline kidney cell lines (CRFK) } \\
\qquad \mathrm{CC}_{50}: 104.8 \mu \mathrm{g} / \mathrm{mL}\end{array}$ & [120] \\
\hline A. rosaeodora & $\begin{array}{l}\text { Jatapu River, Novo Airão, } \\
\text { AM, Brazil }\end{array}$ & Trunk wood & $\begin{array}{l}\text { Linalool }(87.7 \%), \alpha \text {-terpineol }(3.1 \%) \\
\text { trans-linalool oxide }(1.5 \%), \text { and } \\
\text { cis-linalool oxide }(1.5 \%)\end{array}$ & $\begin{array}{c}\text { Cardiovascular (Male Wistar rat model), hypotension } \\
\text { and bradycardia, EO at } 10-20 \mathrm{mg} / \mathrm{kg} \text {; vasorelaxant } \\
\text { effects, } \mathrm{IC}_{50}: 72.35 \mu \mathrm{g} / \mathrm{mL}\end{array}$ & {$[121]$} \\
\hline
\end{tabular}

DPPH: 2,2-Diphenyl-1-picrylhydrazyl; LEC: lowest effective concentrations; MTT: 3-(4,5-dimethylthiazol-2-yl)-2,5-diphenyltetrazolium bromide; SPF: sunscreen protection factor. 


\subsection{Antifungal Activity}

The fungistatic properties of oils from Aniba were tested by the disk diffusion method. The trunkwood oil of $A$. canelilla was evaluated against the human pathogenic fungi Candida albicans, C. krusei, and C. parapsilosis. oil $(5 \mathrm{mg} / \mathrm{mL})$ was active against these fungi with a halo of inhibition $25 \mathrm{~mm}$ to C. krusei and C. albicans and $18 \mathrm{~mm}$ to C. parapsilosis. The oil's main compounds were 1-nitro-2-phenylethane $(73.0 \%)$, methyleugenol $(19.2 \%)$, and safrole (3.7\%). MIC values and standard controls were not reported [77].

Different oil concentrations of Aniba duckei branches were tested on the growth of phytopathogenic fungi Colletotrichum gloesporioides and Fusarium oxysporum, displaying a mycelial inhibition of $65.0 \%$ and $72.09 \%$, respectively, at $2 \%$, and $100 \%$ inhibition for both fungi, at $0.4 \%$. The oil was dominated by linalool $(93.60 \%)$ with lesser amounts of cis-linalool oxide (3.03\%) and $\alpha$-terpinolene (3.37\%). A linalool experiment itself supported its influence on the antifungal activity with a mycelial inhibition of $100 \%$ at a concentration of $0.2 \%$ [29].

Two Aniba oils from Adolpho Ducke Forest Reserve (AM, Brazil) were evaluated against the phytopathogenic fungi Aspergillus flavus, A. niger, Fusarium oxysporum, F. solani, Alternaria alternata, Colletotrichum gloeosporioides, C. musae, and C. guaranicola. The leaf oil from A. canelilla was mainly composed of 1-nitro-2-phenylethane $(87.34 \%)$ and ethyl butanoate $(3.1 \%)$, and the leaf oil from A. parviflora showed linalool (40.02\%), caryophyllene oxide (4.33\%), 1,8-cineole (4.02\%), and $\beta$-phellandrene (4.01\%) as major constituents. Aniba canelilla oil displayed strong activity against $C$. guaranicola (MIC, $0.15 \mu \mathrm{L} / \mathrm{mL}$ ) and A. niger (MIC, $0.3 \mu \mathrm{L} / \mathrm{mL}$ ), equivalent to Mancozeb (MIC, $0.3 \mu \mathrm{L} / \mathrm{mL}$ ) used as a positive control. In addition, the activity was considered significant (MIC, $0.62 \mu \mathrm{L} / \mathrm{mL}$ ) against $F$. solani, F. oxysporum, C. gloeosporioides, C. musae, and A. flavus, and low activity (MIC, $5 \mu \mathrm{L} / \mathrm{mL}$ ) against $A$. alternata. Aniba parviflora oil exhibited higher activity (MIC: $0.62 \mu \mathrm{L} / \mathrm{mL}$ ) against A. flavus, F. solani, and F. oxysporum, while to A. niger, C. guaranicola, C. gloeosporioides, A. alternata, and C. musae, the MIC values varied from 1.25 to $5.0 \mu \mathrm{L} / \mathrm{mL}$. The effects of oils at $5 \mu \mathrm{L} / \mathrm{mL}$ on conidial germination of phytopathogenic fungi also were evaluated and displayed an inhibition rate varying from $83.5 \%$ to $96.7 \%$ in A. canelilla and $69.9 \%$ to $85.3 \%$ in A. parviflora [35].

The essential oils of leaves and branches of $A$. rosaeodora collected in Manaus (AM, Brazil) in different seasons were dominated by linalool in the leaves $(69.0-71.0 \%)$ and in the branches (78-84\%). The samples and racemic linalool (Sigma-Aldrich, St. Louis, MO, USA) exhibited antifungal activity against phytopathogenic fungi. All oils showed significant activity against C. guaranicola, Colletotrichum sp., C. gloeosporioides and A. alternata with MIC values ranging from 0.62 to $5.0 \mu \mathrm{L} / \mathrm{mL}$ [28].

\subsection{Anti-Inflammatory and Antinociceptive Activities}

The antinociceptive activity of 1-nitro-2-phenylethane, isolated from the bark and wood oils of A. canellila, was evaluated using three different rodent (Swiss mice) models of pain: the acetic acid-induced writhing test, the hot-plate latency test, and the formalininduced inflammatory pain model. 1-Nitro-2-phenylethane significantly reduced the action of acetic acid used to induce writhing in mice at the dose of 15,25 , and $50 \mathrm{mg} / \mathrm{kg}$. For the hot plate test, the administration of 1-nitro-2-phenylethane at 50,100, and $200 \mathrm{mg} / \mathrm{kg}$ did not induce alterations in the latency time, compared to the morphine $(10 \mathrm{mg} / \mathrm{kg})$ positive control. The 1-nitro-2-phenylethane ( 25 and $50 \mathrm{mg} / \mathrm{kg}$ ) was tested on two phases of pain model by formalin-induced pain, the early neurogenic and the second inflammatory through the administration of $20 \mu \mathrm{L}$ of $1.0 \%$ formalin solution by intraplantar injection. The 1-nitro-2-phenylethane inhibited the licking response of mice in the second phase suggesting its antinociceptive effects [108]. The effect of 1-nitro-2-phenylethane was evaluated on paw and ear edema inhibition of male Swiss mice and Wistar rats. The anti-inflammatory potential was detected by reduced ear edema $(73.8 \%$ and $79.4 \%)$, induced by croton oil (doses of 25 and $50 \mathrm{mg} / \mathrm{kg}$, body wt.), in comparison to dexamethasone (positive control, $10 \mathrm{mg} / \mathrm{kg}$ ), which reduced edema by $87.01 \%$. The 1-nitro-2-phenylethane showed a 
dose-dependent effect on paw edema induced by dextran. At a dose of $25 \mathrm{mg} / \mathrm{kg}$, 1-nitro2-phenylethane reduced the edema by $15.58 \%, 26.78 \%, 44.92 \%$ and $30.07 \%$, after $30,60,90$, and $120 \mathrm{~min}$. At a dose of $50 \mathrm{mg} / \mathrm{kg}$, it showed inhibition of edema development of $38.1 \%$, $61 \%, 69.09 \%$, and $73.65 \%$, for 30, 60, 90, and $120 \mathrm{~min}$, respectively. Similarly, for paw edema induced by carrageenan, at a dose of $25 \mathrm{mg} / \mathrm{kg}$, 1-nitro-2-phenylethane showed edema reduction of $26.83 \%, 43.91 \%, 41.6 \%$, and $39.85 \%$ after $2,3,4$, and $5 \mathrm{~h}$. At a dose of $50 \mathrm{mg} / \mathrm{kg}$, it inhibited $51.76 \%, 54.46 \%, 47.2 \%$, and $49 \%$, after $2,3,4$, and $5 \mathrm{~h}$, respectively [111].

\subsection{Antioxidant and Photoprotective Activities}

Essential oils have been recognized as natural antioxidants, because they contain compounds such as terpenoids and phenylpropanoids capable of reacting with radicals and reducing or neutralizing oxidative stress [122]. All Aniba oils evaluated below were tested by the 2,2-diphenyl-1-picrylhydrazyl (DPPH) or 3-ethylbenzothiazoline-6-sulfonic acid (ABTS) assays.

Two trunkwood oils of A. canelilla presented 1-nitro-2-phenylethane $(92.1 \%, 70.2 \%)$ and methyleugenol $(4.30 \%, 25.8 \%)$ as major compounds. These oils and pure isolated 1-nitro-2-phenylethane indicated weak activity, with $\mathrm{EC}_{50}$ values of $223.81 \mu \mathrm{g} / \mathrm{mL}$, $172.52 \mu \mathrm{g} / \mathrm{mL}, 792.50 \mu \mathrm{g} / \mathrm{mL}$, respectively, in comparison to Trolox $\left(\mathrm{EC}_{50} 4.67 \mu \mathrm{g} / \mathrm{mL}\right.$ ), the reference standard [27].

The antioxidant activities of $A$. panurensis and A. roseaodora leaf oils showed $\mathrm{EC}_{50}>1000 \mu \mathrm{g} / \mathrm{mL}$ and $733 \mu \mathrm{g} / \mathrm{mL}$, respectively, in comparison to quercetin at $3.13 \mu \mathrm{g} / \mathrm{mL}$. Aniba panurensis oil exhibited $\beta$-caryophyllene (33.5\%), germacrene-D $(25.4 \%)$, and $\alpha$ copaene $(7.5 \%)$, and A. rosaeodora oil displayed linalool (86.0\%), caryophyllene oxide $(2.8 \%)$, and trans-linalool oxide (1.5\%), as their main constituents [70].

The antioxidant activity of $A$. rosaeodora stem oil, collected at Adolpho Ducke Forest Reserve (AM, Brazil), containing linalool (63.16\%), trans-linalool furanoid (9.73\%), and cis-linalool furanoid (7.69\%), was tested with the ABTS and DPPH assays. The oil showed $\mathrm{IC}_{50}$ values of 48.67 (ABTS) and $40.06 \mu \mathrm{g} / \mathrm{mL}$ (DPPH), respectively [93]. The A. rosaeodora leaves and thin branches oil, collected in Adolpho Ducke Forest Reserve (AM, Brazil), containing linalool (93.60\%), $\alpha$-terpinolene (3.37\%), and cis-linalool oxide (3.03\%), and the linalool standard were tested by the ABTS method. The effective concentration necessary to scavenge $50 \%$ of the ABTS $\left(\mathrm{EC}_{50}\right.$ ) was $15.46 \mu \mathrm{g} / \mathrm{mL}$ for $A$. rosaeodora oil and $6.78 \mu \mathrm{g} / \mathrm{mL}$ for linalool isolated [81].

Aniba parviflora leaf and branch oils showed significant antioxidant activity at a concentration of $2.50 \mathrm{mg} / \mathrm{mL}$, with TEAC values of $90.1-287.9 \mathrm{mgTE} / \mathrm{mL}$ for the leaves and 94.1-358.4 mgTE/mL for the branches. $\beta$-Phellandrene (15.1\%), linalool (14.1\%), and $\gamma$-eudesmol (12.9\%) were the main compounds in the leaves, and $\gamma$-eudesmol $(16.8 \%)$, $\beta$-caryophyllene (15.4\%), linalool (12.4\%), $\beta$-phellandrene (6.7\%), and bicyclogermacrene $(6.0 \%)$ in the branches [32].

The photoprotective capacity of $A$. canelilla leaf and branch oils was evaluated by spectrophotometric method, applying a wavelengths scan from 280 to $400 \mathrm{~nm}$ [123]. At a concentration of $1 \%$ in isopropanol, the oils collected during the dry and rainy seasons displayed solar protection factor (FPS) varying from 7.54 to 14.08 in the leaf oil and 5.49-6.93 in the branch oil. Quercetin (FPS 261.23), benzophenone (FPS 289.80), and commercial sunscreen (FPS 72.08) were used as standards [112]. According to Brazilian legislation, a product to be used in photoprotection cosmetics must have an SPF value of at least 6 [124].

\subsection{Cardiovascular Activity}

Cardiovascular effects of intravenous (i.v.) treatment with the essential oil of A. canelilla were evaluated in rodents. The main compounds of the oil were 1-nitro-2-phenylethane (52.4\%), methyleugenol (38.6\%), and selin-11-en- $4 \alpha-\mathrm{ol}(2.5 \%)$. Hypotensive effects of essential oil from A. canelilla bark were assessed in pentobarbital-anesthetized and conscious rats. Intravenous injections of EO (1 to $20 \mathrm{mg} / \mathrm{kg}$ ) induced immediate and dose-dependent decreases in mean aortic pressure and heartbeat at doses of 1 and $5 \mathrm{mg} / \mathrm{kg}$, respectively, 
in both experiments. The EO $(100 \mu \mathrm{g} / \mathrm{mL})$ also showed smooth-muscle relaxant activity in aorta preparations containing endothelium previously contracted with potassium $(60 \mathrm{mM})[85]$.

Increasing concentration injections (1-10 mg/kg) of purified 1-nitro-2-phenylethane from the A. canelilla bark collected at Paragominas (PA, Brazil) caused dose-dependent hypotensive and bradycardic effects at a minimal concentration of $3 \mathrm{mg} / \mathrm{kg}$ in normotensive rats anesthetized with sodium pentobarbital $(50 \mathrm{mg} / \mathrm{kg})$. In aorta preparations containing endothelium, 1-nitro-2-phenylethane (1 to $300 \mu \mathrm{g} / \mathrm{mL}$ ) exhibited vasorelaxant effects after phenylephrine-induced contraction in a concentration-dependent manner with $\mathrm{IC}_{50}$ value of $60.1 \mu \mathrm{g} / \mathrm{mL}$ [113].

Injections of essential oil (1-20 mg/kg) and 1-nitro-2-phenylethane $(1-10 \mathrm{mg} / \mathrm{kg})$, obtained from A. canelilla bark from Paragominas (PA, Brazil), elicited dose-dependent hypotensive and bradycardic effects in rats anesthetized with sodium pentobarbital $(50 \mathrm{mg} / \mathrm{kg})$. At $600 \mu \mathrm{g} / \mathrm{mL}$ of essential oil and 1-nitro-2-phenylethane, maximal relaxations in the superior mesenteric artery were previously contracted with phenylephrine [23].

The constituent 1-nitro-2-phenylethane (NPE), isolated in high-grade purity $(98 \%)$ from the A. canelilla wood bark oil, collected at Paragominas (PA, Brazil), was investigated for its vasodilator effect in rat aorta, using isolated vessel bioassays. The NPE (0.7-1984.6 mM) relaxed the contractions of intact endothelium, induced by Hyp9 (100 mM) and phorbol 12,13-dibutyrate $(1 \mathrm{mM})$, with $\mathrm{IC}_{50}$ values of $119.0 \mu \mathrm{M}$ and $203.1 \mu \mathrm{M}$, respectively. In endothelium-intact mesenteric arterial rings, NPE $(0.2-1984.6 \mu \mathrm{M})$ also relaxed sustained contractions, induced by norepinephrine $(10 \mathrm{mM})$, with an $\mathrm{IC}_{50}$ value of $43.0 \mu \mathrm{M}$. Thus, it is suggested that NPE appeared to exert vasodilatory effects compatible with a drug's profiles that induce stimulation and improve production in aortic tissues [114].

A study investigated the action of 1-nitro-2-phenylethane (NPE) (synthetic), the main constituent of $A$. canelilla oil, in the cardiovascular responses of spontaneously hypertensive rats (SHRs). Intravenous injections of oil (1-20 mg/ $\mathrm{kg}$ ) and NPE (1-10 mg/ kg) elicited dose-dependent hypotensive and bradycardic effects. The vasorelaxant effect, induced by oil and NPE, was also tested in superior mesenteric artery from SHRs, at concentration $0.1-1000 \mu \mathrm{g} / \mathrm{mL}$. Both oil and NPE relaxed superior mesenteric artery (SMA) preparations, pre-contracted with $75 \mathrm{mM} \mathrm{KCl}$, with $\mathrm{IC}_{50}$ values of 294.19 and $501.27 \mu \mathrm{g} / \mathrm{mL}$, respectively. The inhibitory effects of oil and NPE on contractions were induced by the exogenous addition of $\mathrm{Ca}^{2+}(75 \mathrm{mM})$ [24]. The mechanisms underlying the vascular effects of NPE were investigated in rat isolated thoracic aortic preparations, at concentration 0.1-100 $\mu \mathrm{g} / \mathrm{mL}$, in NPE relaxed endothelium-intact or endothelium-denuded aortic preparations pre-contracted with to $\mathrm{KCl}(60 \mathrm{mM})$ or phenylephrine $(1 \mu \mathrm{M})$ [115].

The oil of leaves from Aniba panurensis (Meisn.) Mez and the oil of stems from A. rosaeodora, collected in Adolpho Ducke Forest Reserve (AM, Brazil), were assessed for their antiplatelet potential, using a method based on the measurement of platelet aggregates after exposure to the aggregating agent adenosine diphosphate $(4.27 \mu \mathrm{g} / \mathrm{mL})$. The oils at $1 \%$ were added to the platelet-rich plasma. A. panurensis, rich in $\beta$-caryophyllene (33.5\%), germacrene-D $(25.4 \%)$, and $\alpha$-copaene $(7.5 \%)$ showed less inhibition of $3.57 \%$, while A. rosaeodora, dominated by linalool $(86.0 \%)$, caryophyllene oxide $(2.8 \%)$ and trans-linalool oxide $(1.5 \%)$, exhibited inhibition of $5.19 \%$ in comparison to the standard acetylsalicylic acid $(0.01 \%)$, with $100 \%$ inhibition [70].

Oil of trunkwood from A. rosaeodora, collected in Novo Airão (AM, Brazil), containing linalool $(87.7 \%), \alpha$-terpineol (3.1\%) and geraniol $(1.2 \%)$, was evaluated regarding its cardiovascular effects in normotensive rats (male Wistar), anesthetized with sodium pentobarbital $(50 \mathrm{mg} / \mathrm{kg})$, treated with oil $(1-20 \mathrm{mg} / \mathrm{kg})$. Monitoring of cardiac effects was carried out by measuring blood pressure. The oil at 10 and $20 \mathrm{mg} / \mathrm{kg}$ induced two phases of hypotension and bradycardia. Initially, rapid bradycardia (1-2 s) occurred coincidentally (2-3 s) with arterial hypotension (phase 1), and then a delayed and more lasting decrease in blood pressure associated with second bradycardia (phase 2). In aortic preparations with intact endothelium, the oil $(0.15-771.25 \mu \mathrm{g} / \mathrm{mL})$ relaxed the phenylephrine-induced contractions 
$\left(\mathrm{IC}_{50} 95.08 \mu \mathrm{g} / \mathrm{mL}\right.$ ). The oil-induced vasorelaxant effects were reversible after wash and remained unaffected by the endothelium removal $\left(\mathrm{IC}_{50} 72.35 \mu \mathrm{g} / \mathrm{mL}\right)$ [121].

\subsection{Cytotoxic Activity}

The cytotoxic properties of some Aniba oils were also evaluated using the MTT method. The A. canelilla leaf oil from Adolpho Ducke Forest Reserve (AM, Brazil) showed 1-nitro-2phenylethane $(88.9 \%)$ and $\beta$-caryophyllene $(4.21 \%)$ as the major components. The specimen showed low cytotoxicity against murine peritoneal macrophages from BALB/c mice, with $\mathrm{IC}_{50} 9.3 \mu \mathrm{g} / \mathrm{mL}$, compared to the standard pentamine ( $\left.\mathrm{IC}_{50} 24.4 \mu \mathrm{g} / \mathrm{mL}\right)$ [22].

The $A$. canelilla stem oil, containing 1-nitro-2-phenylethane (83.68\%) and methyleugenol $(14.83 \%)$, was evaluated against human lymphocytes for $24 \mathrm{~h}$ and $48 \mathrm{~h}$. The oil at different concentrations $(0.5 \%, 1.0 \%$ and $2.0 \%)$ did not show significant cytotoxic effects. However, after $24 \mathrm{~h}$ at $2.0 \%$, the mixture of the isolated main constituents (1:1) showed cell viability of $78.65 \%$ and the isolated 1-nitro-2-phenylethane and methyleugenol of $95.51 \%$ and $89.2 \%$, respectively [86].

Aniba parviflora oils, rich in $\beta$-phellandrene (15.1\%), linalool (14.1\%), and $\gamma$-eudesmol $(12.9 \%)$ in the leaves, and $\gamma$-eudesmol $(16.8 \%), \beta$-caryophyllene $(15.4 \%)$, and linalool $(12.4 \%)$ in the branches, were evaluated against human breast adenocarcinoma cells line MCF-7. The leaf and branch oils showed good antiproliferative activity with $\mathrm{IC}_{50}$ values of 67.9 and $102.2 \mu \mathrm{g} / \mathrm{mL}$, respectively. Dimethyl sulfoxide was used as the negative control and tingenone $(100 \mu \mathrm{g} / \mathrm{mL})$ as the positive control [32].

The cytotoxicity of $A$. rosaeodora wood oil was evaluated through the maximum nontoxic concentration (MNTC). The analysis was determined microscopically by observing cell morphological changes at 24,48 , and $72 \mathrm{~h}$ of incubation, followed by MTT assay. The cells used were bovine kidney CRIB, chicken-embryo related CRER, mouse fibroblast cell L929, and feline kidney cell lines CRFK. The oil showed 50\% cytotoxic concentrations $\left(\mathrm{CC}_{50}\right)$ of $104.8 \%$, with a selectivity index of 5 . The oil composition was not reported [120]. The A. rosaeodora leaf and thin branch oil containing linalool $(93.60 \%), \alpha$-terpinolene $(3.37 \%)$, and cis-linalool oxide $(3.03 \%)$, linalool standard $(1000-7.8 \mu \mathrm{g} / \mathrm{mL})$ and the positive control benznidazole $(200-0.78 \mu \mathrm{g} / \mathrm{mL})$ were evaluated by MTT method on cell viability of peritoneal macrophages from Balb $/ \mathrm{C}$ mice. The oil and linalool did not exhibit cell toxicity at the highest concentration analyzed $\left(\mathrm{CC}_{50}>1000 \mu \mathrm{g} / \mathrm{mL}\right)$ [81].

The A. parviflora bark oil, collected in Curuá, municipality of Santarém (PA, Brazil), containing linalool $(16.3 \%), \alpha$-humulene $(14.5 \%), \delta$-cadinene $(10.2 \%), \alpha$-copaene $(9.51 \%)$, and germacrene B ( $7.58 \%)$, was evaluated on the growth of human hepatocellular carcinoma cells in the culture and in the development of tumors in a xenograft model. The oil was selective for HepG2 cells with $\mathrm{IC}_{50}$ values of $9.05 \mu \mathrm{g} / \mathrm{mL}$. Based on their bibliographic survey, the authors considered essential oils with $\mathrm{IC}_{50}$ values $<30 \mu \mathrm{g} / \mathrm{mL}$ the most promising for the development of cytotoxic drugs in cancer therapy. With respect to the development of tumors, the animals treated with the oil showed a reduction in tumor weights $0.40 \mathrm{~g}$ and $0.17 \mathrm{~g}$ at the 40 and $80 \mathrm{mg} / \mathrm{kg}$ doses of oil [119].

\subsection{Nervous System Activity}

Essential oils and their components can induce innumerable physiological actions in the central nervous system, such as analgesic, anxiolytic, relaxing, sedative, and behavior and perception effects, in addition to the treatment of epilepsy and degenerative diseases such as Alzheimer's and Parkinson's diseases [125].

The A. canelilla trunkwood oil, presenting 1-nitro-2-phenylethane $(70.2 \%)$ and methyleugenol $(25.8 \%)$, has displayed acetylcholinesterase inhibitory properties by the bioautography method using the Fast blue salt B as the reagent. The oil and 1-nitro-2phenylethane (98.0\%) showed a value to the detection limit (DL) equivalent to physostigmine (0.01 ng), an alkaloid used as the positive control [116].

The A. rosaeodora and A. parviflora leaf oils and linalool standard $97 \%$ were evaluated in the central nervous system of rodents, employing neurobehavioral tests. The sponta- 
neous locomotion was smaller in the group treated with $3.5 \mathrm{mg} / \mathrm{kg}$ of $A$. rosaeodora oil when compared with the non-treated control group. In the depressive type method, the A. rosaeodora oil ( $35 \mathrm{mg} / \mathrm{kg})$ and linalool $(30 \mathrm{mg} / \mathrm{kg}$ ) caused a reduction in the latency period and an increase in the self-cleaning time, a similar behavior was noted for the control group, fluoxetine $(10 \mathrm{mg} / \mathrm{kg})$. Both oils and linalool standard significantly decreased the immobility time of the animals when compared to the positive control fluoxetine. The major components of the oil from $A$. rosaeodora were linalool $(88.6 \%)$, while in $A$. parviflora were linalool (45.0\%), $\beta$-phellandrene (17.3\%), and $\alpha$-phellandrene $(4.1 \%)$ [71].

The oils from leaves of A. rosaeodora (linalool, 90.5\%) and A. parviflora (linalool 29.6\%, $\beta$-caryophyllene, $10.9 \%$, and $\alpha$-phellandrene, $10.5 \%$ ), standard linalool $97 \%$, and linalool isolated from the oil of $A$. rosaeodora were evaluated as anesthetics in young Colossoma macropomum fish. At concentrations of 0.025 and $0.05 \mu \mathrm{L} / \mathrm{mL}$, the $A$. rosaeodora oil was twice as efficient in light sedation (123.0 s, $68.3 \mathrm{~s}$ ), deep sedation (355 s, $204 \mathrm{~s})$, and deep anesthesia (636.4 s) compared to A. parviflora oil, and standard and isolated linalool, which needed two-fold concentrations to provoke the same effects. Fish exposed to $0.05-0.2 \mu \mathrm{L} / \mathrm{mL}$ of A. rosaeodora oil, $0.1-0.3 \mu \mathrm{L} / \mathrm{mL}$ of $A$. parviflora oil, and both linalool samples reached deep anesthesia 1-10 min. The induction time for all anesthesia stages decreased with the increasing concentration of the anesthetics. The isolated linalool showed the lengthier time for anesthesia induction in some stages and recovery at 0.1 and $0.2 \mu \mathrm{L} / \mathrm{mL}$, in comparison to standard linalool [118]. (3S)-(+)-Linalool and (3R)-(-)-linalool have different properties on the central nervous system, related to depressant effects, analgesic and anti-inflammatory activities [126].

The sedative effects of $A$. rosaeodora trunk wood oil in rats and mice were investigated and showed decreased latency and increased duration of sleeping time at doses of 200 and $300 \mathrm{mg} / \mathrm{kg}$. On the other hand, the combination of the oil $(100 \mathrm{mg} / \mathrm{kg})$ and the sedative agent pentobarbital $(40 \mathrm{mg} / \mathrm{kg})$ increased the action. The blocking effect of oil for $30 \mathrm{~min}$ on rat sciatic nerves from $75.0 \%$ at $2 \mu \mathrm{g} / \mathrm{mL}$ to $95.0 \%$ at $100 \mu \mathrm{g} / \mathrm{mL}$ was irreversible. The main compounds of the EO were linalool (87.7\%), $\alpha$-terpineol $(3.1 \%)$, trans-linalool oxide $(1.5 \%)$, and cis-linalool oxide (1.5\%) [92].

Relaxant and anticonvulsant activities on the central nervous system of $A$. rosaeodora wood oil and linalool were evaluated on adenylate cyclase activity (an enzyme that catalyzes cAMP hydrolysis) in a chick retina model. The decreased levels of cAMP protect against seizures in a variety of epilepsy models. The cAMP accumulation was stimulated by forskolin $(10 \mu \mathrm{M})$, and inhibited by the EO (6 and $17.5 \mathrm{mM})$. The effects were also evaluated in the presence of the 3-isobutyl-1-methylxanthine $(500 \mu \mathrm{M})$, an inhibitor of cAMP, which did not interfere with the positive effects of the EO $(1-6 \mathrm{mM})$ on cAMP production. The oil, (3R)-(-)-linalool and racemic ( \pm )-linalool displayed $\mathrm{IC}_{50}$ values of 130,310 , and $300 \mu \mathrm{M}$, respectively. The inhibition of cAMP takes part in the molecular mechanisms underlying the relaxant and anticonvulsant effects of EO and linalool in the central nervous system. The trunk wood of $A$. rosaeodora collected in Belém (PA, Brazil) was mainly composed of linalool $(84.8 \%)$, $\alpha$-terpineol (2.9\%), and geraniol (1.0\%). Its enantiomeric distribution of linalool was analyzed by GC chiral column and revealed a nearly racemic mixture with the proportion $50.62 \%$ of (3R)-(-)-linalool and $49.38 \%$ of (3S)-(+)-linalool [90].

\subsection{Toxicological Studies}

The toxicity of oils from A. canelilla trunkwood, presenting 1-nitro-2-phenylethane $(92.1 \%, 70.2 \%)$ and methyleugenol $(4.30 \%, 25.8 \%)$, as well as isolated 1-nitro-2-phenylethane, were evaluated by the brine shrimp (Artemia salina) lethality test and showed a median lethal concentration value for the oils $\left(\mathrm{LC}_{50}, 21.61 \mu \mathrm{g} / \mathrm{mL}\right)$ and 1-nitro-2-phenylethane $\left(\mathrm{LC}_{50}, 20.37 \mu \mathrm{g} / \mathrm{mL}\right)$. DMSO was used as negative control [27]. Essential oils with $\mathrm{LC}_{50}$ values equal to or higher than $250 \mu \mathrm{g} / \mathrm{mL}$ are considered non-toxic against $A$. salina [127], and $\mathrm{LC}_{50}$ below $50 \mu \mathrm{g} / \mathrm{mL}$ have highly efficient larvicidal effects [128]. The $A$. canelilla leaf oil collected in Adolpho Ducke Forest Reserve (AM, Brazil), containing 1-nitro-2phenylethane $(88.9 \%), \beta$-caryophyllene $(4.21 \%)$, and $\beta$-phellandrene $(0.80 \%)$ was evaluated 
against $A$. salina. The oil indicated low toxicity $\left(\mathrm{LC}_{50} 68.37 \mu \mathrm{g} / \mathrm{mL}\right)$. DMSO was used as negative control $\left(\mathrm{LC}_{50}>1000 \mu \mathrm{g} / \mathrm{mL}\right)$ and lapachol as positive control $\left(\mathrm{LC}_{50} 23.0 \mu \mathrm{g} / \mathrm{mL}\right)$ [22]

Aniba rosaeodora stem oil, collected in Adolpho Ducke Forest Reserve (AM, Brazil), containing linalool $(63.16 \%)$, trans-linalool furanoid $(9.73 \%)$, and cis-linalool furanoid $(7.69 \%)$, was tested for toxicity using the brine shrimp lethality assay and presented LC $_{50}$ values varying from 282 to $582 \mu \mathrm{g} / \mathrm{mL}$. Potassium dichromate was used as the positive control [93]. Aniba duckei branch oil, at a minimal concentration ( $2 \mu \mathrm{g} / \mathrm{mL})$, showed 100\% larvicidal activity against Artemia franciscana, and at a maximal concentration $(10 \mu \mathrm{g} / \mathrm{mL})$, all larvae died after just $10 \mathrm{~min}$. The oil composition was not reported [35].

Essential oils of Aniba species were also tested against the larvae of A. aegypti. Aniba rosaeodora stems oil showed $\mathrm{LC}_{50} 41.07 \mu \mathrm{g} / \mathrm{mL}$, and phosphorothioate at $100 \mathrm{ppm}$ was used as the positive control [93]. Aniba duckei stem oil exhibited LC 90 54,000 $\mu \mathrm{g} / \mathrm{mL}$ and LC 50 $2200 \mu \mathrm{g} / \mathrm{mL}$ against the larvae of $A$. aegypti [117]. A review carried out with 361 essential oils from 269 plants concluded that essential oils are active against $A$. aegypti larvae with $\mathrm{LC}_{50}<100 \mathrm{mg} / \mathrm{L}$ [128]. The toxicological potential of $A$. duckei branch oil and the standards (3R)-(-)-linalool and ( \pm )-linalool were evaluated against Aedes aegypti larvae. The branch oil was composed of linalool $(89.34 \%), \alpha$-terpineol $(3.06 \%)$, and cis-linalool oxide (1.94\%). The best larvicidal activity was detected for the oil $\left(\mathrm{LC}_{50} 250.61 \mu \mathrm{g} / \mathrm{mL}\right)$, while (3R)-(-)linalool and racemic $( \pm)$-linalool showed $\mathrm{LC}_{50}$ values of $279.89 \mu \mathrm{g} / \mathrm{mL}$ and $346 \mu \mathrm{g} / \mathrm{mL}$, respectively. The organophosphate Temephos (100 ppm) and mineral water containing $0.04 \%$ Tween $(20 \mathrm{~mL})$ were used as the positive and negative control, respectively [81].

The toxicity of $A$. rosaeodora stem oil, presenting linalool $(93.60 \%), \alpha$-terpinolene $(3.37 \%)$, and cis-linalool oxide (3.03\%), was evaluated by the Artemia salina lethality test and showed an $\mathrm{LC}_{50} 282 \mathrm{mg} / \mathrm{L}$ [82], classified as nontoxic [127].

\subsection{Other Activities}

The $A$. canelilla leaf oil, dominated by 1-nitro-2-phenylethane (88.9\%), inhibited promastigotes of Leishmania amazonensis, the etiological agent of leishmaniasis, with an $\mathrm{IC}_{50}$ value of $40 \mu \mathrm{g} / \mathrm{mL}$, in comparison to pentamidine ( $\mathrm{IC}_{50} 4.80 \mu \mathrm{g} / \mathrm{mL}$ ), the reference drug [22].

The anti-trypanosomal activity of $A$. canelilla stem EO, rich in 1-nitro-2-phenylethane $(83.68 \%)$ and methyleugenol (14.83\%), was evaluated against Trypanosoma evansi. The assays were performed using the oil, the two main isolated constituents, and a mixture (1:1) at concentrations ranging from 0.5 to $2.0 \%$. The tested oil presented a trypanocidal profile similar to the positive control, diminazene aceturate $(0.5 \%)$. After $6 \mathrm{~h}$, no parasites were found alive (complete motility cessation) in all oil concentrations tested. The compound 1-nitro-2-phenylethane $(0.5 \%)$ was able to reduce the number of live trypanosomes to zero after only $3 \mathrm{~h}$; methyleugenol and the mixture (2.0\%) caused the death of the trypanosomes after $1 \mathrm{~h} \mathrm{[86].}$

The antiviral activity of oil from $A$. rosaeodora trunkwood, collected at Zoobotanical Park of the Emilio Goeldi Museum, located in Belém (PA, Brazil), showed cytopathic effects through visual microscopic analysis and inhibited the viral growth of avian metapneumovirus ( $\left.\mathrm{EC}_{50}: 20.86 \mu \mathrm{g} / \mathrm{mL}\right)$. The oil composition was not reported [120].

The leaves and thin branches oil from $A$. rosaeodora, collected at Adolpho Ducke Forest Reserve (AM, Brazil), containing linalool (93.60\%), $\alpha$-terpinolene (3.37\%), and cislinalool oxide $(3.03 \%)$, were evaluated against epimastigote and intracellular amastigote forms of Trypanosoma cruzi, as well as the linalool standard. The oil showed the $\mathrm{IC}_{50}$ values $150.5 \mu \mathrm{g} / \mathrm{mL}$ and $911.6 \mu \mathrm{g} / \mathrm{mL}$ for epimastigotes and intracellular amastigotes, respectively, while the linalool $\mathrm{IC}_{50}$ values ranged from 198.6 to $249.6 \mu \mathrm{g} / \mathrm{mL}$ and benznidazole, the positive control, from $\mathrm{IC}_{50} 1.805$ to $0.482 \mu \mathrm{g} / \mathrm{mL}$ for both forms, respectively [81].

\subsection{Biological Activities from Commercial Aniba Rosaeodora Essential Oils}

Although most biological activities reported for commercial A. rosaeodora oils do not describe the plant's part or chemical composition, it is essential to know the wide application given to them. The antimicrobial activity of oils obtained from Sunspirit Oils 
Pty Ltd., Australia, was evaluated by agar dilution and broth microdilution methods and exhibited activity against Acinetobacter baumanii, Aeromonas sobria, and E. coli (MIC 1.2\%), Salmonella typhimurium, S. aureus, and C. albicans (MIC 0.25\%), E. faecalis, K. pneumoniae and Serratia marcescens (MIC 0.5\%) using agar dilution assay; Mueller Hinton agar, with 0.5\% $(v / v)$ tween-20 was used as positive growth control. However, the assays performed by the microdilution method against C. albicans, E. coli and S. aureus showed MIC values of $0.12 \%$, the EO composition and standard were not mentioned. The results obtained by each of these methods may differ as many factors vary between assays [129,130], these include differences in microbial growth, exposure of micro-organisms to the oil, the solubility of oil or oil components, and the use and quantity of an emulsifier. These and other elements may account for the significant differences in MICs obtained by the agar and broth dilution methods in this study [131].

A rosewood oil sample purchased from Erbamea (Istrana, Treviso, Italy), containing linalool $(60.1 \%)$, limonene $(19.2 \%)$, geraniol $(7.8 \%)$, and cymene $(4.1 \%)$ showed antibacterial activity by the broth microdilution method. The MIC values were $250 \mu \mathrm{g} / \mathrm{mL}$ to Bacillus cereus and A. baumannii, $500 \mu \mathrm{g} / \mathrm{mL}$ to B. subtilis, S. aureus and E. coli, and $2000 \mu \mathrm{g} / \mathrm{mL}$ to Serratia marcescens and Yersinia enterocolitica. In addition, the combination of the oil with the drug gentamicin was evaluated for its synergistic effect. The interaction was defined quantitatively as a fractional inhibitory concentration (FIC). the synergism is indicated when FIC values are below 0.5 . The oil in association with gentamicin revealed a strong synergistic mode of action. MIC values were reduced to an interval varying from 10 to $100 \mu \mathrm{g} / \mathrm{mL}$. Mueller Hinton Broth was used as positive growth control [95]. An A. rosaeodora wood oil, commercially obtained from Brazil, was mainly composed of linalool (80.0\%) and exhibited antibacterial activity against B. cereus, Micrococcus luteus, Alcaligenes faecalis, and P. aeruginosa, with inhibition zones varying from $12 \mathrm{~mm}$ to $19 \mathrm{~mm}$, and against S. aureus, S. faecalis, and Enterobacter cloacae with inhibition zones from $5 \mathrm{~mm}$ to $7 \mathrm{~mm}$. The same oil indicated antifungal potential against C. albicans and Aspergillus niger, with inhibition zones of $33 \mathrm{~mm}$ and $32 \mathrm{~mm}$, respectively, and Rhizopus oligosporus with only a $2 \mathrm{~mm}$ inhibition zone. The assays were performed by the disk diffusion method. The origin of the sample, MIC values, and reference standards was not reported [132]. Rosewood oil sample purchased from Stony Mountain Botanicals, Ltd. (Loudonville, OH, USA) was evaluated against Aeromonas salmonicida subsp. salmonicida, a bacterium that causes fish furunculosis, by the disk diffusion method. The inhibition zone of the oil was $16.7 \mathrm{~mm}$, which is considered a moderate inhibition. The MIC value was not determined [133]. The diameter of inhibition zones, including the disc diameter, is considered as weak (10-13.9 mm), moderate (14-18 mm), or strong (>18 mm), according to [107]. Another rosewood oil sample, purchased from Anthémis Aromatherapie (Oosterstreek, The Netherlands), was evaluated by the broth dilution method against $B$. cereus and showed MIC value $1.0 \%$ to vegetative cells and MIC value $>1.00 \%$ to spore germination [134].

The antifungal activity of a rosewood oil sample obtained from the Institute for Medicinal Plant Research "Dr. Josif Pancic", Serbia, containing 81.27\% of linalool, was evaluated by the disk diffusion method. The inhibition of mycelial growth and inhibition of spore germination was performed by macro-dilution and micro-dilution assays. The oil was active against all fungi in the micro-dilution method, with MIC value from 1 to $10 \mu \mathrm{L} / \mathrm{mL}$ for Alternaria alternata, Aureobasidium pullulans, Cladosporium cladosporioides, C. fulvium, Fusarium tricinctum, F. sporotrichoides, Phomopsis helianthin, and Phoma macdonaldii. Meanwhile, in the macro-dilution method, the MIC ranged from 0.5 to $7.5 \mu \mathrm{L} / \mathrm{mL}$ for A. alternata, A. pullulans, C. fulvium, P. helianthin, and P. macdonaldii. Bifonazole was used as a positive control [94]. Rosewood oil samples obtained commercially in Pretoria and Johannesburg, South Africa, were tested against Geotrichum citri-aurantii, a postharvest pathogen of Citrus, by incorporating $0.5 \mu \mathrm{L} / \mathrm{mL}$ of oil into the culture medium, and showed mycelial growth inhibition of $12.1 \%$, which was considered low. Kenopel ${ }^{\circledR} 200 S \mathrm{~L}(1 \mu \mathrm{L} / \mathrm{mL})$ was used as positive control [135]. 
The nematicidal activity from A. rosaeodora oil purchased from Berje (Bloomfield, NJ, USA) was evaluated against Bursaphelenchus xylophilus by immersion bioassay during a 24-h exposure. The oil at $10 \mathrm{mg} / \mathrm{mL}$ had a significant lethal activity of $94 \%$ mortality and toxicity $\mathrm{LC}_{50} 2.99 \mathrm{mg} / \mathrm{mL}$. Ethanol-Triton X-100 solution was used as control, and fenitrothion was used as a standard nematicide but was ineffective $\left(\mathrm{LC}_{50}>10 \mathrm{mg} / \mathrm{mL}\right)$ [136]. The lethal activity was considered strong, with mortality above $80 \%$ [137].

The cytotoxic potential of commercial A. rosaeodora oil was also evaluated. A sample of unknown origin containing linalool $(80 \%)$ and $\alpha$-terpineol $(4.5 \%)$ was tested against human epidermoid carcinoma cell line (A431), human epidermal keratinocytes CRL-2404 (HEK001), immortalized $\mathrm{HaCaT}$ cells (HaCaT), and on normal primary human epidermal keratinocytes (NHEK). The MTT assay showed a reduction in cell viability observed in A431 and $\mathrm{HaCaT}$ cells ( $<20 \%$ viability) at $0.4 \mu \mathrm{L} / \mathrm{mL}$ of EO for $4 \mathrm{~h}$, whereas HEK001 and NHEK cells were much less affected ( $>70 \%$ viability), the prolonged incubation for $12 \mathrm{~h}$ in the HEK001 and NHEK cells reduced viability to approximately 50\%. The EO triggered the production of reactive oxygen species, induced depolarization of the mitochondrial membrane, and caused caspase-dependent cell death [97].

The insecticidal and larvicidal effects of commercial samples of rosewood oil have also been evaluated. A sample obtained from the Fragrance and Flavour Development Center, India, was tested as a repellent against $A$. aegypti using the cage and cone bioassay methods. The oil was effective as a repellent until $1.5 \mathrm{~h}$, compared with synthetic repellents $N, N$ diethyl- $m$-toluamide (DEET), and $N, N$-diethylphenylacetamide (DEPA), used as positive controls, and provided complete protection ranging from 5 to $6 \mathrm{~h}$. The EO exhibited 10\%, $66 \%$, and $100 \%$ knockdown effects at $0.1 \%, 1 \%$, and $5 \%$, respectively, and showed a practical knockdown dose value $\left(\mathrm{KT}_{50}\right)$ of $2.029 \%$. Malathion and acetone were used as positive and negative controls, respectively. The gas chromatograph coupled-electroantennogram detection showed that linalool and oxide linalool elicited a spick response in the antenna of $A$. aegypti female mosquito. However, the concentrations of these compounds were not mentioned [138]. A sample obtained from Edens Garden, San Clemente (CA, USA) was evaluated as a vapor for enhancement of deltamethrin efficacy in pyrethroid-susceptible and resistant strains of the A. aegypti mosquito. Vapor bioassays were made by exposing mosquitoes to the vapor of essential oil $(100 \mu \mathrm{L})$, which showed $48.33 \%$ mortality, ([139]). The larvicidal activity of EO from the heartwood of A. rosaeodora obtained from Guangzhou Yuxitang Cosmetics Co., Ltd. (China) was tested against Aedes albopictus larvae at 100 ppm the EO showed $5.0 \%$ of mortality [140].

The oil purchased from Oshadhi Ltd. (Cambridge, England) containing linalool (44.4\%), linalyl acetate $(31.4 \%)$, and $\beta$-caryophyllene (10.5\%), and pure linalool $(97 \%$, Sigma-Aldrich, St. Louis, MO, USA), were evaluated against the adzuki bean beetle (Callosobruchus chinensis). For this study, 10 and $100 \mathrm{ng}$ of oil and the pure linalool per filter paper strip were submitted for the repellence test and $0-20 \mu \mathrm{L}$ of oil to oviposition assays. Only the pure linalool exhibited male insect repellency in higher concentrations (100 ng), and neither pure linalool nor the oil was effective oviposition deterrent [96].

Aniba rosaeodora oil, purchased from a commercial company with unknown origin, was tested regarding its anesthetic efficacy in goldfish (Carassius auratus). Linalool was the main compound from the oil $(86.23 \%)$, followed by cis-linalool oxide $(1.06 \%)$ and $\beta$-selinene $(0.95 \%)$. The lowest effective concentration (LECs) for the oil was $0.25 \mu \mathrm{L} / \mathrm{mL}$, which showed rapid induction and recovery of anesthetic effect. No mortality or adverse effects occurred with the fish. Thus rosewood oil was considered a new potential anesthetic agent for fish species [98].

A study showed the comparative effects of (3S)-(+)-linalool, (3R)-(-)-linalool, and ( \pm )linalool on the behavioral parameters of anticonvulsant drugs in mice. The $( \pm)$-linalool $(200 \mathrm{mg} / \mathrm{kg}$ ) was more effective than (3S)-(+)-linalool and (3R)-(-)-linalool because it increased the latency of convulsions in a pentylenetetrazole-induced seizure model, showing the synergistic action of its constituents. In the picrotoxin-induced seizure model, both (3R)$(-)$-linalool and $( \pm)$-linalool presented activity at the dose of $200 \mathrm{mg} / \mathrm{kg}$. When evaluated at 
maximal electroshock-induced seizure models, (3S)-(+)-linalool, (3R)-(-)-linalool and $( \pm)-$ linalool decreased the convulsion time of the mice in the doses of 200 and $300 \mathrm{mg} / \mathrm{kg}$ [141].

\section{Conclusions}

The genus Aniba has a predominantly Amazonian distribution and many species have been used as traditional herbal medicines. This review demonstrated the high chemical and biological potential of essential oils from their species. The multivariate analysis of the chemical classes present in the essential oils allowed the identification of chemical markers, which contributed to fill the morphological and phylogenetic gaps of the genus. The benzenoids and phenylpropanoid were well represented for A. canelilla, A. guianensis, A. gardineri and A. puchury-minor species. On the other hand, A. rosaeodora and A. duckei were characterized by the high concentration of oxygenated monoterpenes. The oils of A. fragrans, A. gardneri, A. hostmanniana, A. parviflora, A. riparia, A. parviflora, A. rosaeodora, A. terminalis, and A. puchury-minor showed significant chemical diversity for their main compound classes such as terpenoids, benzenoids, and phenylpropanoids.

Aniba essential oils and their compounds have a wide range of pharmacological activities: 1-Nitro-2-phenylethane, a major component in A. canelilla essential oils, is responsible for the cinnamon-like odor of the plant, and has shown hypnotic, anticonvulsant, anxiolytic, vasorelaxant, hypotensive, and anti-inflammatory activities. The essential oils of A. rosaeodora, A. duckei, A. fragrans and A. parviflora are rich in linalool, which give these species a floral-like odor. Linalool has shown antimicrobial, antiparasitic, antiinflammatory, and central nervous system effects. Both enantiomers of linalool have shown anxiolytic and anticonvulsant effects, but (3R)-(-)-linalool is apparently more active than (3S)-(+)-linalool in terms of sedative activity. The high concentrations of linalool or 1-nitro2-phenylethane in Aniba essential oils likely account for the traditional uses of these plant species as well as the biological activities of the oils.

Author Contributions: R.C.S.d.T., J.K.A.M.X. and J.K.R.d.S. conducted the bibliographic research, supervision and writing - review and editing. W.N.S., J.G.S.M. and J.K.R.d.S. revised, edited, and provided critical feedback. All authors approved the final manuscript. All authors have read and agreed to the published version of the manuscript.

Funding: This research was supported by Aromatic Plant Research Center (APRC, https: / /aromaticplant. org/). accessed on 2 September 2021.

Data Availability Statement: The data presented in this study are available on request from the corresponding author.

Acknowledgments: We are grateful for CAPES (Coordenação de Aperfeiçoamento de Pessoal de Nível Superior-Coordination for the Improvement of Higher Education Personnel) for providing a scholarship to J.K.A.M.X.

Conflicts of Interest: The authors declare no conflict of interest.

\section{References}

1. The Angiosperm Phylogeny Group. An update of the Angiosperm Phylogeny Group classification for the orders and families of flowering plants: APG IV. Bot. J. Linn. Soc. 2016, 181, 1-20. [CrossRef]

2. Brasil, F.D.; Lauraceae in Flora do Brasil 2020 em Construção. Lauraceae in Flora do Brasil 2020 em construção. In Jard. Botânico do Rio Janeiro; 2020. Available online: http:/ /www.floradobrasil.jbrj.gov.br/reflora/floradobrasil/FB23347 (accessed on 23 April 2020).

3. Kubitzki, K.; Renner, S. Lauraceae I (Aniba and Aiouea). Flora Neotrop. 1982, 31, 1-124. Available online: http:/ /www.jstor.org/ stable/4393757 (accessed on 2 September 2021).

4. De Moraes, P.L.R. Flora das cangas da Serra dos Carajás, Pará, Brasil: Lauraceae. Rodriguésia 2018, 69, 81-117. [CrossRef]

5. Bastos, A.M. Os paus rosas da indústria da essência. Rodriguesia 1943, 7, 45-54.

6. Richter, H.G. Wood and Bark Anatomy of Lauraceae. I. Aniba Aublet. IAWA J. 1981, 2, 79-87. [CrossRef]

7. Ribeiro, J.E.L.S.; Hopkins, M.J.G.; Vicentini, A.; Sothers, C.A.; Costa, M.A.S.; Brito, J.M.; Souza, M.A.D.; Martins, L.H.P.; Lohmann, L.G.; Assunção, P.A.C.L.; et al. (Eds.) Flora da Reserva Ducke: Guia de Identificação das Plantas Vasculares de uma Floresta de Terra Firme na Amazônia Central; INPA-DFID: Manaus, AM, USA, 1999; p. 800. 
8. Quinet, A. Sinopse taxonômica da família Lauraceae no Estado do Rio de Janeiro, Brasil. Acta Bot. Bras. 2005, 19, 563-572. [CrossRef]

9. Vattimo, Í.D. Anatomia da folha das espécies conhecidas de pau-rosa. X-Citomorfologia das epidermes superior e inferior de Aniba permollis (Nees) Mez (Lauraceae). Acta Amaz. 1975, 5, 45-50. [CrossRef]

10. Loureiro, A.A. Estudo anatômico macro e microscópico de 10 espécies do Gênero Aniba (Lauraceae) da Amazônia. Acta Amaz. 1976, 6, 5-85. [CrossRef]

11. Urbinati, C.V.; Da Silva, R.C.R.; Da Silva, S.S.; Lisboa, P.L.B.; Mori, F.A. Structure of the secondary xylem of Aniba Aubl. species from the Brazilian Amazon. Acta Bot. Bras. 2014, 28, 484-488. [CrossRef]

12. De Morais, A.A.; Rezende, C.M.A.D.M.; Mourão, J.C.; Gottlieb, O.R.; Marx, M.C.; Von Bülow, M.V.; Da Rocha, A.I.; Magalhaes, M.T. Óleos essenciais de espécies do gênero Aniba. Acta Amaz. 1972, 2, 41-44. [CrossRef]

13. Gottlieb, O.R.; Kubitzki, K. Chemosystematics of Aniba. Biochem. Syst. Ecol. 1981, 9, 5-12. [CrossRef]

14. Chanderbali, A.S.; Van der Werff, H.; Renner, S.S. Phylogeny and historical biogeography of Lauraceae: Evidence from the chloroplast and nuclear genomes. Ann. Missouri. Bot. Gard. 2001, 88, 104-134. [CrossRef]

15. Angrizani, R.C.; Contim, L.A.S.; Lemes, M.R. Development and Characterization of Microsatellite Markers for the Endangered Amazonian Tree Aniba rosaeodora (Lauraceae). Appl. Plant. Sci. 2013, 1, 1200516. [CrossRef] [PubMed]

16. Xavier, J.; Maia, L.; Figueiredo, P.; Folador, A.; Ramos, A.; Andrade, E.; Maia, J.; Setzer, W.; da Silva, J. Essential Oil Composition and DNA Barcode and Identification of Aniba species (Lauraceae) Growing in the Amazon Region. Molecules 2021, $26,1914$. [CrossRef]

17. Franciscon, C.H.; Miranda, I.D.S. Distribution and conservation of Aniba Aubl. (Lauraceae Jussieu) species in Brazil. Biota Neotropica 2018, 18. [CrossRef]

18. Gottlieb, O. Chemosystematics of the lauraceae. Phytochemistry 1972, 11, 1537-1570. [CrossRef]

19. Fernandes, J.B.; Gottlieb, O.R.; Xavier, L.M. Chemosystematic implications of flavonoids in Aniba riparia. Biochem. Syst. Ecol. 1978, 6, 55-58. [CrossRef]

20. Rossi, M.H.; Yoshida, M.; Maia, J.G.S. Neolignans, styrylpyrones and flavonoids from an Aniba species. Phytochemistry 1997, 45, 1263-1269. [CrossRef]

21. Ferreira, Z.S.; Gottlieb, O.R.; Roque, N.F. Chemosystematic implications of benzyltetrahydroisoquinolines in Aniba. Biochem. Syst. Ecol. 1980, 8, 51-54. [CrossRef]

22. Silva, J.R.D.A.; Carmo, D.F.M.D.; Reis, M.; Machado, G.M.C.; Leon, L.L.; da Silva, B.O.; Ferreira, J.L.P.; Amaral, A.C.F. Chemical and biological evaluation of essential oils with economic value from Lauraceae species. J. Braz. Chem. Soc. 2009, 20, 1071-1076. [CrossRef]

23. Interaminense, L.D.F.L.; De Siqueira, R.J.B.; Xavier, F.E.; Duarte, G.P.; Magalhães, P.J.C.; Da Silva, J.K.; Maia, J.G.S.; Sousa, P.J.D.C.; Leal-Cardoso, J.H.; Lahlou, S. Cardiovascular effects of 1-nitro-2-phenylethane, the main constituent of the essential oil of Aniba canelilla, in spontaneously hypertensive rats. Fundam. Clin. Pharmacol. 2010, 25, 661-669. [CrossRef]

24. Interaminense, L.D.F.L.; dos Ramos-Alves, F.E.; de Siqueira, R.J.B.; Xavier, F.; Duarte, G.P.; Magalhaes, P.; Maia, J.G.S.; Sousa, P.J.D.C.; Lahlou, S. Vasorelaxant effects of 1-nitro-2-phenylethane, the main constituent of the essential oil of Aniba canelilla, in superior mesenteric arteries from spontaneously hypertensive rats. Eur. J. Pharm. Sci. 2013, 48, 709-716. [CrossRef]

25. Maia, J.G.S.; Andrade, E.H.A.; Couto, H.A.R.; Da Silva, A.C.M.; Marx, F.; Henke, C. Plant sources of amazon rosewood oil. Quim Nova 2007, 30, 1906-1910. [CrossRef]

26. Maia, J.G.S.; Andrade, E.H.D.A. Database of the Amazon aromatic plants and their essential oils. Quim Nova 2009, 32, 595-622. [CrossRef]

27. Da Silva, J.K.R.; Sousa, P.J.C.; Andrade, E.H.A.; Maia, J.G.S. Antioxidant Capacity and Cytotoxicity of Essential Oil and Methanol Extract of Aniba canelilla (H.B.K.) Mez. J. Agric. Food Chem. 2007, 55, 9422-9426. [CrossRef] [PubMed]

28. Pimentel, R.B.; Souza, D.P.; Albuquerque, P.M.; Fernandes, A.V.; Santos, A.S.; Duvoisin, S.; Gonçalves, J.F. Variability and antifungal activity of volatile compounds from Aniba rosaeodora Ducke, harvested from Central Amazonia in two different seasons. Ind. Crop. Prod. 2018, 123, 1-9. [CrossRef]

29. Gomes, P.R.B.; Cunha, M.J.O.; DE Sousa, D.A.; Reis, J.B.; Melo, A.V.; De Freitas, A.C.; Hunaldo, V.K.L.; Fontenele, M.A.; De Paula, M.D.L.; Louzeiro, H.C.; et al. Chemical Study and Antifungal Activity of the Essential Oil of the Branches of Aniba duckei Kostermans. J. Essent. Oil Bear. Plants 2019, 22, 1554-1561. [CrossRef]

30. Zellner, B.D.; Presti, M.L.; Barata, L.E.S.; Dugo, P.; Dugo, G.; Mondello, L. Evaluation of Leaf-Derived Extracts as an Environmentally Sustainable Source of Essential Oils by Using Gas Chromatography-Mass Spectrometry and Enantioselective Gas Chromatography-Olfactometry. Anal. Chem. 2005, 78, 883-890. [CrossRef] [PubMed]

31. Tranchida, P.Q.; Souza RC, Z.; Barata LE, S.; Mondello, M.; Dugo, P.; Dugo, G.; Mondello, L. Analysis of Macacaporanga (Aniba parviflora) leaf essential oil by using comprehensive two-dimensional gas chromatography combined with rapid scan-ning quadrupole mass spectrometry. Chromatogr Today 2008, 95, 5-9.

32. Da Silva, J.K.R.; Maia, J.G.S.; Dosoky, N.S.; Setzer, W.N. Antioxidant, Antimicrobial, and Cytotoxic Properties of Aniba parviflora Essential Oils from the Amazon. Nat. Prod. Commun. 2016, 11, 1025-1028. [CrossRef] [PubMed]

33. Sarrazin, S.; Oliveira, R.; Maia, J.; Mourão, R. Antibacterial Activity of the Rosewood (Aniba rosaeodora and A. parviflora) Linalool-rich Oils from the Amazon. Eur. J. Med. Plants 2016, 12, 1-9. [CrossRef] 
34. Batista, L.; Sarrazin, S.L.; De Moura, V.; Dos Santos, I.G.; Junior, S.D.; Albuquerque, P.M. Composição química, atividade antimicrobiana e antioxidante do óleo essencial de Aniba parviflora (Meisn) Mez. Rev. Fitos 2019, 13, 181-191. [CrossRef]

35. De Souza, D.P.; Pimentel, R.B.; Santos, A.S.; Albuquerque, P.M.; Fernandes, A.V.; Junior, S.D.; Oliveira, J.T.; Ramos, M.V.; Rathinasabapathi, B.; Gonçalves, J.F. Fungicidal properties and insights on the mechanisms of the action of volatile oils from Amazonian Aniba trees. Ind. Crop. Prod. 2019, 143, 111914. [CrossRef]

36. May, P.H.; Barata, L.E.S. Rosewood Exploitation in the Brazilian Amazon: Options for Sustainable Production. Econ. Bot. 2004, 58, 257-265. [CrossRef]

37. Lima, P.G.C.; Coelho-Ferreira, M.; Oliveira, R. Plantas medicinais em feiras e mercados públicos do Distrito Florestal Sustentável da BR-163, estado do Pará, Brasil. Acta Bot. Bras. 2011, 25, 422-434. [CrossRef]

38. Gonzaga, A.L. Madeira: Uso e Conservação; IPHAN/Monumenta: Brasília, Brazil, 2006; p. 246.

39. Marques, C.A. Importância econômica da família Lauraceae. Floram 2001, 8, 195-206.

40. Lawless, J. The Encyclopedia of Essential Oils: The Complete Guide to the Use of Aromatic Oils in Aromatherapy, Herbalism, Health, and Well Being; Conari Press: San Francisco, CA, USA, 2013.

41. Maia, J.G.S.; Mourão, R.H.V. Amazon Rosewood (Aniba rosaeodora Ducke) Oils. In Essential Oils in Food Preservation, Flavor and Safety; Elsevier: Amsterdam, The Netherlands, 2016; pp. 193-201. [CrossRef]

42. Berg, M.E.V.D.; Silva, M.H.L. Ethnobotany of a traditional ablution in Pará, Brazil. Bol. do Mus Para Emílio Goeldi 1986, $2,213-218$.

43. Price, S.; Price, L. Aromatherapy for Health Professionals, 3rd ed.; Churchill Livingstone: London, UK, 2007.

44. de Moura, V.M.; Freitas-De-Sousa, L.; Dos-Santos, M.C.; Raposo, J.D.A.; Lima, A.E.; de Oliveira, R.B.; da Silva, M.N.; Mourão, R.H.V. Plants used to treat snakebites in Santarém, western Pará, Brazil: An assessment of their effectiveness in inhibiting hemorrhagic activity induced by Bothrops jararaca venom. J. Ethnopharmacol. 2015, 161, 224-232. [CrossRef]

45. Corrêa, M.P. Dicionário das plantas úteis do Brasil e das exóticas cultivadas: HL, Volume 4; Ministério da Agricultura, Instituto Brasileiro de Desenvolvimento Florestal: Rio de Janeiro, Brazil, 1984.

46. Martins, E.C. Plantas Medicinais de uso na Amazônia; Graficentro/Cejup: Belém, Brazil, 1889.

47. Almeida, E.R. Plantas Medicinais Brasileiras: Conhecimentos Populares e Científicos, 1st ed.; Hemus Ltd.: São Paulo, Brazil, 1993.

48. Pedrollo, C.T.; Kinupp, V.F.; Shepard, G.; Heinrich, M. Medicinal plants at Rio Jauaperi, Brazilian Amazon: Ethnobotanical survey and environmental conservation. J. Ethnopharmacol. 2016, 186, 111-124. [CrossRef]

49. Veja, M. Etnobotánica de la Amazonia Peruana; Ediciones Aby Yala: Quito, Ecuador, 2001.

50. Santos, J.; Reis, A.; Parry, S.; Leão, F.; Carvalho, J. Caracterização Etnobotânica de Essências Florestais com Fins Medicinais Utilizadas pela Etnia Xipaya, no Município de Altamira-PA. Biota Amaz. 2016, 6, 1-8. [CrossRef]

51. Maia, J.G.S.; Zoghbi, M.G.B.; Andrade, E.H.A. Plantas Aromáticas na Amazônia e Seus Óleos Essenciais; Museu Emílio Goeldi: Belém, Brazil, 2001; p. 230.

52. Normah, M.N.; Chin, H.F.; Reed, B.M. (Eds.) Conservation of Tropical Plant. Species, 3rd ed.; Springer: New York, NY, USA, 2013. [CrossRef]

53. IUCN. The IUCN Red List of Threatened Species. Available online: https://www.iucnredlist.org (accessed on 17 January 2021).

54. Martinelli, G.; Moraes, M.A. Livro Vermelho da Flora do Brasil, 1rd ed.; Andrea Jacobsson: Rio de Janeiro, Brasil, 2013 ; p. 1100.

55. Mitja, D.; Lescure, J.-P.; Emperaire, L. Du bois pour du parfum: Le bois de rose doit-il disparaître? In Le for t en Jeu l'Extrativisme en Amazonie Centrale; IRD Éditions: Paris, France, 1996; pp. 93-102. [CrossRef]

56. Contim, L.A.S.; Contim, L.S.R. A tecnologia produtiva do pau-rosa (Aniba rosaeodora Ducke) como aliada ao desenvolvi-mento sustentável da região amazônica. Inclusão Soc. 2018, 12, 199-207.

57. IBAMA. Portaria No. 037/92-N: Lista oficial de Espécies de Flora Brasileira Ameaçadas de Extinção. 1992. Available online: https://www.mma.gov.br/estruturas/179/_arquivos/179_05122008033627.pdf (accessed on 16 August 2020).

58. IBAMA. Portaria No. 01/98. 1998. Available online: http://snif.florestal.gov.br/images/pdf/legislacao/portarias/portaria_ ibama_01_1998.pdf (accessed on 16 August 2020).

59. Sampaio, P.T.B. Propagação Vegetativa do PAU-Rosa (Aniba rosaeodora Ducke) Pelo Método da Estaquia. Ph.D. Thesis, Universidade Federal do Amazonas, Manaus, Brazil, 1987.

60. Sampaio, P.T.B.; Ferraz, I.D.K.; Camargo, J.L.C. Pau-rosa, Aniba rosaeodora Ducke. In Manual de Se-Mentes da Amazônia, 1st ed.; Ferraz, I.D.K., Ed.; INPA: Manaus, Brazil, 2003; p. 6.

61. Magalhães, L.M.S.; Alencar, J.D.C. Fenologia do pau-rosa (Aniba duckei Kostermans), Lauraceae, em floresta primária na Amazônia Central. Acta Amaz. 1979, 9, 227-232. [CrossRef]

62. Spironello, W.R.; Sampaio, P.D.T.B.; Ronchi-Teles, B. Produção e predação de frutos em Aniba rosaeodora Ducke var. amazonica Ducke (Lauraceae) em sistema de plantio sob floresta de terra firme na Amazônia Central. Acta Bot. Bras. 2004, 18, 801-807. [CrossRef]

63. Jardim, L.S.; Sampaio, P.D.T.B.; Costa, S.D.S.; Gonçalves, C.D.Q.B.; Brandão, H.L.M. Efeito de diferentes reguladores de crescimento na regeneração in vitro de pau-rosa (Aniba rosaeodora Ducke). Acta Amaz. 2010, 40, 275-279. [CrossRef]

64. Taveira, F.S.N. Plantas Aromáticas da Serra de Carajás Como Prováveis Marcadores Biogeoquímicos de Solos Mineralizados. Ph.D. Thesis, Universidade Federal do Pará, Belém, Brazil, 1991.

65. Lima, M.D.P.; Silva, T.M.D.; Da Silva, J.D.; Zoghbi, M.D.G.B.; Andrade, E.H.A. Essential oil composition of leaf and fine stem of Aniba canelilla (Kunth) Mez from Manaus, Brazil. Acta Amaz. 2004, 34, 329-330. [CrossRef] 
66. Silva, M.D.F.D.; Taveira, F.S.; Maia, J.G.S.; Conserva, L.M.; Yoshida, M.; Gottlieb, O.R. The natural occurrence of magnosalicin diastereomers. Phytochemistry 1997, 45, 1527-1528. [CrossRef]

67. Taveira, F.S.; Silva, M.D.F.D.; Maia, J.G.S. Essential Oil of Aniba puchury-minor (Mart.) Mez Occurring in the Amazon. J. Essent. Oil Bear. Plants 2003, 6, 27-30. [CrossRef]

68. De Lima, W.; Rojas-Fermin, L.-B.; Koteich-Khatib, S.; Lucena, M.E.; Arzola, J.C. Volatile Constituents of the Leaves of Aniba hostmanniana (Lauraceae) and their Antibacterial Activities. Nat. Prod. Commun. 2015, 10, 1321-1322. [CrossRef]

69. Luz, A.I.R.; Da Silva, J.D.; Zoghbi, M.D.G.B.; Andrade, E.H.D.A.; Maia, J.G.S. Essential Oil from Aniba riparia (Nees) Mez. J. Essent. Oil Res. 2002, 14, 218-219. [CrossRef]

70. Alcântara, J.M.; Yamaguchi, K.K.D.L.; Junior, V.F.D.V.; Lima, E.S. Composição química de óleos essenciais de espécies de Aniba e Licaria e suas atividades antioxidante e antiagregante plaquetária. Química Nova 2010, 33, 141-145. [CrossRef]

71. dos Santos, R.Q.; Maia, C.S.F.; Junior, E.A.F.; Melo, A.S.; Pinheiro, B.; Maia, J.G.S. Linalool-rich essential oils from the Amazon display antidepressant-type effect in rodents. J. Ethnopharmacol. 2018, 212, 43-49. [CrossRef] [PubMed]

72. Souza, R.D.C.Z.D. Avaliação das Frações Voláteis de Espécies de Aniba por Microextração em Fase Sólida Acoplada a Cromatografia Gasosa (SPME-GC) e Cromatografia Gasosa Bidimensional Abrangente (GC $\times$ GC). Ph.D. Thesis, Universidade Estadual de Campinas, Campinas, Brazil, 2011. Available online: http:/ /www.repositorio.unicamp.br/handle/REPOSIP/248376 (accessed on 18 August 2019).

73. Zoghbi, M.G.B.; Ohashi, S.T.; Salomão, R.O.; Guilhon, G.M.S.P. Chemical variability of Aniba rosaeodora oils. Glob. J. Sci. Front. Res. B Chem. 2015, 15, 780 .

74. Amazonas, D.R.; Oliveira, C.; Barata, L.E.S.; Tepe, E.J.; Kato, M.J.; Mourão, R.H.V.; Yamaguchi, L.F. Chemical and Genotypic Variations in Aniba rosiodora from the Brazilian Amazon Forest. Molecules 2020, 26, 69. [CrossRef] [PubMed]

75. Andrade, E.H.A.; Zoghbi, M.D.G.B.; Maia, J.G.S. Volatiles from Aniba terminalis Ducke. J. Essent. Oil Res. 2003, 15, 81-82. [CrossRef]

76. Santana, A.; Ohashi, S.; De Rosa, L.; Green, C. Brazilian rosewood oil the prospect for sustainable production and oil quality management. Int. J. Aromather. 1997, 8, 16-20. [CrossRef]

77. Lupe, F.A. Estudo da Composição Química de Óleos Essenciais de Plantas Aromáticas da Amazônia. Ph.D. Thesis, Universidade Estadual de Campinas, São Paulo, Brazil, 2007.

78. Fidelis, C.H.; Augusto, F.; Sampaio, P.T.; Krainovic, P.; Barata, L.E. Chemical characterization of rosewood (Aniba rosaeodora Ducke) leaf essential oil by comprehensive two-dimensional gas chromatography coupled with quadrupole mass spectrometry. $J$. Essent. Oil Res. 2012, 24, 245-251. [CrossRef]

79. Fidelis, C.H.; Sampaio, P.T.; Krainovic, P.; Augusto, F.; Barata, L.E. Correlation between maturity of tree and GC $\times$ GC-qMS chemical profiles of essential oil from leaves of Aniba rosaeodora Ducke. Microchem. J. 2013, 109, 73-77. [CrossRef]

80. Krainovic, P.M.; de Almeida, D.R.A.; Junior, V.F.D.V.; Sampaio, P.D.T.B. Changes in rosewood (Aniba rosaeodora Ducke) essential oil in response to management of commercial plantations in Central Amazonia. For. Ecol. Manag. 2018, 429, 143-157. [CrossRef]

81. Teles, R.D.M.; Filho, V.E.M.; De Souza, A.G. Chemical Characterization and Larvicidal Activity of Essential Oil from Aniba duckei Kostermans against Aedes aegypti. Int. J. Life Sci. Sci. Res. 2017, 3, 1495-1499. [CrossRef]

82. Everton, G.O.; Júnior, P.S.S.; Araújo, R.J.P.; Ferreira, A.M.; Gomes, P.R.B.; Rosa, P.V.S.; Pereira, A.P.M.; Filho, V.E.M. Chemical profile and antimicrobial potential of essential oils of Cymbopogon citratus (DC.) Stapf, Ocimum basilicum Linn and Aniba rosaeodora Ducke. Sci. Plena 2020, 16, 061502. [CrossRef]

83. Oger, J.-M.; Richomme, P.; Guinaudeau, H.; Bouchara, J.P.; Fournet, A. Aniba canelilla (H.B.K.) Mez Essential Oil: Analysis of Chemical Constituents, Fungistatic Properties. J. Essent. Oil Res. 1994, 6, 493-497. [CrossRef]

84. Taveira, F.; de Lima, W.; Andrade, E.; Maia, J. Seasonal essential oil variation of Aniba canelilla. Biochem. Syst. Ecol. 2002, 31, 69-75. [CrossRef]

85. Lahlou, S.; Magalhaes, P.; de Siqueira, R.J.B.; Figueiredo, A.F.; Interaminense, L.F.L.; Maia, J.G.S.; Sousa, P.J.D.C. Cardiovascular Effects of the Essential Oil of Aniba canelilla Bark in Normotensive Rats. J. Cardiovasc. Pharmacol. 2005, 46, 412-421. [CrossRef]

86. Giongo, J.L.; Vaucher, R.A.; Da Silva, A.S.; Oliveira, C.B.; de Mattos, C.B.; Baldissera, M.D.; Sagrillo, M.R.; Monteiro, S.G.; Custódio, D.L.; de Matos, M.S.; et al. Trypanocidal activity of the compounds present in Aniba canelilla oil against Trypanosoma evansi and its effects on viability of lymphocytes. Microb. Pathog. 2017, 103, 13-18. [CrossRef] [PubMed]

87. Kreutz, T.; Lucca, L.G.; Loureiro-Paes, O.A.; Teixeira, H.F.; Veiga, V.F.; Limberger, R.P.; Ortega, G.G.; Koester, L.S. Optimization, validation and application of headspace solid-phase microextraction gas chromatography for the determination of 1-nitro-2phenylethane and methyleugenol from Aniba canelilla (H.B.K.) Mez essential oil in skin permeation samples. J. Chromatogr. A 2018, 1564, 163-175. [CrossRef] [PubMed]

88. Marcano, E.E.; Padilla-Baretic, A.; Rojas-Fermín, L.; Mora-Vivas, F.D.; Ferrer-Pereira, H. Chemical composition of wood essential oil of Aniba cinnamomiflora C. K. Allen from venezuelan andes. Colomb. For. 2016, 19, 233-238. [CrossRef]

89. Zoghbi, M.G.B.; Andrade, E.H.A.; Santos, A.S.; Da Silva, M.H.L.; Maia, J.G.S. Constituintes voláteis de espécies de Lauraceae com ocorrência na Floresta Nacional de Caxiuanã-Melgaço-PA. In Estação Científica Ferreira Penna; Dez Anos de Pesquisa: Belém, Brazil, 2003; pp. 1-3.

90. Sampaio, L.D.F.S.; Maia, J.G.S.; Parijós, A.M.; Souza, R.Z.; Barata, L.E.S. Linalool from Rosewood (Aniba rosaeodora Ducke) Oil Inhibits Adenylate Cyclase in the Retina, Contributing to Understanding its Biological Activity. Phytother. Res. 2011, $26,73-77$. [CrossRef] 
91. Aguilar, C.A.L.; Lima, K.R.D.S.; Manno, M.C.; Maia, J.G.S.; Neto, D.L.F.; Tavares, F.B.; Roque, T.J.L.R.; Mendonça, R.D.C.A.D.; Carmo, E.S.N.D. Rosewood (Aniba rosaeodora Ducke) oil in broiler chickens diet. Rev. Bras. Saúde Prod. Anim. 2014, 15, 108-119. [CrossRef]

92. De Almeida, R.N.; Araújo, D.A.M.; Gonçalves, J.C.R.; Montenegro, F.C.; de Sousa, D.P.; Leite, J.R.; Mattei, R.; Benedito, M.A.C.; de Carvalho, J.G.B.; Cruz, J.S.; et al. Rosewood oil induces sedation and inhibits compound action potential in rodents. J. Ethnopharmacol. 2009, 124, 440-443. [CrossRef]

93. Ferreira, A.M.; Filho, V.E.M.; Mafra, N.S.C.; Sales, E.H.; Júnior, P.S.S.; Everton, G.O. Constituintes químicos, toxicidade, potencial antioxidante e atividade larvicida frente a larvas de Aedes aegypti do óleo essencial de Aniba rosaeodora Ducke. Res. Soc. Dev. 2020, 9, e520985663. [CrossRef]

94. Simić, A.; Soković, M.D.; Ristić, M.; Grujić-Jovanović, S.; Vukojevic, J.; Marin, P.D. The chemical composition of some Lauraceae essential oils and their antifungal activities. Phytotherapy Res. 2004, 18, 713-717. [CrossRef] [PubMed]

95. Rosato, A.; Piarulli, M.; Corbo, F.; Muraglia, M.; Carone, A.; Vitali, M.E.; Vitali, C. In Vitro Synergistic Action of Certain Combinations of Gentamicin and Essential Oils. Curr. Med. Chem. 2010, 17, 3289-3295. [CrossRef] [PubMed]

96. Chiluwal, K.; Kim, J.; Bae, S.D.; Park, C.G. Essential oils from selected wooden species and their major components as repellents and oviposition deterrents of Callosobruchus chinensis (L.). J. Asia Pac. Ėntomol. 2017, 20, 1447-1453. [CrossRef]

97. Soeur, J.; Marrot, L.; Perez, P.; Iraqui, I.; Kienda, G.; Dardalhon, M.; Meunier, J.-R.; Averbeck, D.; Huang, M.-E. Selective cyto-toxicity of Aniba rosaeodora essential oil towards epidermoid cancer cells through induction of apoptosis. Mutat. Res. Toxicol. Environ. Mutagen. 2011, 718, 24-32. [CrossRef] [PubMed]

98. Kizak, V.; Can, E.; Danabaş, D.; Can, S. Evaluation of anesthetic potential of rosewood (Aniba rosaeodora) oil as a new anesthetic agent for goldfish (Carassius auratus). Aquaculture 2018, 493, 296-301. [CrossRef]

99. De Araujo, V.C.; Corrêa, G.C.; Maia, J.G.S.; Da Silva, M.L.; Gottlieb, O.R.; Marx, M.C.; Magalhães, M.T. Óleos essenciais da Amazonia contendo linalol. Acta Amaz. 1971, 1, 45-47. [CrossRef]

100. Sangwan, R.S.; Farooqi, A.; Shabih, F. Regulation of essential oil production in plants. Plant. Growth Regul. $2001,34,3-21$. [CrossRef]

101. Barbosa, P.C.S.; Fernandes, K.S.; Manhães, A.P.; Carneiro, S.B.; Sampaio, P.D.T.B.; Wiedemann, L.S.M.; Junior, V.F.D.V. New and sustainable essential oils obtained from the long-term explored cinnamomum-like Aniba canelilla. J. Appl. Res. Med. Aromat. Plants 2017, 5, 60-71. [CrossRef]

102. Manhães, A.P.; Da Veiga-Júnior, V.F.; Wiedemann, L.S.M.; Fernandes, K.S.; Sampaio, P.D.T.B. Biomass production and essential oil yield from leaves, fine stems and resprouts using pruning the crown of Aniba canelilla (H.B.K.) (Lauraceae) in the Central Amazon. Acta Amaz. 2012, 42, 355-362. [CrossRef]

103. Da Cunha, L.N. Influência sazonal no teor de linalol do óleo essencial da Aniba duckei Kostermans cultivada em ambiente natural na reserva florestal Ducke. Ciênc. Nat. 2011, 33, 7-15. Available online: https:/ / www.redalyc.org/articulo.oa?id=467546359001 (accessed on 2 September 2021).

104. Da Silva, I.G.R.; De Sousa, E.M.; De Moraes, A.A.B.; De Sarges, M.D.S.R.; Cascaes, M.M.; Nascimento, L.D.D.; Andrade, E.H.D.A. Avaliação sazonal do rendimento e composição química do óleo essencial das folhas de Aniba parviflora (Meisn) Mez. (Lauraceae). Braz. J. Dev. 2020, 6, 41334-41345. [CrossRef]

105. Sadgrove, N.J. Comparing essential oils from Australia's 'Victorian Christmas Bush' (Prostanthera lasianthos Labill., Lamiaceae) to closely allied new species: Phenotypic plasticity and taxonomic variability. Phytochemistry 2020, 176, 112403. [CrossRef] [PubMed]

106. Gottlieb, O.R.; Koketsu, M.; Magalhães, M.T.; Maia, J.G.S.; Mendes, P.H.; Da Rocha, A.I.; Da Silva, M.L.; Wilberg, V.C. Óleos essenciais da Amazônia VII. Acta Amaz. 1981, 11, 143-148. [CrossRef]

107. Chantraine, J.-M.; Dhénin, J.-M.; Moretti, C. Chemical Variability of Rosewood (Aniba rosaeodora Ducke) Essential Oil in French Guiana. J. Essent. Oil Res. 2009, 21, 486-495. [CrossRef]

108. Carović-Stanko, K.; Orlic, S.; Politeo, O.; Strikić, F.; Kolak, I.; Milos, M.; Šatović, Z. Composition and antibacterial activities of essential oils of seven Ocimum taxa. Food Chem. 2010, 119, 196-201. [CrossRef]

109. Sartoratto, A.; Machado, A.L.M.; Delarmelina, C.; Figueira, G.M.; Duarte, M.C.T.; Rehder, V.L.G. Composition and antimicrobial activity of essential oils from aromatic plants used in Brazil. Braz. J. Microbiol. 2004, 35, 275-280. [CrossRef]

110. de Lima, A.B.; Santana, M.; Cardoso, A.S.; da Silva, J.K.R.; Maia, J.G.S.; Carvalho, J.C.T.; Sousa, P.J.C. Antinociceptive activity of 1-nitro-2-phenylethane, the main component of Aniba canelilla essential oil. Phytomedicine 2009, 16, 555-559. [CrossRef]

111. Vale, J.K.L.; Lima, A.B.; Pinheiro, B.G.; Cardoso, A.S.; Silva, J.K.R.; Maia, J.G.S.; de Sousa, G.E.P.; da Silva, A.B.F.; Sousa, P.J.C.; Borges, R.S. Evaluation and Theoretical Study on the Anti-inflammatory Mechanism of 1-Nitro-2-phenylethane. Planta Medica 2013, 79, 628-633. [CrossRef]

112. Júnior, E.Q.D.F.; Albuquerque, P.M.; Da Silva, G.F. Estudo Fitoquímico E Análise De Fotoproteção Dos Extratos E Óleos Essenciais De Aniba canelilla (H.B.K) MEZ. J. Eng. Exact Sci. 2017, 3, 0614-0620. [CrossRef]

113. de Siqueira, R.J.B.; Macedo, F.I.B.; Interaminense, L.D.F.L.; Duarte, G.P.; Magalhaes, P.; Brito, T.S.; da Silva, J.K.R.; Maia, J.G.S.; Sousa, P.J.D.C.; Leal-Cardoso, J.H.; et al. 1-Nitro-2-phenylethane, the main constituent of the essential oil of Aniba canelilla, elicits a vago-vagal bradycardiac and depressor reflex in normotensive rats. Eur. J. Pharmacol. 2010, 638, 90-98. [CrossRef]

114. Brito, T.S.; Lima, F.J.; Aragão, K.S.; de Siqueira, R.J.; Sousa, P.J.; Maia, J.G.; Filho, J.D.; Lahlou, S.; Magalhães, P.J. The vasorelaxant effects of 1-nitro-2-phenylethane involve stimulation of the soluble guanylate cyclase-cGMP pathway. Biochem. Pharmacol. 2012, 85, 780-788. [CrossRef] 
115. Arruda-Barbosa, L.; Rodrigues, K.M.S.; Souza-Neto, F.D.C.V.; Duarte, G.P.; Borges, R.S.; Magalhães, P.J.C.; Lahlou, S. Vasorelaxant effects of 1-nitro-2-phenylethene in rat isolated aortic rings. Vasc. Pharmacol. 2014, 63, 55-62. [CrossRef]

116. Silva, N.N.S.; Silva, J.; Alves, C.N.; Andrade, E.H.D.A.; Da Silva, J.K.R.; Maia, J.G.S. Acetylcholinesterase Inhibitory Activity and Molecular Docking Study of 1-Nitro-2-Phenylethane, the Main Constituent of Aniba canelilla Essential Oil. Chem. Biol. Drug Des. 2014, 84, 192-198. [CrossRef] [PubMed]

117. Souza, K.S.; Chaar, J.S.; Oliveira, K.M.T.; Gomes, E.O.; Portela, C.N.; Pohlit, A.M.; Quignard, E.L.J.; Nunomura, S.M.; Tadei, W.P.; Mouchrek Filho, V.E.; et al. Atividade biológica de extratos, hidrolatos e óleos voláteis de pau-rosa (Aniba duckei Kostermans) e quantificação de linalol no hidrolato de folhas. Rev. Bras. Plantas Med. 2007, 9, 1-7.

118. Baldisserotto, B.; Barata, L.E.S.; Silva, A.S.; Lobato, W.F.F.; Silva, L.L.; Toni, C.; Silva, L.V.F. Anesthesia of tambaqui Colossoma macropomum (Characiformes: Serrasalmidae) with the essential oils of Aniba rosaeodora and Aniba parviflora and their major compound, linalool. Neotrop. Ichthyol. 2018, 16, e170128. [CrossRef]

119. de Oliveira, F.P.; Rodrigues, A.C.B.D.C.; de Lima, E.J.S.P.; Silva, V.R.; Santos, L.D.S.; da Anunciação, T.A.; Nogueira, M.L.; Soares, M.B.P.; Dias, R.B.; Rocha, C.A.G.; et al. Essential Oil from Bark of Aniba parviflora (Meisn) Mez (Lauraceae) Reduces HepG2 Cell Proliferation and Inhibits Tumor Development in a Xenograft Model. Chem. Biodivers. 2021, 18, e2000938. [CrossRef] [PubMed]

120. Kohn, L.K.; Queiroga, C.L.; Martini, M.C.; Barata, L.E.; Porto, P.S.S.; Souza, L.; Arns, C.W. In vitroantiviral activity of Brazilian plants (Maytenus ilicifolia and Aniba rosaeodora) against bovine herpesvirus type 5 and avian metapneumovirus. Pharm. Biol. 2012, 50, 1269-1275. [CrossRef] [PubMed]

121. De Siqueira, R.J.; Rodrigues, K.M.S.; Da Silva, M.T.B.; Junior, C.A.B.C.; Duarte, G.P.; Magalhaes, P.; dos Santos, A.A.; Maia, J.G.S.; Da Cunha, P.J.S.; Lahlou, S. Linalool-rich Rosewood Oil Induces Vago-vagal Bradycardic and Depressor Reflex in Rats. Phytother. Res. 2013, 28, 42-48. [CrossRef]

122. Amorati, R.; Foti, M.C.; Valgimigli, L. Antioxidant Activity of Essential Oils. J. Agric. Food Chem. 2013, 61, 10835-10847. [CrossRef] [PubMed]

123. Mansur, J.S.; Breder, M.V.; Mansur, M.C.A.; Azuley, R.D. Determinação do fator de proteção solar por espectrofotometria. An. Bras. Dermatol. 1986, 61, 121-124.

124. Agência Nacional de Vigilância Sanitária (ANVISA). Resolução RDC no 30, de 1 de junho de 2012. Aprova o regulamento técnico Mercosul sobre Protetores Solares em Cosméticos e dá Outras Providências. In Agência Nacional de Vigilância Sanitária (ANVISA); Diário Oficial da União: Brasília, Brazil, 2012.

125. Dobetsberger, C.; Buchbauer, G. Actions of essential oils on the central nervous system: An updated review. Flavour Fragr. J. 2011, 26, 300-316. [CrossRef]

126. Aprotosoaie, A.C.; Hancianu, M.; Costache, I.-I.; Miron, A. Linalool: A review on a key odorant molecule with valuable biological properties. Flavour Fragr. J. 2014, 29, 193-219. [CrossRef]

127. Dolabela, M.F. Triagem In Vitro Para Atividade Antitumoral e Anti Trypanossoma Cruzi de Extratos Vegetais, Produtos Naturais e Susbstâncias Sintéticas. Ph.D. Thesis, Universidade Federal de Minas Gerais, Belo Horizonte, Brazil, 1997.

128. Dias, C.N.; Moraes, D.F.C. Essential oils and their compounds as Aedes aegypti L. (Diptera: Culicidae) larvicides: Review. Parasitol. Res. 2013, 113, 565-592. [CrossRef]

129. Janssen, A.M.; Scheffer, J.J.C.; Svendsen, A.B. Antimicrobial Activity of Essential Oils: A 1976-1986 Literature Review. Aspects of the Test Methods. Planta Med. 1987, 53, 395-398. [CrossRef]

130. Hili, P.; Evans, C.S.; Veness, R.G. Antimicrobial action of essential oils: The effect of dimethylsulphoxide on the activity of cinnamon oil. Lett. Appl. Microbiol. 1997, 24, 269-275. [CrossRef]

131. Hammer, K.A.; Carson, C.; Riley, T.V. Antimicrobial activity of essential oils and other plant extracts. J. Appl. Microbiol. 1999, 86, 985-990. [CrossRef]

132. Chao, S.C.; Young, D.G.; Oberg, C.J. Screening for Inhibitory Activity of Essential Oils on Selected Bacteria, Fungi and Viruses. J. Essent. Oil Res. 2000, 12, 639-649. [CrossRef]

133. Starliper, C.E.; Ketola, H.G.; Noyes, A.D.; Schill, W.; Henson, F.G.; Chalupnicki, M.A.; Dittman, D. An investigation of the bactericidal activity of selected essential oils to Aeromonas spp. J. Adv. Res. 2014, 6, 89-97. [CrossRef]

134. Corthouts, J.; Michiels, C.W. Inhibition of nutrient- and high pressure-induced germination of Bacillus cereus spores by plant essential oils. Innov. Food Sci. Emerg. Technol. 2016, 34, 250-258. [CrossRef]

135. Regnier, T.; Combrinck, S.; Veldman, W.; Du Plooy, W. Application of essential oils as multi-target fungicides for the control of Geotrichum citri-aurantii and other postharvest pathogens of citrus. Ind. Crop. Prod. 2014, 61, 151-159. [CrossRef]

136. Kong, J.-O.; Lee, S.-M.; Moon, Y.-S.; Ahn, Y.-J. Nematicidal Activity of Plant Essential Oils against Bursaphelenchus xylophilus (Nematoda: Aphelenchoididae). J. Asia Pacific Èntomol. 2006, 9, 173-178. [CrossRef]

137. Abbott, W.S. A Method of Computing the Effectiveness of an Insecticide. J. Econ. Ėntomol. 1925, 18, 265-267. [CrossRef]

138. Uniyal, A.; Tikar, S.N.; Singh, R.; Shukla, S.V.; Agrawal, O.P.; Veer, V.; Sukumaran, D. Repellent effect, knockdown study and electrophysiological responses of essential oils against Aedes aegypti. J. Entomol. Zool Stud. 2014, 2, 351-357.

139. O'Neal, S.T.; Johnson, E.J.; Rault, L.C.; Anderson, T.D. Vapor delivery of plant essential oils alters pyrethroid efficacy and detoxification enzyme activity in mosquitoes. Pestic. Biochem. Physiol. 2019, 157, 88-98. [CrossRef] 
140. Sheng, Z.; Jian, R.; Xie, F.; Chen, B.; Zhang, K.; Li, D.; Chen, W.; Huang, C.; Zhang, Y.; Hu, L.; et al. Screening of larvicidal activity of 53 essential oils and their synergistic effect for the improvement of deltamethrin efficacy against Aedes albopictus. Ind. Crop. Prod. 2020, 145, 112131. [CrossRef]

141. de Sousa, D.; Nóbrega, F.F.F.; Santos, C.C.M.P.; De Almeida, R.N. Anticonvulsant Activity of the Linalool Enantiomers and Racemate: Investigation of Chiral Influence. Nat. Prod. Commun. 2010, 5, 1847-1851. [CrossRef] [PubMed] 